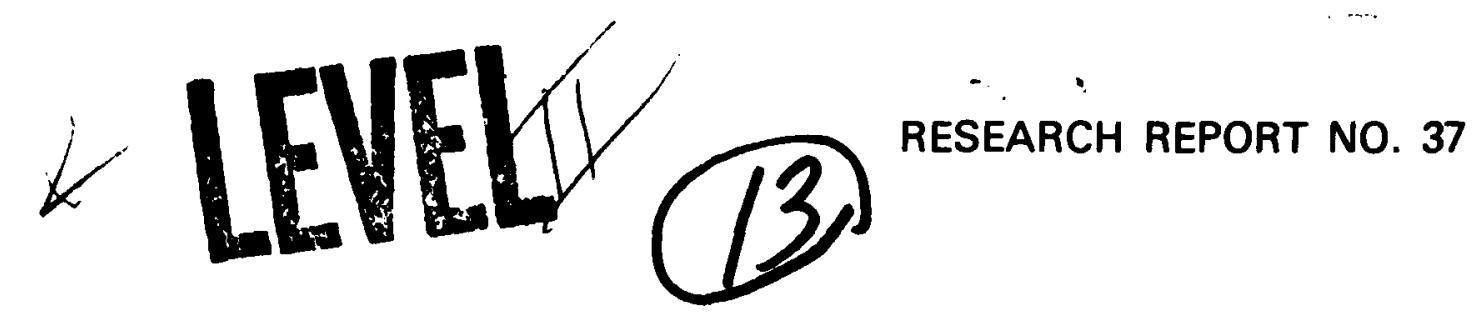

\title{
EEO EXTERNAL RELEVANT LABOR FORCE ANALYSIS
}

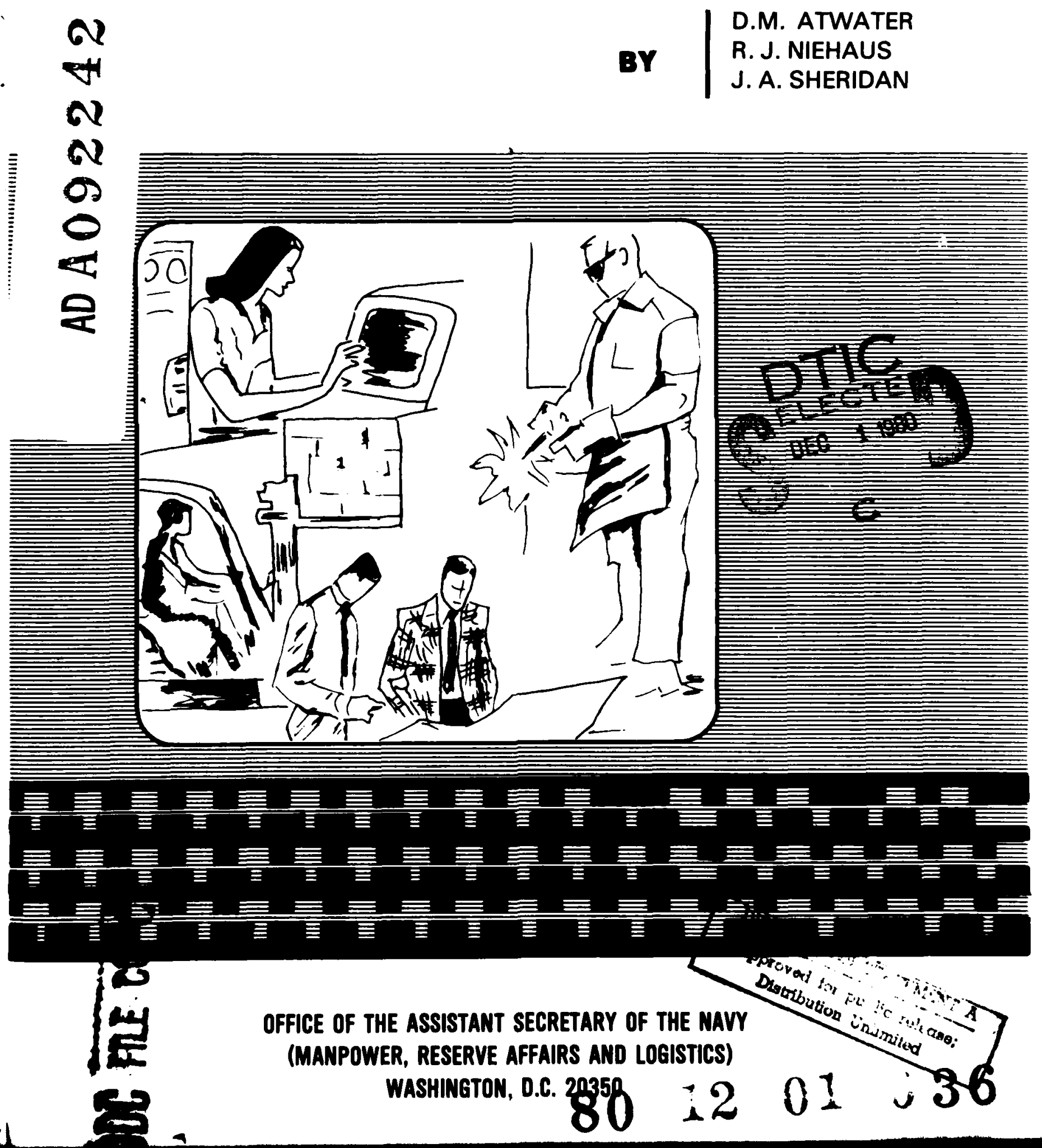




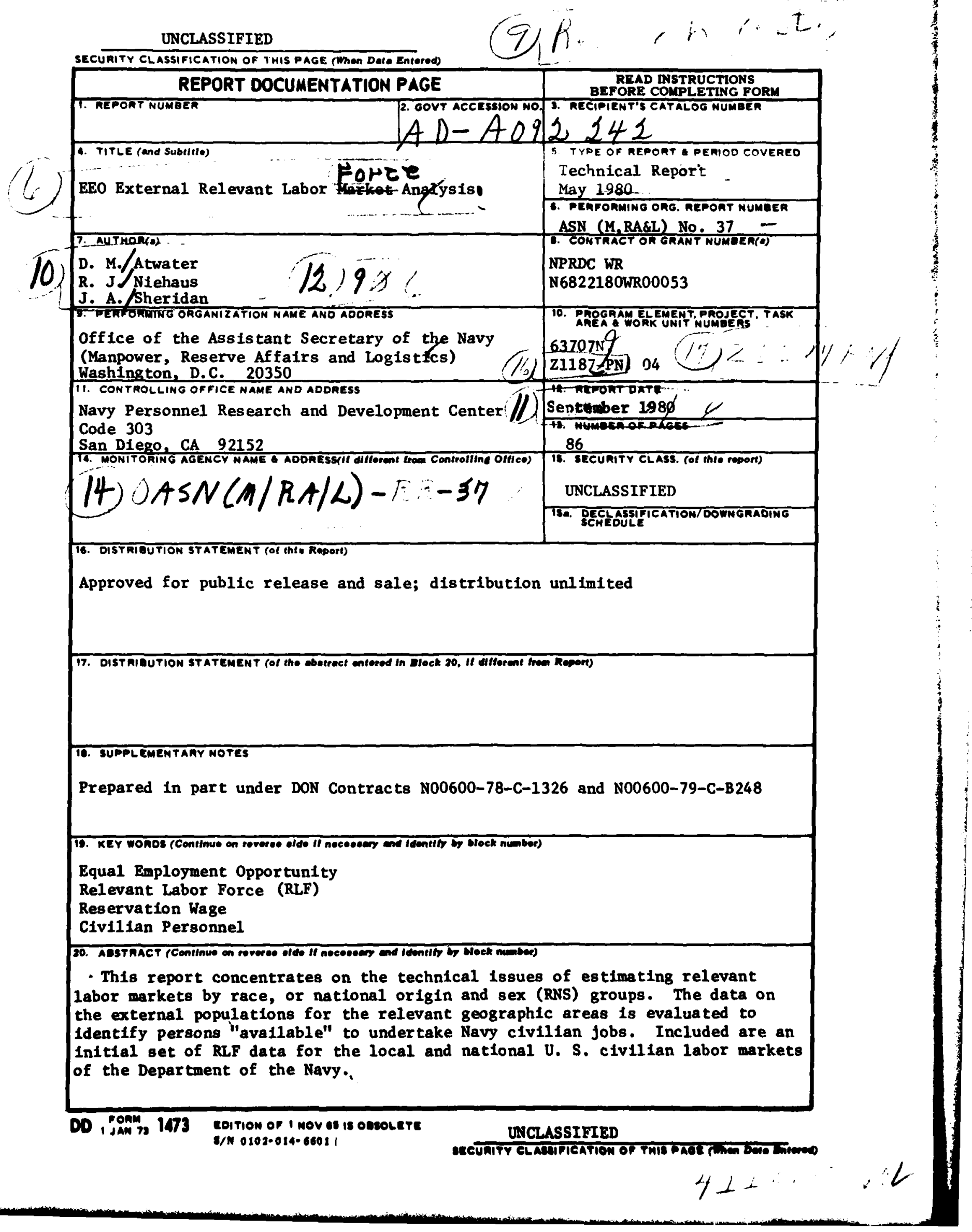


Research Report No. 37

EEO EXTERNAL RELEVANT LABOR FORCE ANALYSIS

by

\author{
D. M. Atwater* \\ R. J. Niehaus**

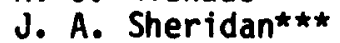 \\ *University of California, Los Angeles \\ * Office of the Assistant Secretary of the Navy \\ (Manpower, Reserve Affairs and Logistics) \\ $\star \star \star$ Paradigm Consul tants, Inc., Tinton Falls, N.J.
}

September 1980

This report was prepared as part of the EEO Policy Analysis advanced development project sponsored by the Navy Personnel Research and Development Center. It was accompl ished under NPRDC work Request N6822180WR00053 with the Office of the Deputy Assistant Secretary of the Navy (Equal Opportunity). Data presented in this report was developed under Department of the Navy Contracts N00600-78-C-1326 and N00600-79-C-B248 with Paradigm Consultants, Inc. Reproduction in whole or in part is permitted for any purpose of the U.S. Government.

\author{
Office of the Assistant Secretary of the Navy \\ (Manpower, Reserve Affairs and Logistics) \\ Navy Department \\ Washington, D.C. 20350
}




\section{Introduction}

The development of numerical measures for Equal Employment Opportunity (EEO) policies analysis must include knowledge of the external labor market. In addition to comparisons with more general civilian labor force (CLF) data, comparisons are needed with the relevant labor force (RLF) data. The use of these measurements in connection with Title VII of the Civil Rights Act of 1964 touches on the most difficult and fundamental issues of EEO. Discussion of the implications for the management of and accountability for EEO goals is discussed by Niehaus and Nitterhouse (14). This report concentrates on the computational issues of estimating relevant external labor markets by race, or national origin and sex (RNS) groups. Also included are an initial set of local and national RLF data for the Department of the Navy U. S. civilian labor markets.

\section{The Labor Market Analysis Methodology}

The external labor market analysis which is being used seeks to match jobs with people as shown in Figure 1. The initial step in the process is to specify the key characteristics of jobs (which in this case are particular to the Department of the Navy). Data on the external civilian populations for the relevant geographic areas is then evaluated to identify people "available" to undertake the prescribed work.

IFor a discussion of the use of computer-assisted human resources planning techniques as applied to EEO see Chapters III, IV and XIII of Niehaus (13)

2The initial technical discussion of the Navy's EEO relevant labor force (RLF) studies are provided in Atwater, Niehaus, and Sheridan (2), (3). Also see Chapter IV of Niehaus (13) 


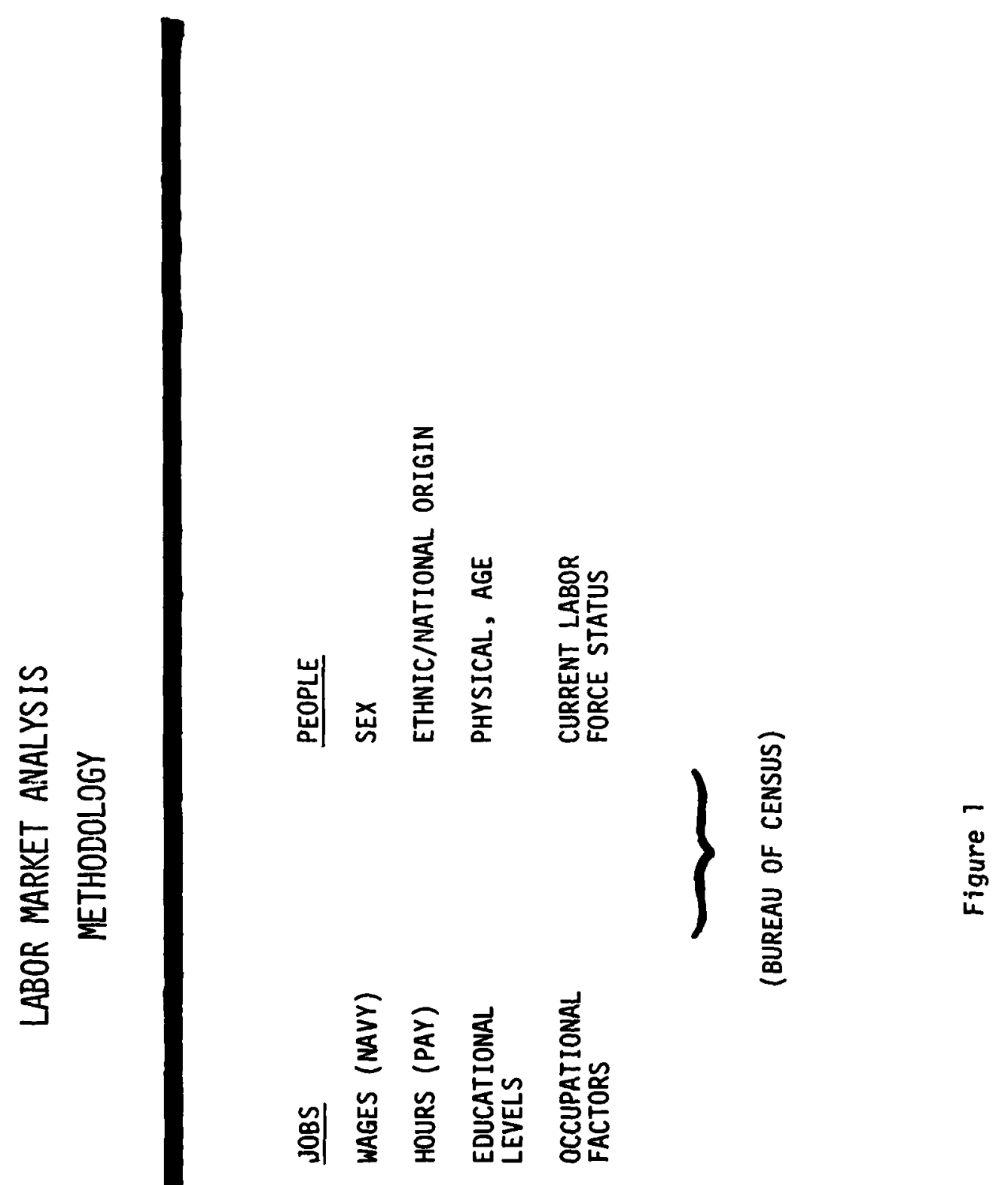


The jobs are grouped into occupational and pay level categories. The initial version of the analysis uses major occupational groups which are consistent with the Professional, Administrative, Technical, Clerical and Other General Schedule (PATCO) coding scheme of the U.S. Office of Personnel Management (OPM). Since over $90 \%$ of the Navy's Professionals (i.e. jobs normally requiring a bachelor's or professional degree for entry) are scientists and engineers, the Professional category is further divided into two groups: Scientists and Engineers and Other Professional. In addition to the PATCO related white collar jobs the Navy has established two additional major occupation groups (Craftsmen and Operatives, and Laborers) to cover the large (over 130,000) blue collar civilian work force.

Grouping of the wage or pay levels was also done. For the white collar (General Schedule) groups, this was done as GS 1-4 $(\$ 7,210-13,064$ in October 1979); GS 5-8 (\$10,049-20,049); GS 9-12 (\$17,035-32,110); GS 13-15 $(\$ 29,375-50,112)$ and GS 16-18 (now Senior Executives (SES) $\$ 47,889-50,112$ ). Blue collar (ungraded) levels are Apprentice, Semi-skilled, Journeymen, Leader and Supervisor, with the prevailing local wages applying. It should be noted that the pay levels overlap so that persons could be "available" for more than one job. Thus, jobs are also characterized by a wage or salary band. A craftsmen and operatives apprentice job which pays a minimum of $\$ 5.00$ an hour and a maximum of $\$ 9.00$ an hour would have a wage band of $(\$ 5.00-\$ 9.00)$. 


\section{Labor Market Geographic Area Methodology}

Geographic and educational criteria were determined for each of the major occupation groups and grade/level groupings. Once constructed, these criteria were checked with Navy civilian personnel staffing experts. The occupation education requirements are clear for the Scientists and Engineers and $\underline{\text { Other }}$ Professional job categories. Also the geographic area is national since the U.S. Office of Personnel Management registers are national and the student bodies of many professional schools and universities are drawn from diverse areas.

The Administrative job category criteria change as one moves up the career hierarchy. At the entry levels the labor market is local or regional depending on the type of administrative job involved. Educational requirements can also vary considerably with on-the-job experience substituted for formal education. As one moves up to higher grades, the criteria becomes broader indicating the enlarged recruitment area and the need for more qualifications. The Technical job categories for the Navy are essentially two different labor markets. At the high end the job content approaches that of a highly specialized professional. This is particularly true for the Navy since there are a considerable number of draftsmen, engineering and electronics technicians in the laboratories. The Clerical occupation labor market is locally oriented. The other General Schedule occupations are a mixture with the greatest proportion being firemen, guards, and police. In most cases the labor market for the blue collar jobs is local. 
Considerable effort was expended to define precisely the geographic areas of the local labor markets for each Naval installation with over 200 civilian employees. The specification of geographic area is of particular concern to the Navy since in many cases the concentrations of installations are at the edges of Standard Metropolitan Statistical Areas (SMSA's) or in isolated locations. For example, Mare Island Shipyard draws its workforce from a combination of counties from the Vallejo-fairfield Napa SMSA and the San Francisco-0akl and SMSA. A sample of new hire or accession data for FY 78 was collected by Zip Code. A minimum of 500 records were collected for each Navy local labor market. For local labor markets where there were significantly less than 500 new hires, a percentage $(35,50$ or $100 \%$ depending on required sample sizes) of the total Navy work force in an area was included in the data collection. Zip Code data on 35,000 of the Navy's 280,000 U.S. civilian employees was eventually collected.

The Zip Code data was then matched with the counties of the local areas. The matches then were reviewed using a Rand McNally Road Atlas coupled with a Department of Defense map of major installations. Any anomolies in the local recruitment data were then corrected so that equidistant areas would be accorded equal treatment. For very local jobs such as the clerical and blue collar occupations the recruitment area dropped off at 15-20 miles with high consistency. This distance factor will become even more of an indicator of the local labor market with the increases in commuting costs due to the increases in gasoline prices. The current Navy local labor markets are provided in Appendix A.

${ }^{3}$ For a discussion of the successful use of applicant flow data to map a recruitemnt area in connection with a discrimination suit see Bloch and Penninaton 
In addition to Zip Code, occupation, and grade, data was collected on years of education and employment status at time of hire. The education data is being used to evaluate the years of education normally required for a specific type of job. In all non-professional job streams, no minimum educational requirements are set at the entry levels. This ensures that opportunities for entry into Navy employment are evaluated to include those with less than a high school education.

The data on employment status at time of hire covers: (1) unemployed, (2) employed, private sector, (3) employed, state or local government, (4) employed, Federal government, and (5) not in the work force (i.e. in school, etc.). The employment status at time of hire data is also being used to estimate the percentage of Navy employees which were hired from the Federal work force.

\section{The Relevant Labor Pool Methodology}

The relevant labor pool from the civilian population can be depicted as shown in Figure 2. The complete circle represents the civilian population of a labor market with the part of the circle on the left representing the civilian labor force (CLF) as defined by the U.S. Labor Department. The rectangle indicates the relevant labor pools for a particular job category. The relevant 


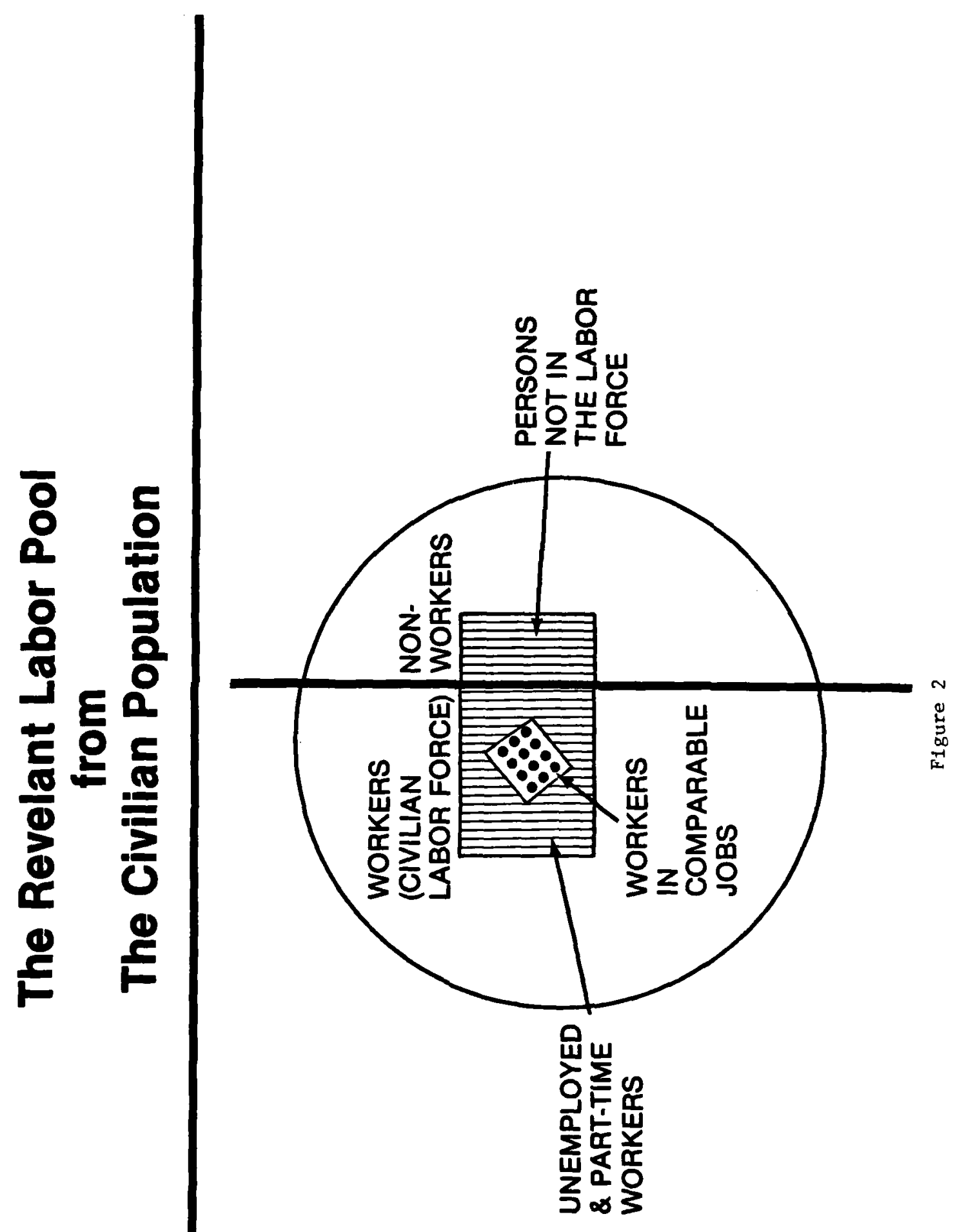


labor pool consists of qualified and qualifiable applicants who are: (1) workers in comparable jobs and (2) unemployed or part-time workers in comparable jobs and (3) persons not in the labor force, such a discouraged workers and those who had jobs in the past five years with qualifiable skills. It is noteworthy that for some job categories, the inclusion of non-worker data adds as much as $50 \%$ to the representation of minorities and women.

Measurement of those who are to be included in the relevant labor pool is done using data obtained from: (1) the Public Use Sample (PUS) of the 1970 Census; (2) the $1976 \mathrm{HEW}$ Survey of Income and Education (SIE); and (3) the 1978 Current Population Survey (CPS). (In 1981, these data sources will be replaced by the 1980 Census). For those in the civilian labor force the data on persons can be matched directly to the jobs using an economic analysis technique called the reservation wage. It was first developed in the 1930's and more recently extended by researchers at the Rand Corporation and at various universities.

Workers who have earned wages that fall within a defined Navy jobs's wage band are said to be wage available. For persons who are not currently working, an "oxpected" or reservation wage is calculated and used to match up with the Navy s offered wage band. The reservation wage is defined as the minimum wage needed to attract a person to begin work in a defined job. This method says that:

4 See Robbins (15)

5 See Atwater (1), Cocan (6), Gronau (6), (7) Hanoch (9), (10) Heckman (11), (12), and Welch and Kosters (16)

6 See Atwater and Sheridan (4) 
(1) An employed person will not changes jobs if what is perceived as the "expected wage" is less than he or she is earning.

(2) A person without a job will not take one that offers a lower expected wage than what he or she gives up and expends by working.

The accuracy of analysis based on the reservation wage principle requires only that persons act as though they consciously calculate expected wages. The statistical procedure used is a refined version of regression analysis. It begins with the public data files excluding no potential worker. A first regression analysis is made using education, experience, and wage data to estimate market wages. These results in turn are used with additional data on hours of work, wages, number of children, alternative wages, and education, to estimate annual hours of work. This second set of results is then compared with Navy data to estimate the value of time for the RNS grups. These data in turn are multiplied by Census Bureau population weights to obtain the potential available for specific job category.

The relevant labor pool includes persons who are unemployed, workers who are employed part-time and persons who are not in the labor force (ex. housewives and discouraged workers) as well as current workers in comparable jobs. Thus, qualified or qualifiable non-workers are counted in developing the affirmative action standards. Only persons who are institutionalized (in hospitals or penal institutions, or are presently in school) or are under 16 years of age or over 65 years of age are excluded from the matching or sorting process. Both workers and non-workers are processed through the same three step sorting sequence.

${ }^{7}$ For the underlying mathematics for the Navy application, see Appendix A of (3). 
Workers and non-workers who meet the wage criteria are then sorted against the educational and occupational skill/experience requirements. Because wage bands, skill requirements and educational factors are overlapping across Navy jobs, persons are often available for more than one specified job.

The labor market analysis reflects projected changes in each identified labor market. Base calclations for 1970, 1976 and 1978 are provided so that changes in the availability of women and minorities can be tracked and projected out to 1983. For example, if $25 \%$ of women who had children under the age of 6 were available for a Navy job in 1970, and 50\% were available in 1978 the projected figure in 1983 using the regession equation would be over 65\%. This projection process is an additional affirmative action aspect of the RLF method.

In the analysis, both the existing workforce as well as the new entrants must be used to make the supply ratio calculations. For example if $20 \%$ of the graduates in 1981 professional occupation were projected to be women (say $2000 / 10,000$ ) and $10 \%$ (or $10,000 / 100,000$ ) in the 1980 existing workforce are women, then the RLF standards for 1981 would be $12,000 / 100,000$ or 10.9\%. (This assumes 10,000 persons left the occupation). 
Other pertinent data such as increased college enrollments of minorities and women are also factored into the calculation of future RLF standards. For example, since engineering school graduates are becoming increasingly represented among women and minorities, even larger proportions are factored into the 1983 RLF supply ratios. When the 1980 Census data becomes available it can be used to update the projections.

\section{The Matching Process}

The first step of the matching process is to extract from public file (i.e. Census, etc.) necessary data for the geographic area involved. The national data are the same for all Navy labor markets. The local data cover the areas determined by the previously described Zip Code study. Figure 3 provides the designation of jobs as being local or national. In later versions data for regional labor markets will be incorporated.

The matching process to determine who is available for a specific Navy job uses three sorting criteria. These are: a wage factor, an occupational skill/experience factor, and an education factor. For craft journeyman positions, three illustrative criteria might be: (1) (\$8.00-\$15.00) per hour 
U. S. NAVY GEOGRAPHIC CRITERIA FOR LABOR MARKET SUPPLY RATIOS

GENERAL SCHEDULE

\begin{tabular}{|l|c|c|c|c|c|}
\cline { 2 - 5 } & GS 1-4 & $5-8$ & $9-12$ & $13-15$ & $16-18$ \\
\hline $\begin{array}{l}\text { Scientists and } \\
\text { Engineers }\end{array}$ & - & National & National & National & National \\
\hline $\begin{array}{l}\text { Other } \\
\text { Professional }\end{array}$ & - & National & National & National & National \\
\hline Administrative & Local & Local & Local & National & National \\
\hline Technical & Local & Local & Local & Local & - \\
\hline Clerical & Local & Local & Local & - & - \\
\hline Other & Local & Local & Local & - & - \\
\hline
\end{tabular}

UNGRADED

\begin{tabular}{|l|l|l|l|l|l|}
\cline { 2 - 5 } & Apprentice & $\begin{array}{l}\text { Helper \& } \\
\text { Semi-Skilled }\end{array}$ & Journeymen & Leader & Supervisor \\
\hline $\begin{array}{l}\text { Craf tsmen } \\
\text { and Operatives }\end{array}$ & Local & Local & Local & Local & Local \\
\hline $\begin{array}{l}\text { Gardners } \\
\text { and Laborers }\end{array}$ & - & Local & Local & Local \\
\hline
\end{tabular}

Figure 3 
wage band, (2) previous craft work experience required and (3) no specified minimum years of completed education required. Persons who meet the criteria for a specific job are counted in the "available" or relevant labor force.

An example of the sorting process is shown in Figure 4. Here, are three individuals (Census I.D.'s 305,415 , and 2012 ) and one job (paying $\$ 6.00-\$ 14.00$ per hour, requiring 16 years of education (a college education, with a background in science). All the individuals obtained in step one are run through a decision table for the job as shown in step two. In this case, Census 1.D. No. 2012 is the only one which fits all the required match. In an actual application, all persons in a given labor market are run against all jobs. The result is the establishnent of the proportions of the "available" force by RNS group for a specific set of jobs. If 500 persons are "available" for a Navy job and 100 are black females, then the proportion of black females would be $20 \%$. The available external group of persons for a Navy job is referred to as the relevant external labor force (RLF). The RNS proportions are used as RLF numerical standards or measures for which internal adjustments are made and minimum EEO goals are generated for each Navy job.

\section{Navy External RLF Data}

Data for the Department of the Navy labor markets as of 1979 are provided in Appendix B. Similar data has been projected for 1983. It is emphasized that these data are particular to Navy civilian jobs and may not apply to organizations with different occupation and wage distributions. 
EXTERNAL RELEVANT LABOR FORCE (RLF)

METHODOLOGY

1. Obtain the People Date for the Georgraphic Area Involved

\begin{tabular}{|c|c|c|c|c|c|}
\hline $\begin{array}{l}\text { CENSUS } \\
\text { I.D. }\end{array}$ & SEX & $\begin{array}{l}\text { RACE/ } \\
\text { NAT. OR. }\end{array}$ & WAGE & ENUC & OCCUPATION \\
\hline $\begin{array}{r}305 \\
415 \\
2012\end{array}$ & $\begin{array}{l}M \\
F \\
M\end{array}$ & $\begin{array}{l}\text { Black } \\
\text { White } \\
\text { Asian }\end{array}$ & $\begin{array}{r}\$ 5.50 \\
7.00 \\
12.00\end{array}$ & $\begin{array}{l}13 \\
12 \\
16\end{array}$ & $\begin{array}{l}\text { Carpenter } \\
\text { House Wife } \\
\text { Scientist }\end{array}$ \\
\hline 三 & & & & & \\
\hline
\end{tabular}

II. Run the Process for each Job Category

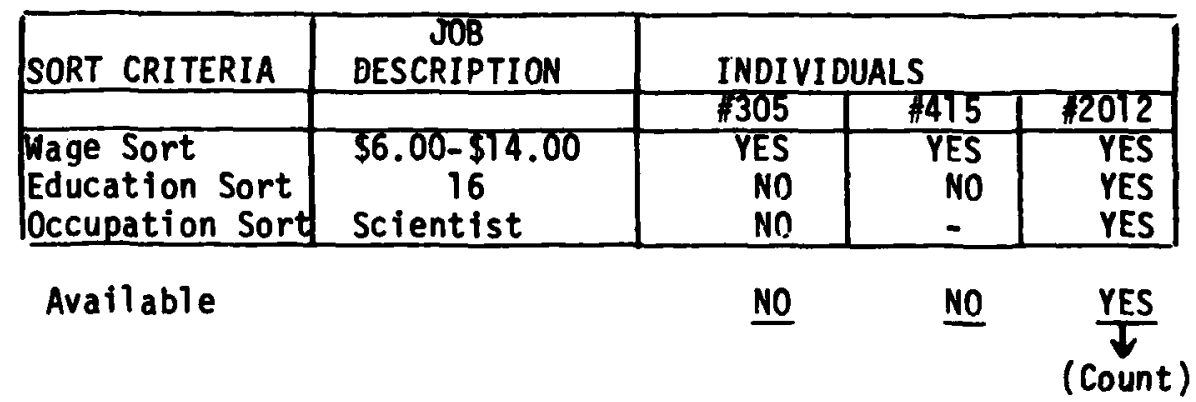

III. Obtain the Proportions

Count all "available" persons for each job and provide the RNS proportions for the specific job categorfes. 
As an aid to interpreting the data in Appendix B, it is useful to examine some of the data more closely. In almost all of the data, at least some shift towards minorities and women are shown over time. This indicates their increased availability for participation in the complete spectrum of Navy jobs. This is shown, for example, in Figure 5 which displays national data for scientists and engineers. These data for the external wage bands are equivalent to the wage bands of GS 5-8, GS 9-12, and GS 13-15 levels respectively. The 1978 data are actual and the 1983 data are projected. In this five year period a strong shift towards minorities and women is projected. For example, in the GS 5-8 category the availability of white males will shift on a proportionate basis from $82.7 \%$ to 74.0\% as the other RNS categories increase.

Similar shifts towards minorities and women can be seen in the local data. Figure 6 provides the projected 1979 and 1983 local relevant labor force (RLF) data for the San Diego Navy labor market. It is clear that the dynamics of increased opportunties are beginning to be reflected in the composition of the work force.

\section{Future Research}

The data in Appendix B are the first set of RLF data the Navy has had for use in connection with EEO policy development. One of the objectives in publishing the data is to invite review by others to assist in their improvement. The use of the RLF data is only part of an affirmative action system. 


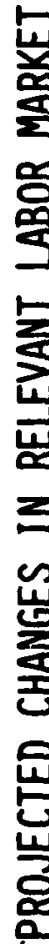

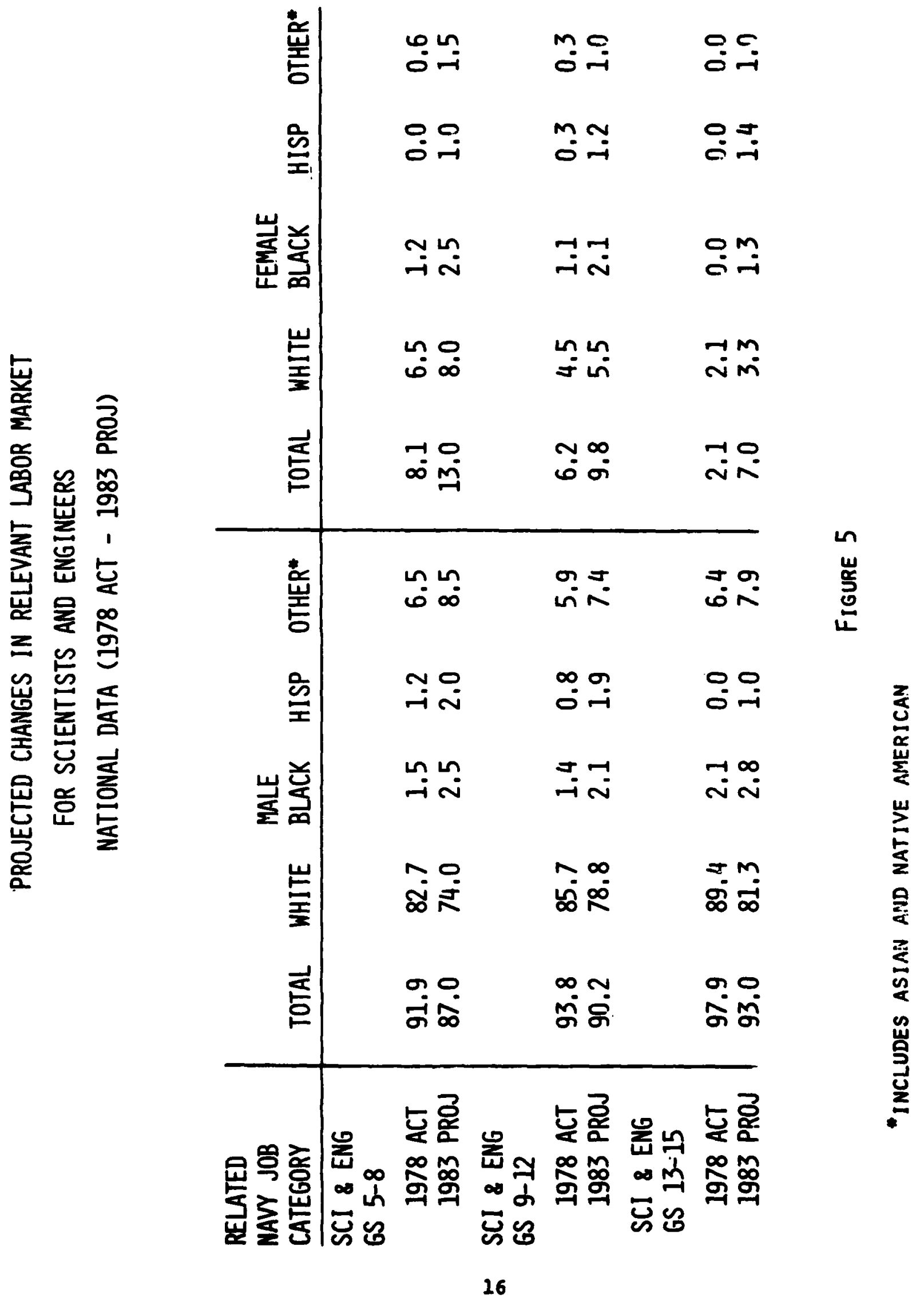




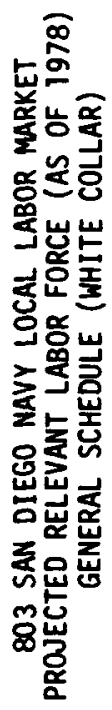

\begin{tabular}{|c|c|c|c|c|c|c|c|c|c|c|c|}
\hline $\begin{array}{l}\text { 垔 } \\
\text { 宫 }\end{array}$ & कं & बू & $\dot{0}^{\circ}$ & जi & $\begin{array}{l}\text { مु० } \\
\text { im }\end{array}$ & $\ddot{\circ}$ & $\stackrel{\square}{\square}$ & $\stackrel{9}{-\pi}$ & $\ddot{~}$ & 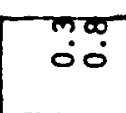 & अه \\
\hline 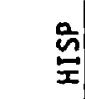 & má & má & mó & जim & กْ & ìm & जi & $\dddot{m}$ & $\ddot{m}$ & 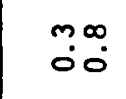 & $\stackrel{\square}{\circ}$ \\
\hline ب. & तim & نْ & $\ddot{0}$ & هُ & هُ & $\ddot{0}$ & بْ: & ن̊. & iे: & $\stackrel{m}{0}_{0}^{\infty}$ & $\begin{array}{l}+\infty \\
00\end{array}$ \\
\hline 㞾 岕 & مْ & 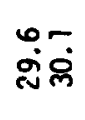 & 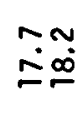 & $\begin{array}{l}\mathscr{m} \\
\dot{\sigma} \mathscr{\sigma}\end{array}$ & تீ: & نㅇํㅇ & 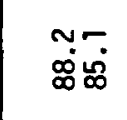 & ஸ் & تீ: & $\stackrel{m}{\infty} \underset{\sigma}{\infty}$ & $\hat{\sim}$ \\
\hline $\overrightarrow{\underline{\sigma}}$ & mo & జं & ஹִm & $\begin{array}{l}\infty \\
\tilde{\sigma} \dot{0} \\
\dot{\sigma}\end{array}$ & $\begin{array}{l}00 \\
0 \\
0 \\
0\end{array}$ & $\begin{array}{l}\infty \\
\dot{m} \\
\dot{m}\end{array}$ & भूa & พั๐ & लू. & 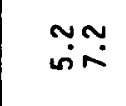 & gin \\
\hline 营 & ن & $\ddot{\circ}$ & $\ddot{0}$ & im & ஸ̊ & :3: & $\ddot{0}$ & $\ddot{0}$ & $\dot{m}_{0}^{m}$ & 我 & "0. \\
\hline 氙 & $\stackrel{\text { N }}{\text { N }}$ & iि & mó & $\begin{array}{l}\text { जo } \\
\text { im }\end{array}$ & nim & 30 & $\ddot{0}$ & $\ddot{0} 0$ & $\ddot{m}$ & $\underset{*}{\sim} \dot{*}$ & लिं \\
\hline 崖 & Nָ & $\ddot{0}$ & mo & $\hat{\sim} \tilde{m}$ & "̊. & $\begin{array}{l}m+ \\
00\end{array}$ & $\ddot{\circ}$ & $\ddot{0}$ & mó & $\begin{array}{l}\text { no } \\
\ddot{\sim}\end{array}$ & ڤ. \\
\hline 岂 & تْ & 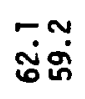 & $\ddot{8}$ & लिं & "ా & นี่ & जo: & $\vec{\omega}$ & 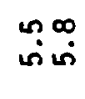 & ஜீ: & ரே \\
\hline 홍 & †ㅇㅇㅇ & $\begin{array}{l}09 \\
\dot{6} \\
0\end{array}$ & 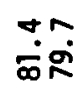 & ஸ்̃ & में & 行 & $\overrightarrow{0}$ & $\stackrel{\infty}{\sim}$ & $\stackrel{+}{0}$ & $\begin{array}{l}\infty \infty \\
\dot{\alpha} \tilde{\alpha}\end{array}$ & ஜ் \\
\hline$\stackrel{\infty}{\complement}$ & पू̊日్ & 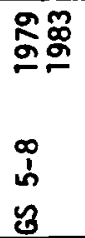 & 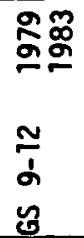 & 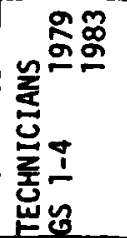 & 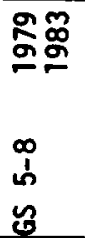 & 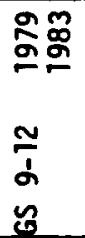 & 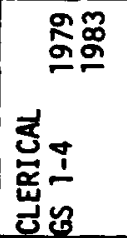 & 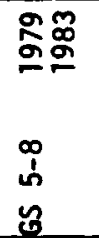 & 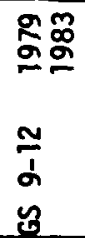 & 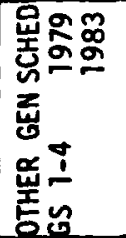 & 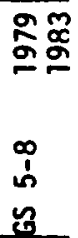 \\
\hline
\end{tabular}




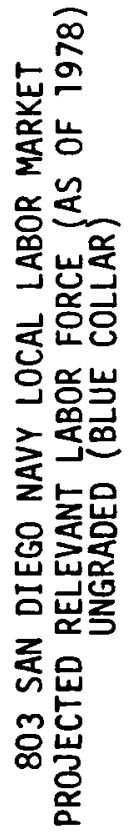

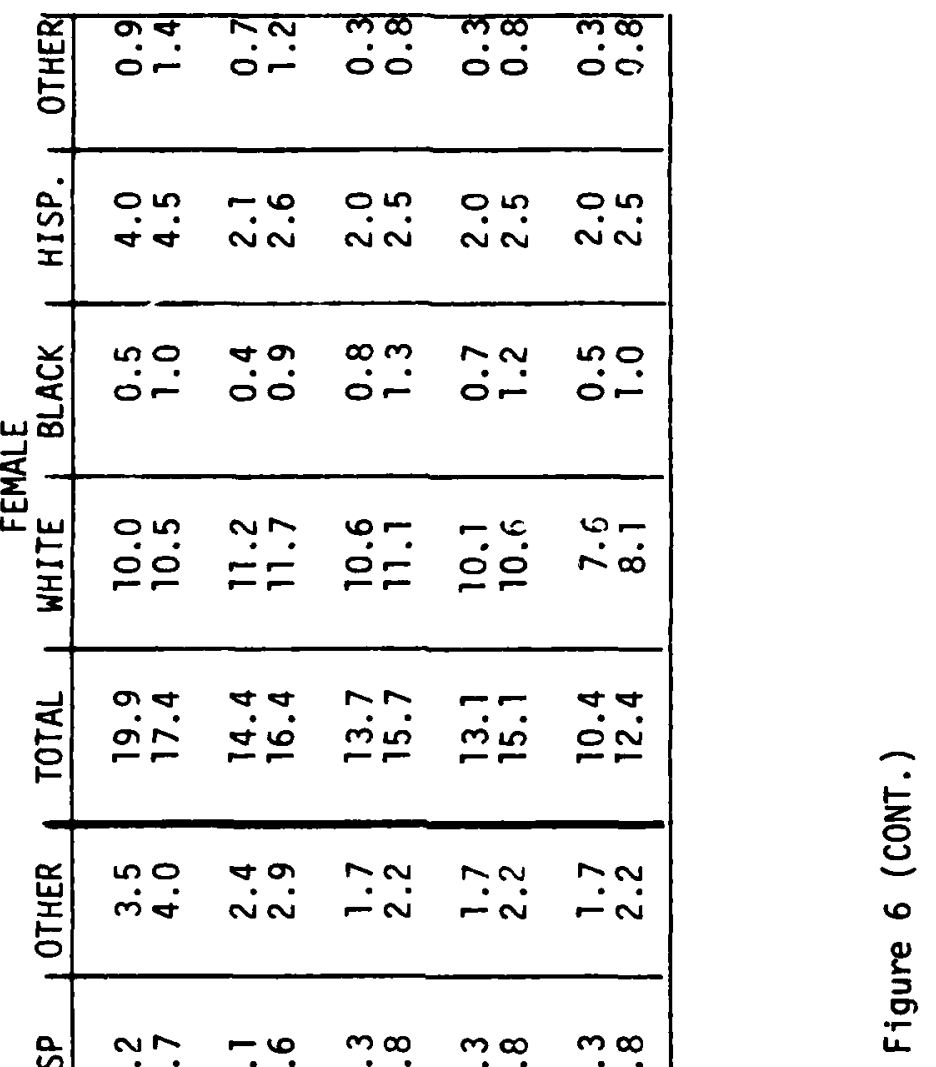


Data on the civilian labor force (CLF) which is not skill or wage specific is also needed to adequately represent affirmative action concerns and meet external reporting requirements of Equal Employment Opportunity Commission (EEOC) and OPM. These affirmative action concerns and how they fit into an EEO accountability system extend well beyond the technical computation of external RLF data. These issues are discussed in detail in (14). However, further technical work remains in the refinement of the RLF data estimation process.

For some of the occupations further detail in the RLF data appears useful. For example, it would be useful to separate the professional occupations into scientists, engineers, mathematicians, accountants, etc. Further specificity also appears to be needed for the technician occupations since the Navy employs a considerable number of engineering technicians who exhibit different RNS profiles than do management technicians. These extensions to the analysis are underway.

Another area of technical concern which was not addressed is consideration of regional recruitment areas. Examples of these would be higher graded engineering technicians, mid-level administrative personnel, and highly skilled craftsmen. Research to understand better the demographic characteristics of these jobs with a regional recruitment area is underway. Once the findings of this research is completed, the data in Appendix $B$ will be amended accordingly. 
The issue of the relationships between the external non-federal labor market and the Federal labor market is being studied. This is particularly important for upper level jobs since applicants for the most part come from the Federal agencies. The Zip Code data will be used to obtain the percentages of new hires or accessions which come from the Federal agencies. These percentages will be used with data obtained from the OPM to obtain supply ratios for the Federal work force. Then, these data will be combined on a proportionate basis with the external non-Federal supply ratios in Appendix $B$ to obtain a better estimate of the Navy's external relevant labor force.

General economic considerations which extend the present analyses include the impact of unemployment, inflation, transportation and housing costs. Studies are underway looking at the projected impact of the above factors on changes in wages of different RNS groups as they relate to Navy jobs.

Mobility patterns are a significant factor on the availability of workers. This applies to both the external and internal labor markets. Preliminary internal mobility studies indicate that minorities and women in non-professional Navy jobs are less mobile than white males (i.e. have lower observed loss rates). Further study of this phenomenon and its relationship with external demographic mobility patterns is underway. This research involves coupling external demographic models with internal flow models as part of strategic policy making.

The main purpose of this report was to describe the Navy's EEO external labor market analysis capabilities and to provide the initial set of data developed with this capability. As indicated above, considerable opportunities for improvement of this data remain. 


\section{References}

(1) Atwater, D. M., Calculating Potential Labor Force Participation for Specific.Job Classifications in Local Labor Markets: An Econometric Method, A.T. \&T. HRD Technical Report, 1976.

(2) Atwater, D. M., R. J. Niehaus, and J. A. Sheridan "External Labor Market Analysis and EEO Goals Planning" OCP Research Report No. 33 (Washington, D.C.: U.S. Navy Office of Civilian Personnel, 1978)

(3) Atwater, D. M., R. J. Niehaus, and J. A. Sheridan "EEO Goals Development in the Naval Sea Systems Command" OASN(M,RA\&L) Research Report No. 35 (Washington, D.C.: Office of the Assistant Secretary of the Navy (Manpower, Reserve Affairs and Logistics, 1978)

(4) Atwater, D. M. and J. Sheridan, Assessing the Availability of NonWorkers for Jobs (forthcoming).

(5) Bloch, H. R. and R. L. Pennington "Use of Applicant Flow Data in a Discrimination Suit" Public Personnel Management Vol. 9. No. 1 Jan - Feb 1980.

(6) Cogan, J. "Labor Supply with Time and Money Costs of Participation" The Rand Corporation, R-2044, Santa Monica, California, Autust 1976

(7) Gronau, R. "The Intrafamily Allocation of Time: The Value of the Hous ewife's Time", American Economic Review 63:4, September 1973

(8) Gronau, R. "The Effects of Children on the Housewife's Value of Time", Journal of Political Economics, March/April 1973

(9) Hanoch, G. "An Economic Analysis of Earnings and Schooling "Journal of Human Resources, Summer 1969

(10) Hanoch, G. "A Multivariate Model of Labor Supply: Methodology for Estimation", the Rand Corporation, R-1869-HEW/ASPE, Santa Monica, California, September 1976

(11) Heckman, J. J., "Sample Selection Bias as a Specification Error" The Rand Corporation, R-1983-HEW, Santa Monica, California, August, 1978.

(12) Heckman, J. J. "Shadow Prices, Market Wages, and Labor Supply", Econometrica 42:4 July 1974

(13) Niehaus, R. J., Computer-Assisted Human Resources Planning (New York: Wiley Interscience, 1979)

(14) Niehaus, R. J. and D. Nitterhouse "Planning and Accountability Systems for EEO and Affirmative Action Policy" OASN (M, RA\&L) Research Report No. 38 (Washington, D.C.: Office of the Assistant Secretary of the Navy (Manpower, Reserve Affairs and Logistics, 1986) (forthcoming)

Robbins, L., "On the Elasticity of Income in Terms of Effort, Econometrica, Vol. 10, June, 1930.

(16) Welch, F. and M. Kosters, "The Effects of Minimum Wage on the Distribution of Changes in Aggregate Employment," American Economic Review, June, 1972. 
Appendix A

NAVY LOCAL LABOR MARKETS

FOR EEO RELEVANT LABOR FORCE ANALYSIS

Navy Code

007

013

014

018

021

030

034

035

039

044

045

050

055

112

115

136

153

219

220

229

233

332

338

359

522

525

531

546

547

549

601

602

604

616

623

625

627

648

651

660

674

706

743

765

\section{Principal City}

Charleston

Pensacola

Jacksonville

Cherry Point-Camp Lejeune

Louisville

Albany

Orlando

Memphis

Beaufort-Parris Island

Key West

Panama City

Bay St. Louis

Pascagoula-Gul foort

Southeast Maine

Newport

New London

Boston

Crane

Indianabolis

Great Lakes

Cleveland

New Orleans

Corpus Christi

Dallas-Fort Worth

Bayonne (MSC LANT)

Long Island

Lakehurst

Colts Neck

Trenton

New York

Washington

Norfolk

Philadel phia

Mechanicsburg

Annapolis

Patuxent River

Yorktown

Dahlgren

North Philadelphia

Warminster-Willow Grove

Quantico

Bremerton

Oak Harbor

Seattle
State

SC

$\mathrm{FL}$

FL

KY

GA

$\mathrm{FL}$

TN

SC

$\mathrm{FL}$

$\mathrm{FL}$

MS

MS

ME

RI

MA

IN

IN

IL

$\mathrm{OH}$

LA

TX

$T X$

NJ

NY

NJ

NJ

NJ

NY

DC

VA

PA

PA

$M D$

$M D$

VA

VA

PA

PA

VA

WA

WA

WA 
Navy Code

803
805
808
809
810
811
817
824
826
828
837
840
841
852
854
857
858
861
876
942

Principal City

State

San Diego

San Francisco-Alameda

Pearl Harbor

Vallejo

Long Beach

Port Hueneme

China Lake

Corona

San Mateo

San Bernadino

Oakland (MSC PAC)

San Jose

Monterey

Lemoore

Concord

Yuma

Stockton

Falion

Fi Toro

Kansas City
CA

CA

$\mathrm{HI}$

CA

$C A$

$C A$

$C A$

$C A$

$C A$

CA

$C A$

$C A$

CA

CA

CA

$A Z$

CA

NV

$C A$

MO 
Appendix B

Relevant Labor Force Statistics for Navy Labor Markets

The relevant labor force statistics were first estimated using the "available" labor pool methodology. In some cases the sample sizes were too small to obtain a reliable estimate. In such instances, the data was developed by a number of means (i.e. repeating the next lower values, using data from similar local areas, using trends evident across areas, etc). Further improvement of the data are possible particularly after the results of the 1980 Census are available. 


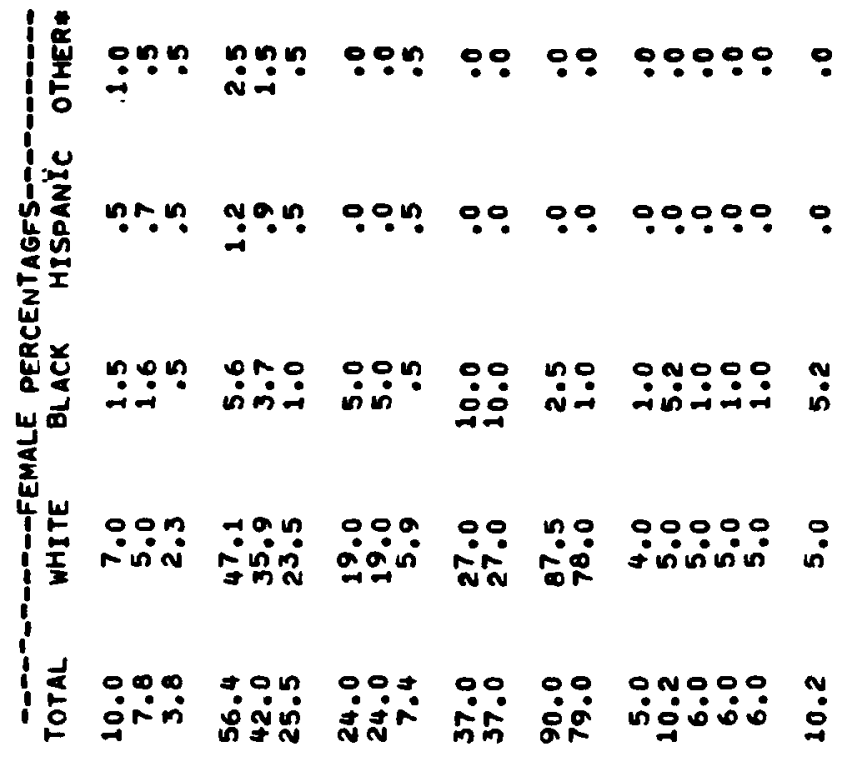

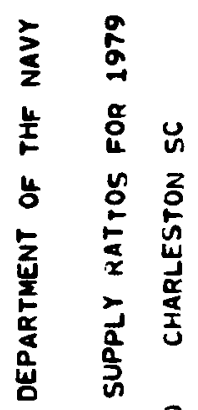

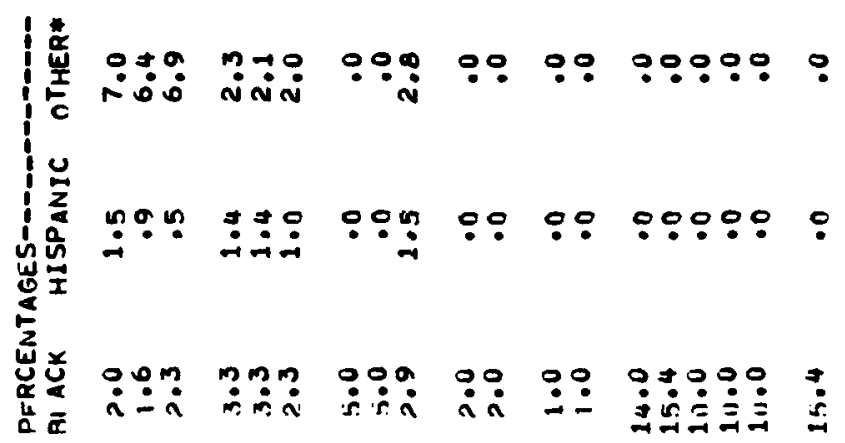

ב

委

|

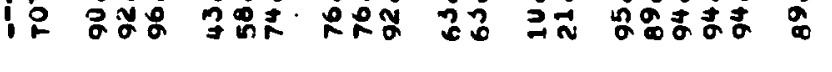

嵌

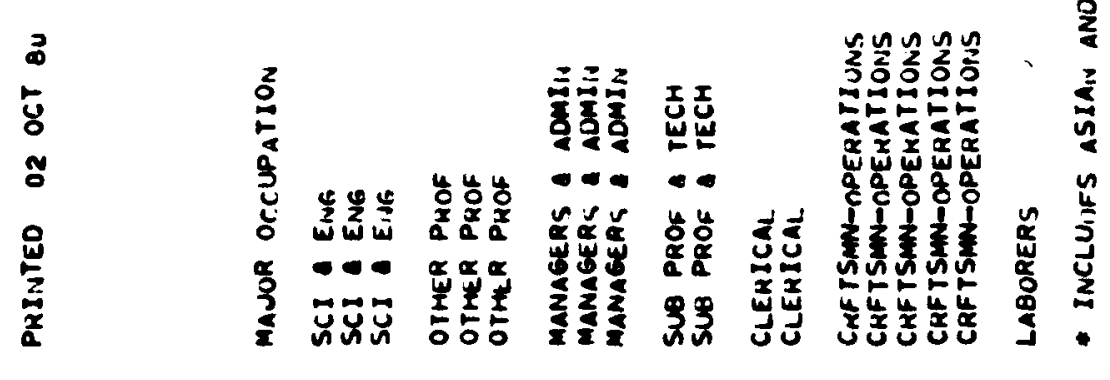



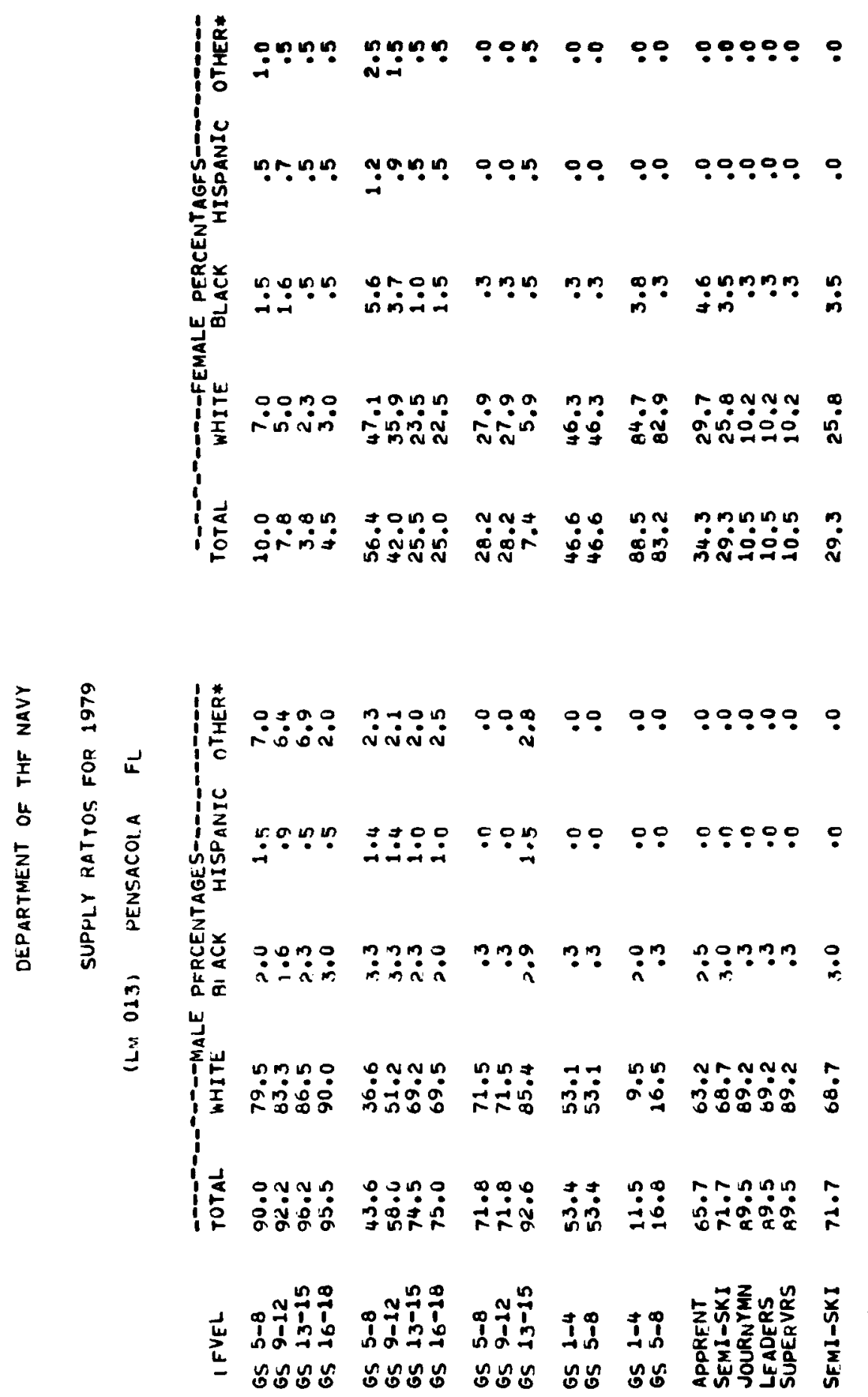

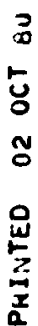

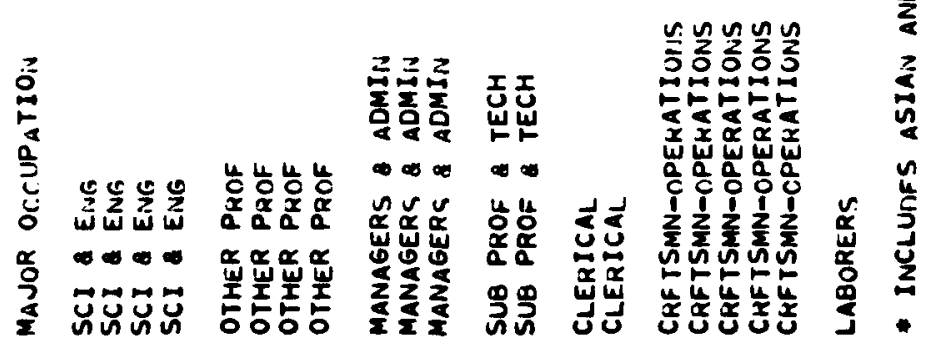




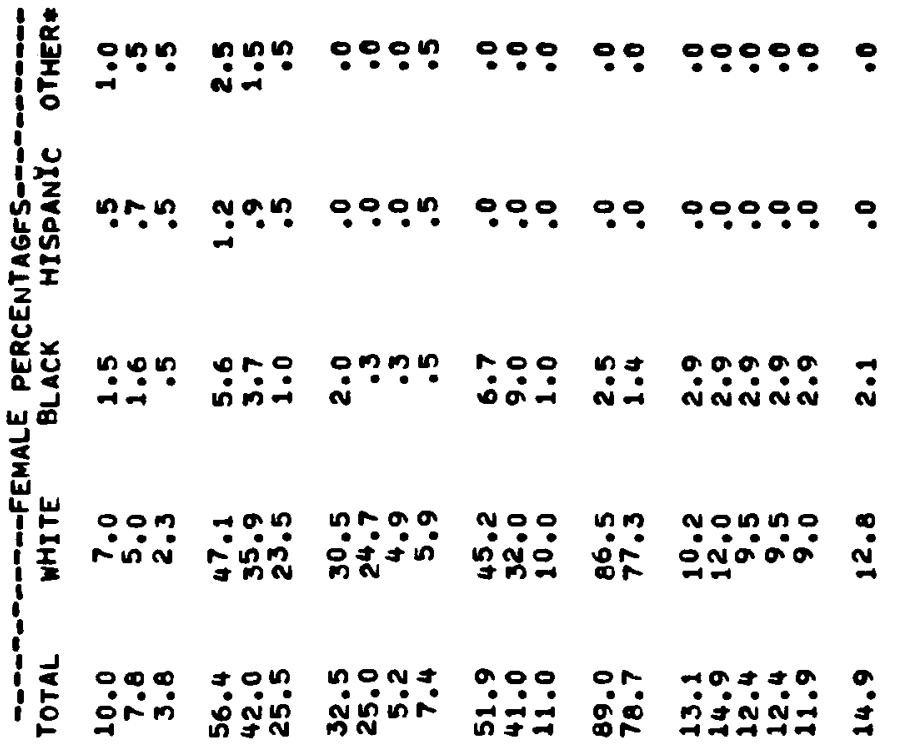

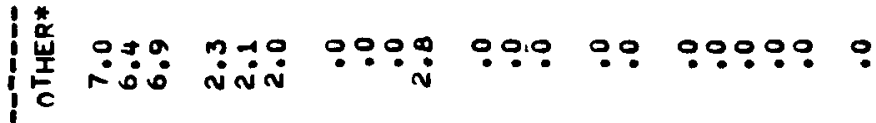

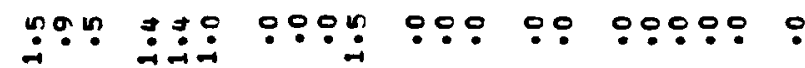

政

버ㅇㅓㅗ

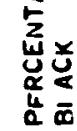

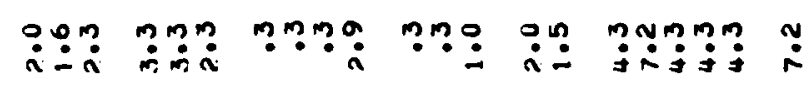

峞

至

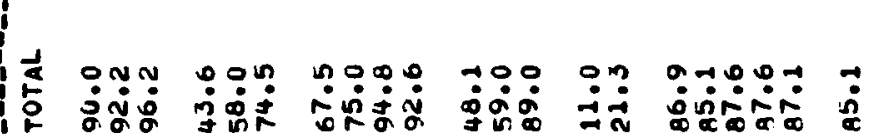

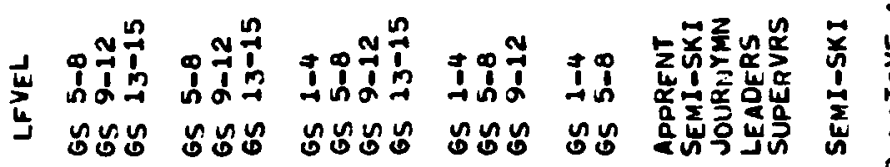

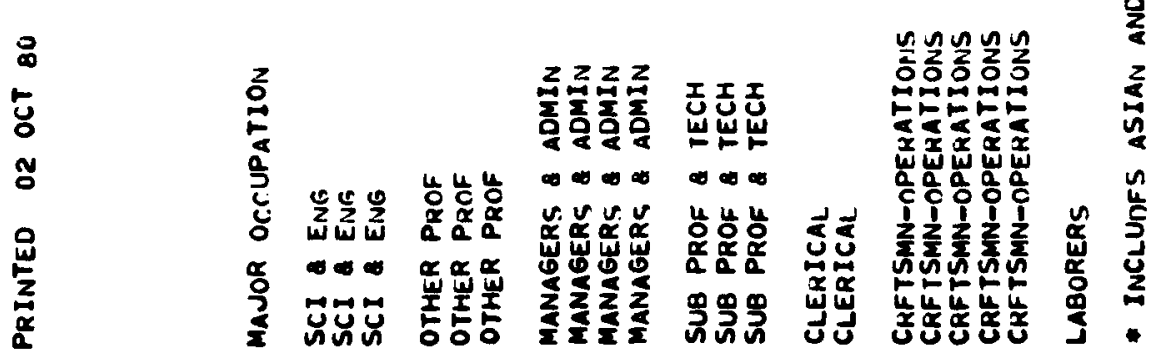




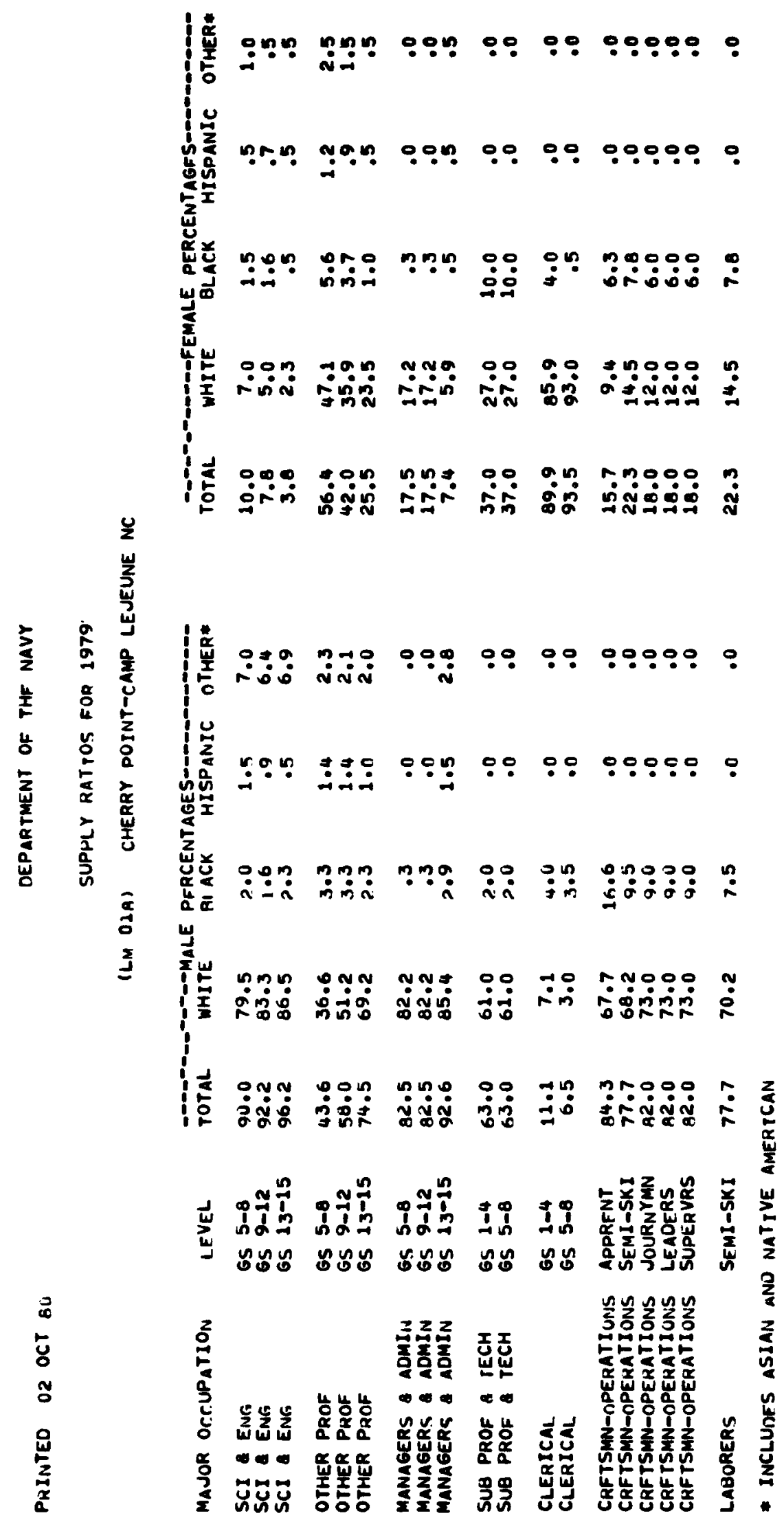



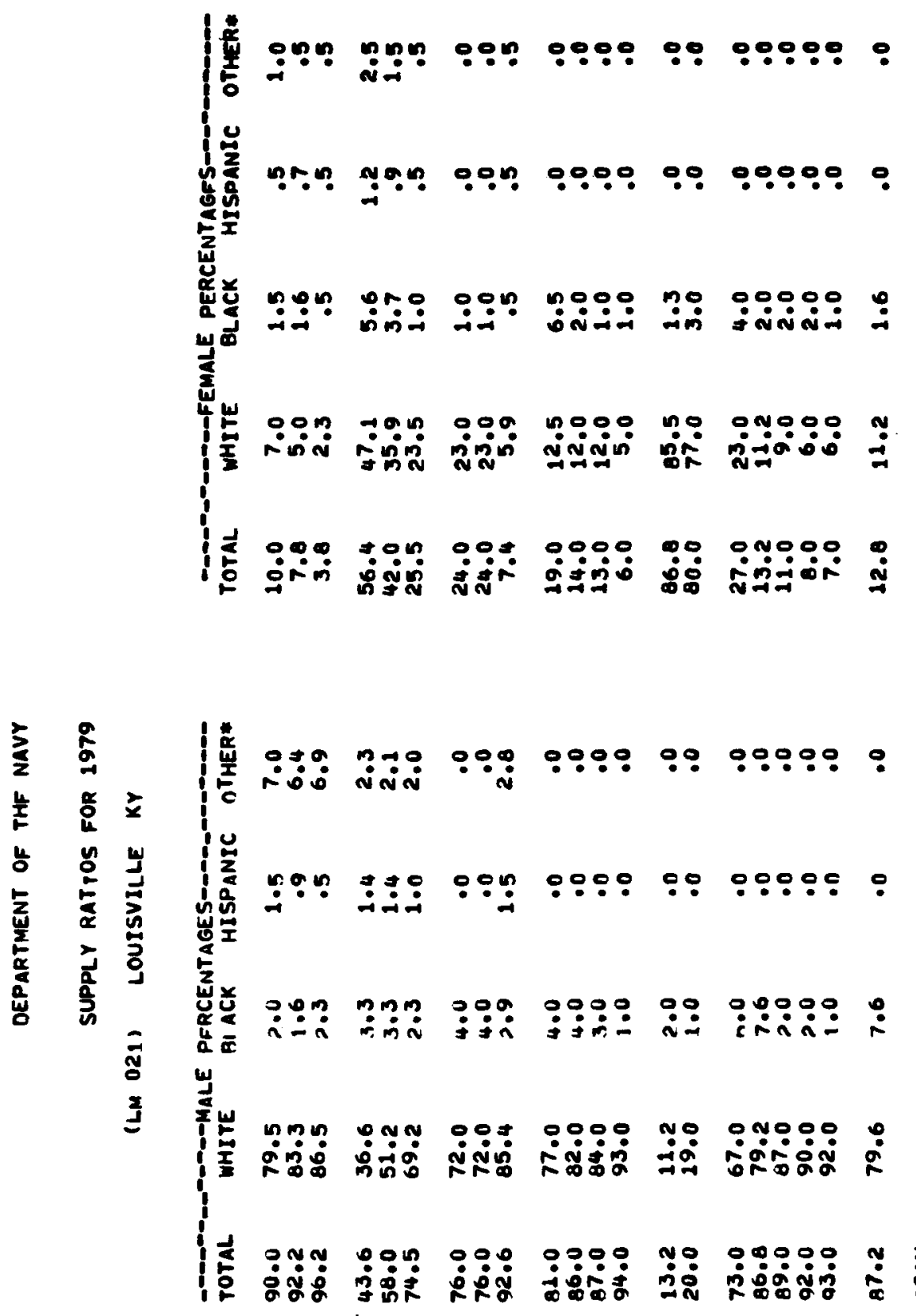
岀

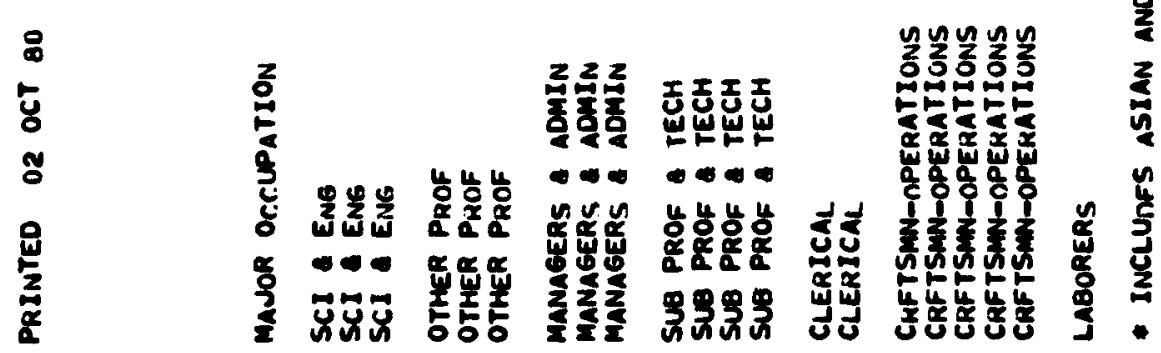




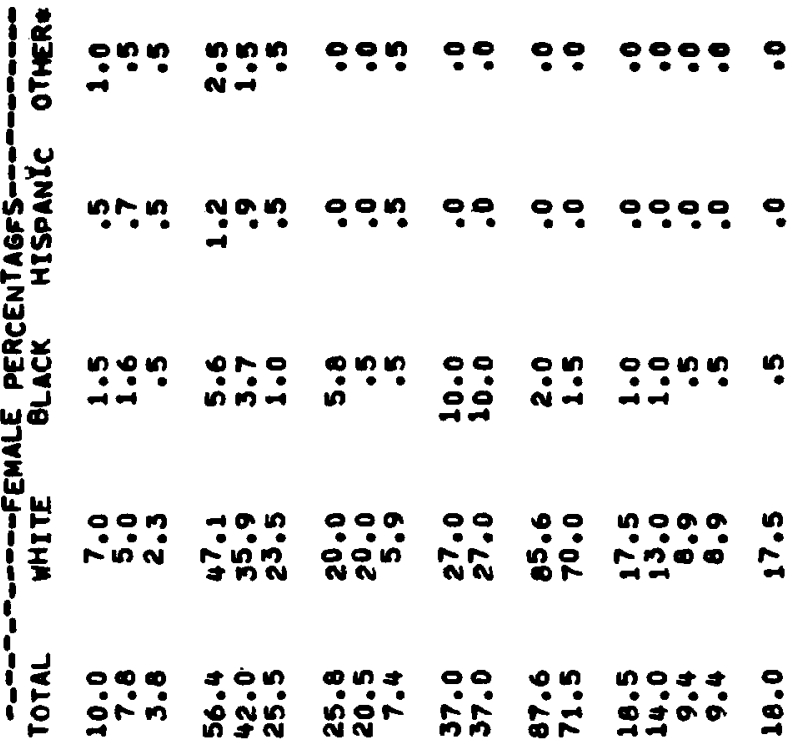

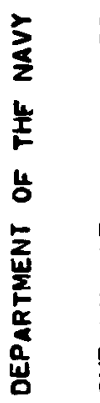

|

is

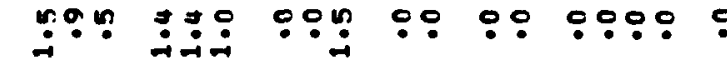

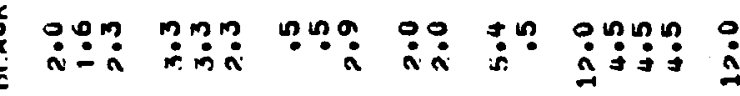

岂

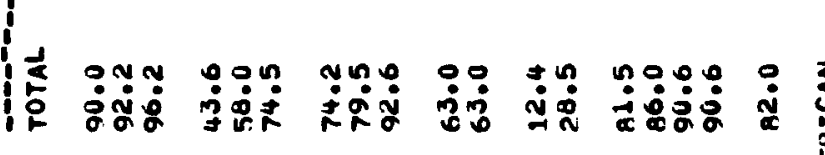

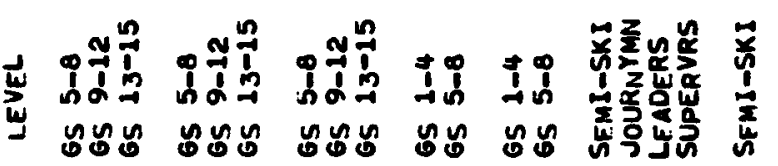

:

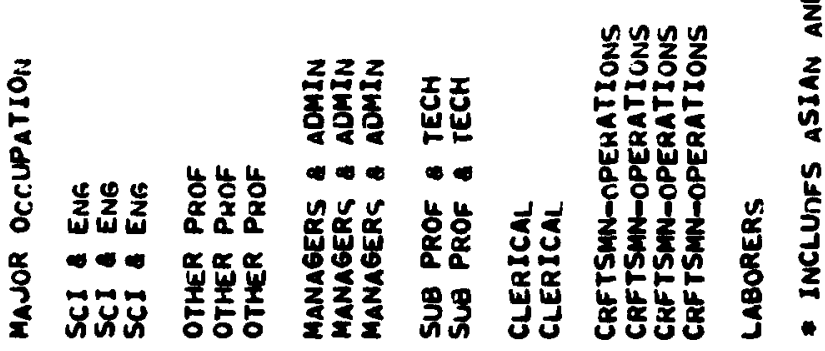



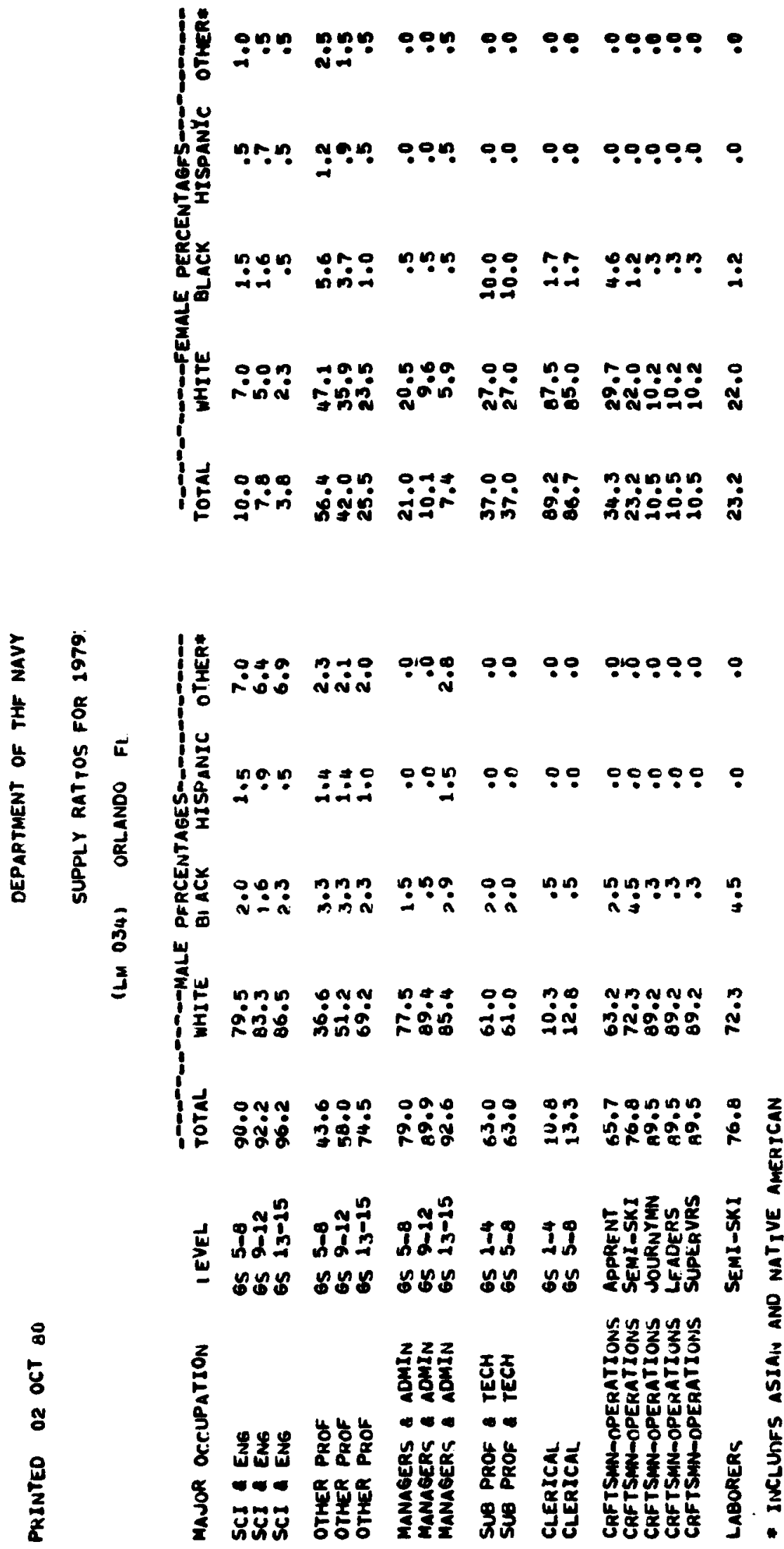

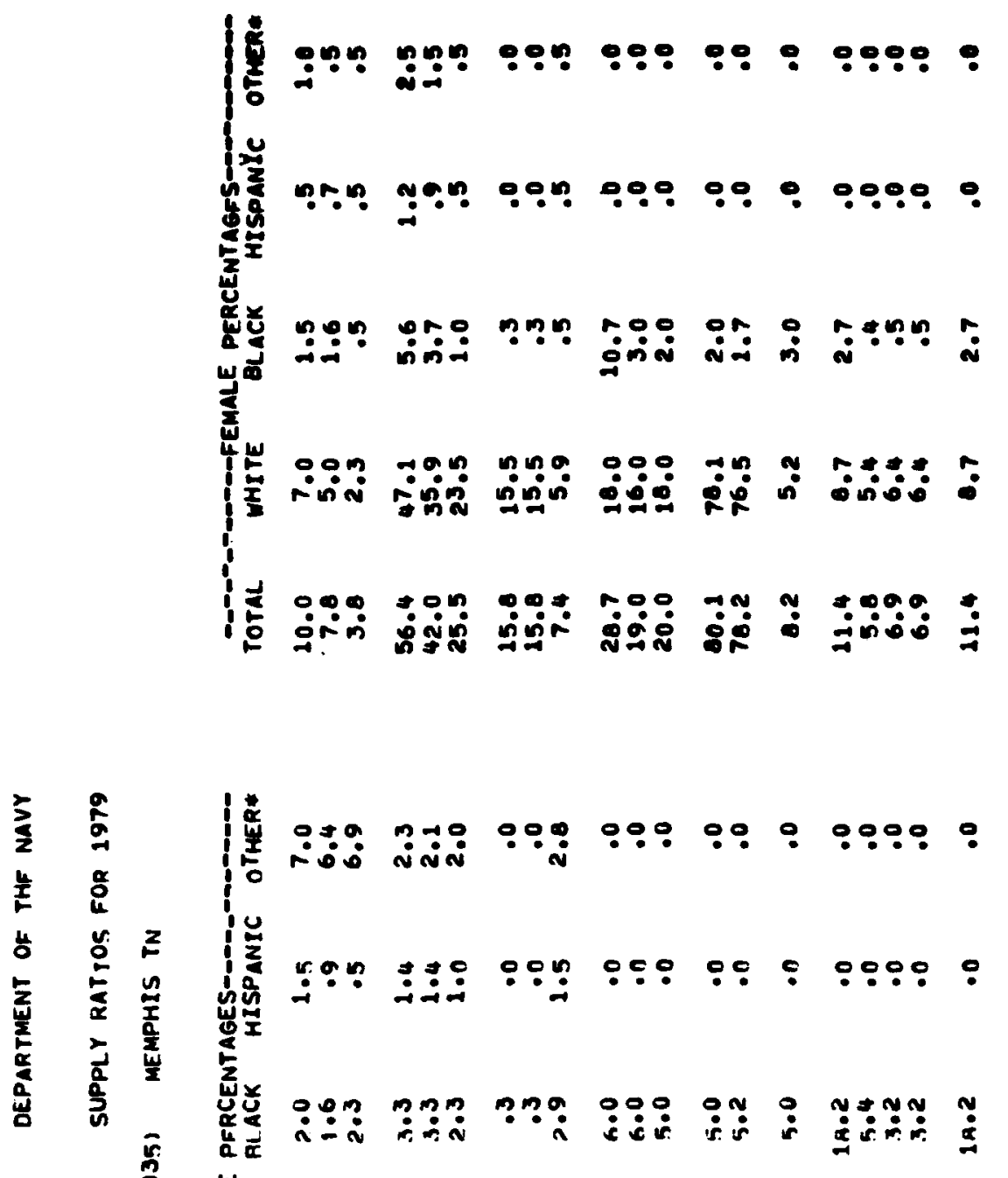
20

岁

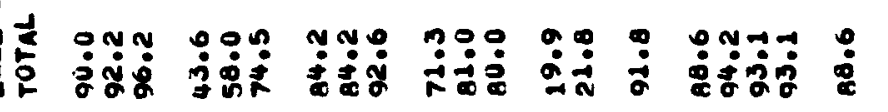

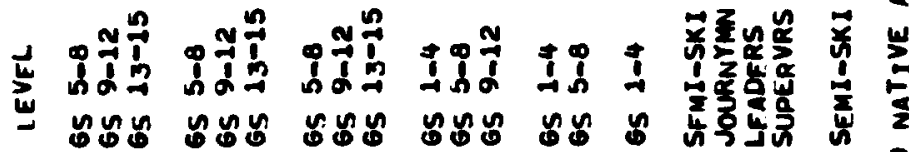

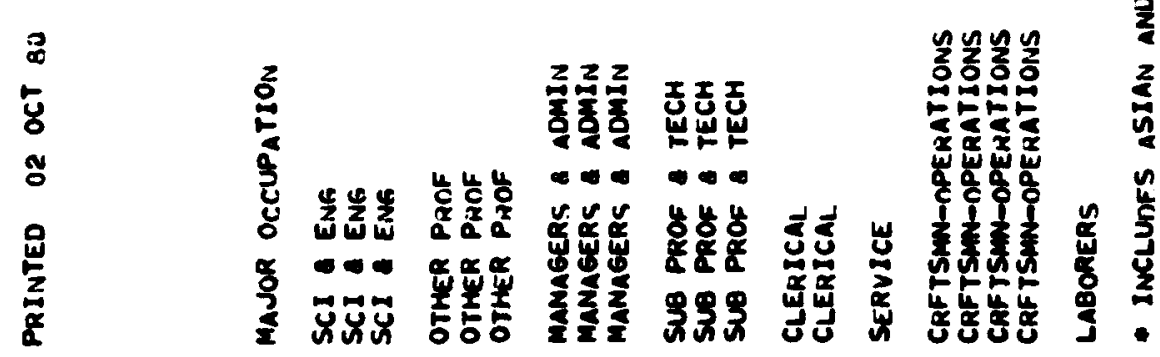




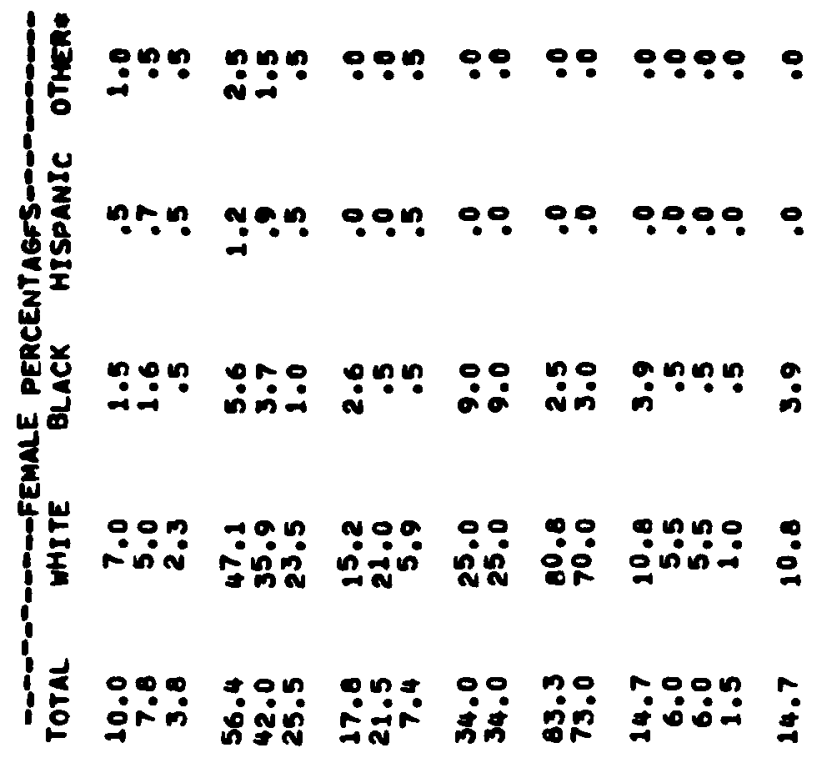

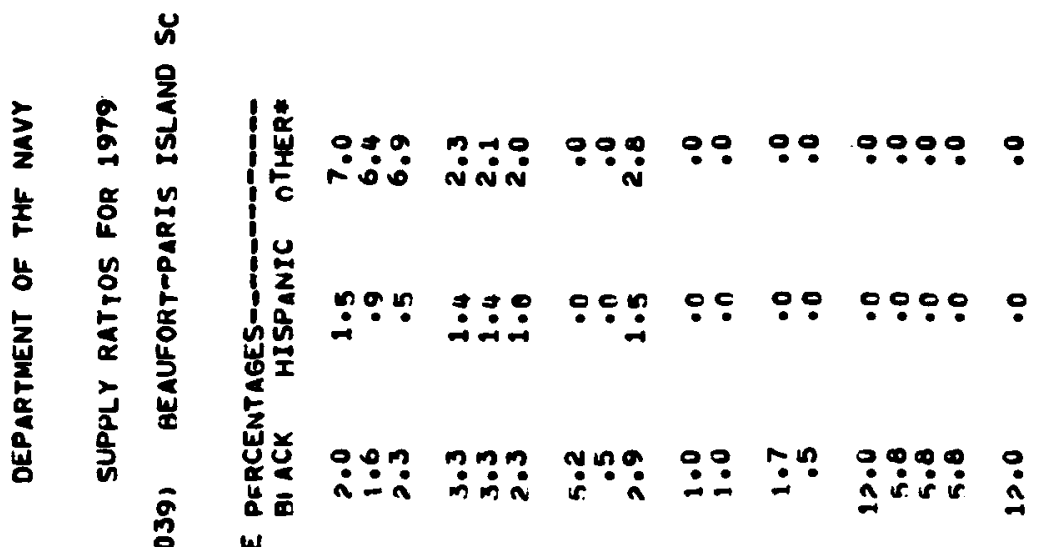

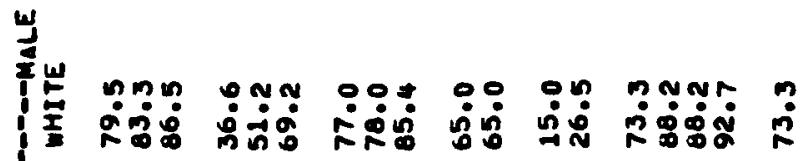

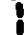

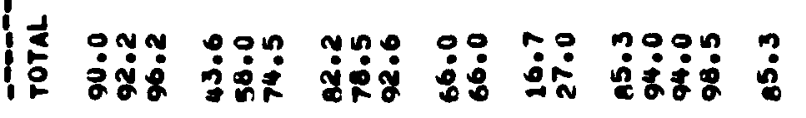

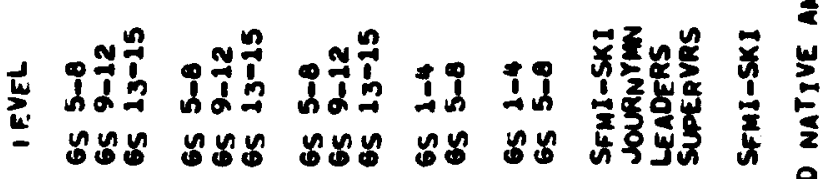

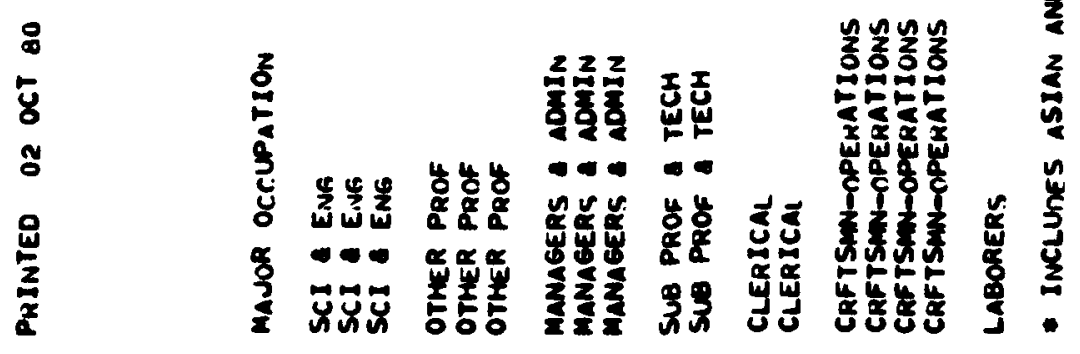



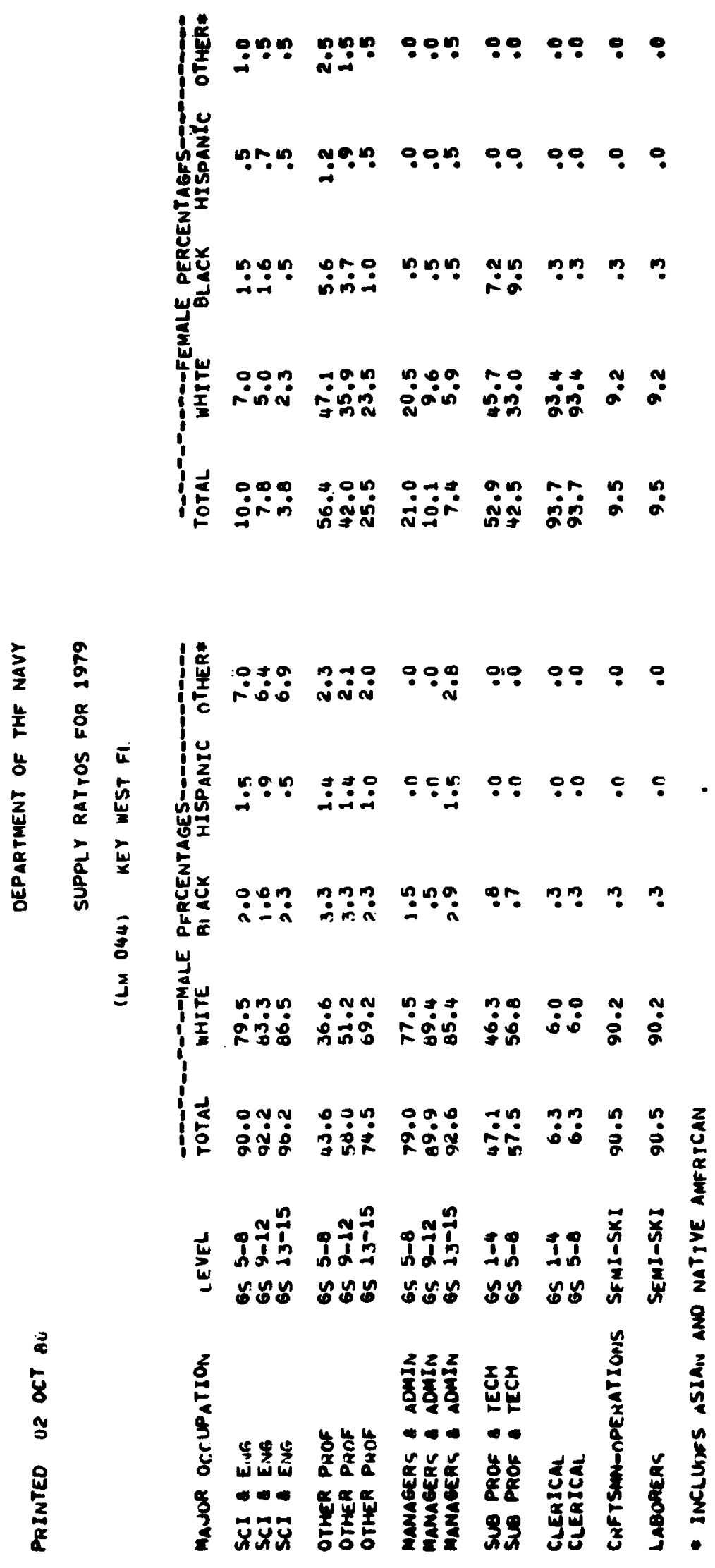

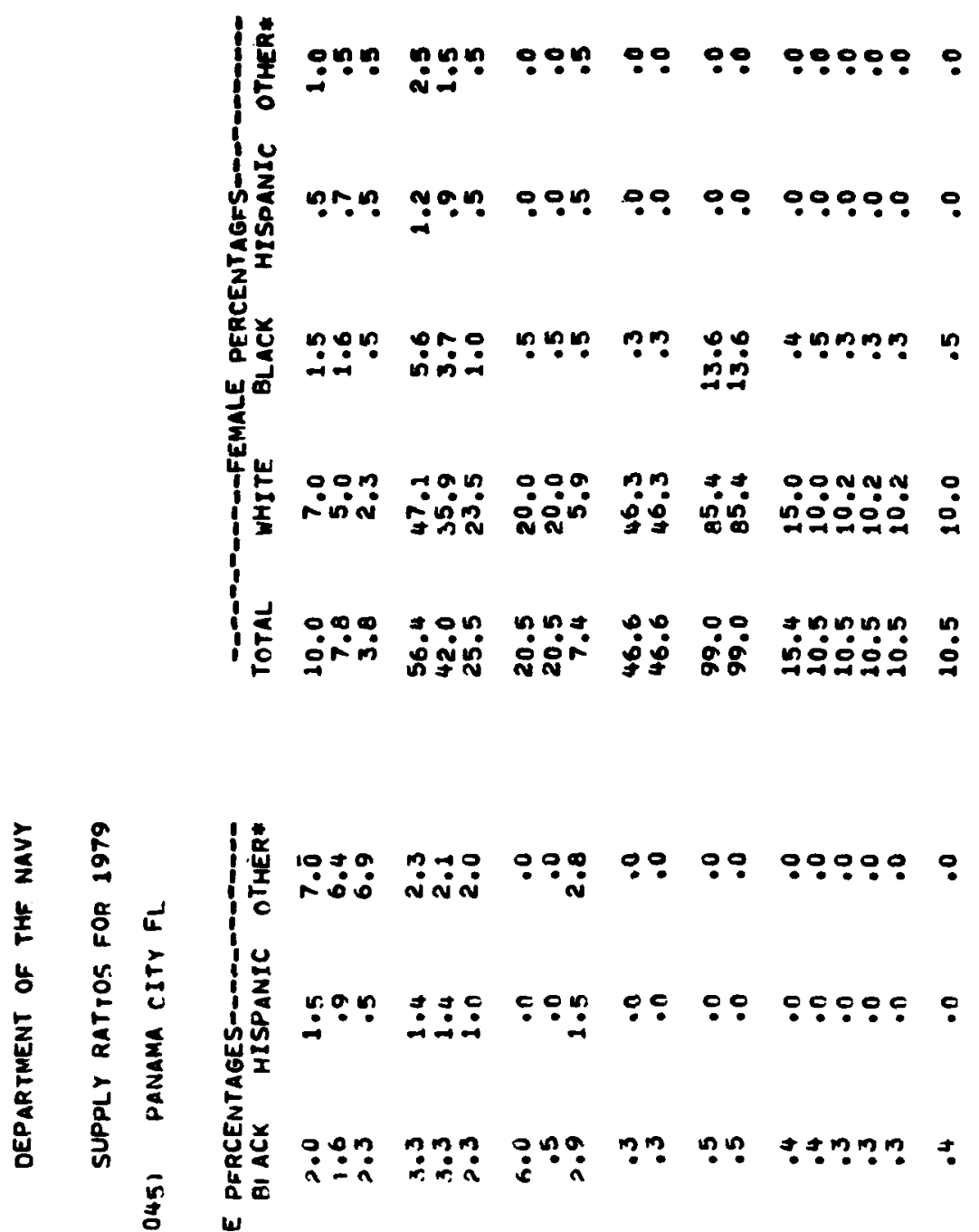

至 \{ 워

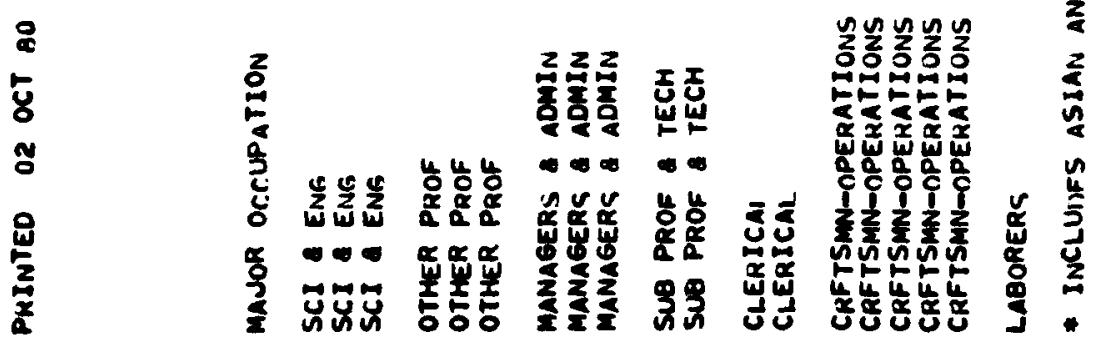




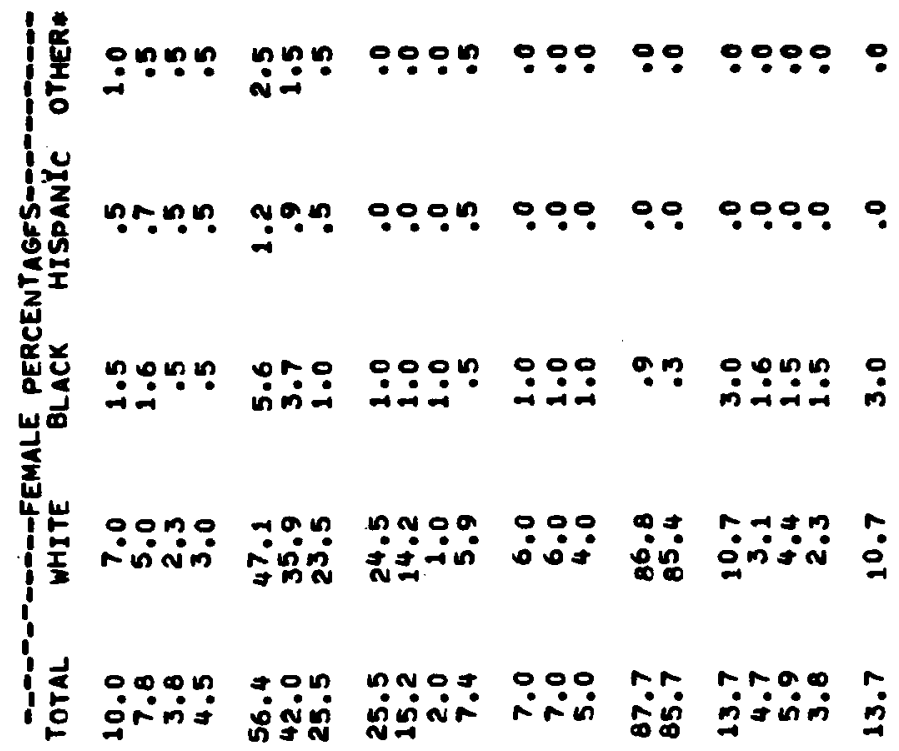

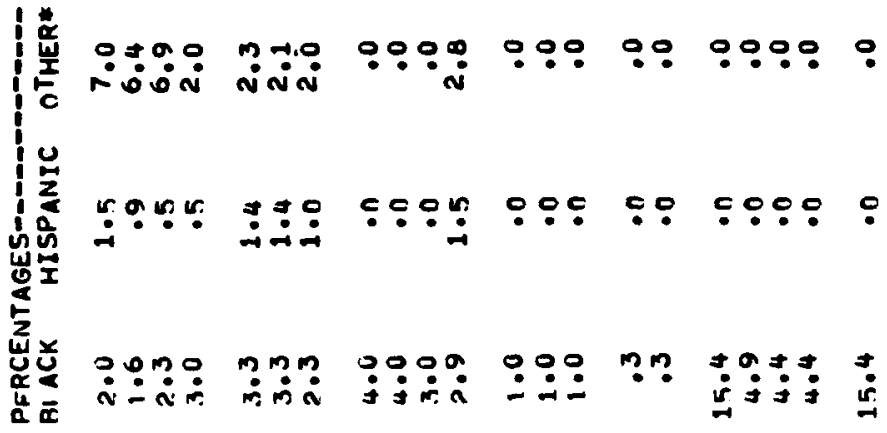
岁

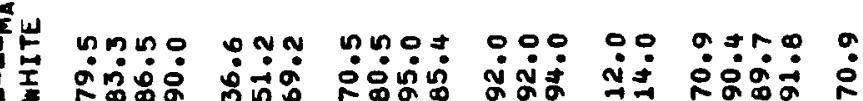

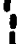

送

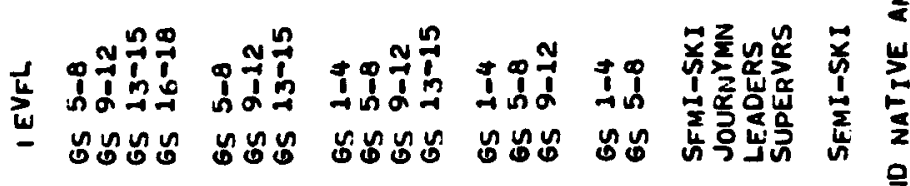

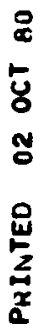

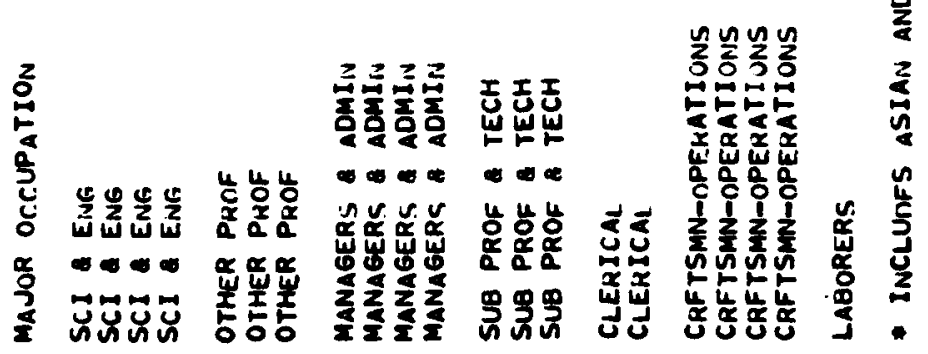




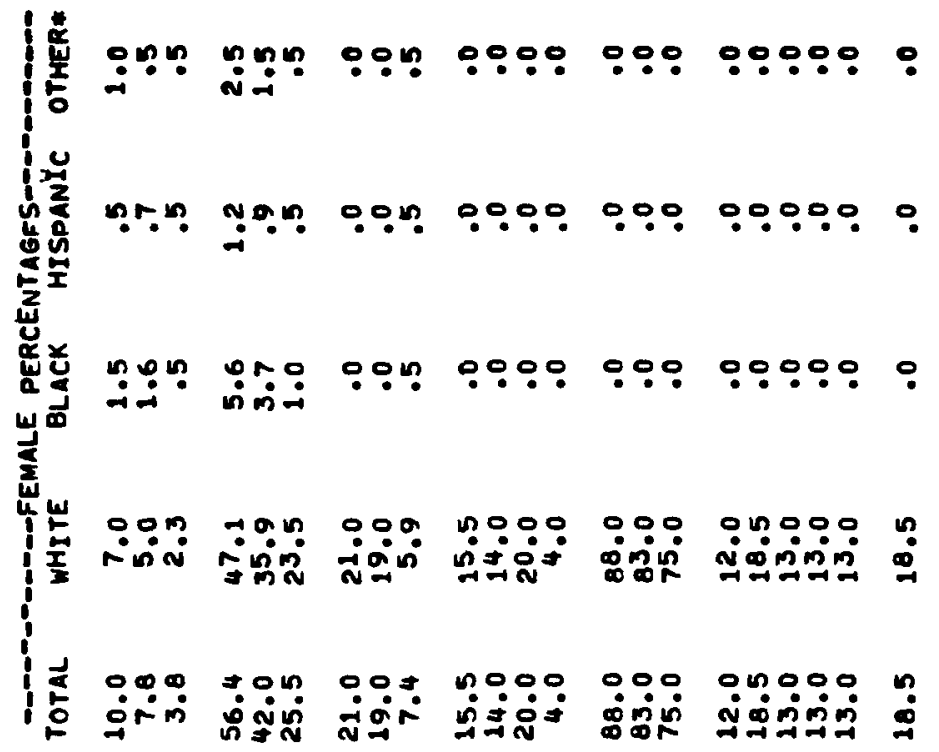

竞

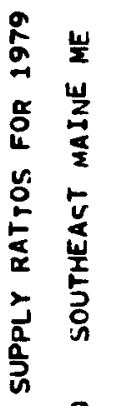

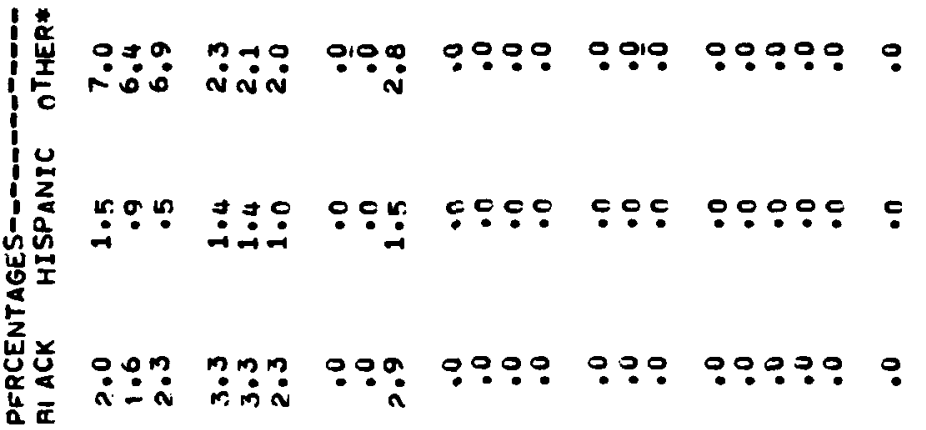

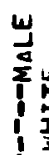

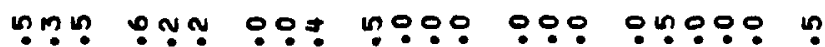

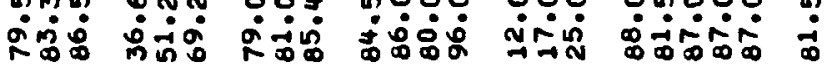
1

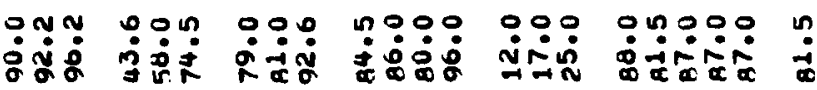

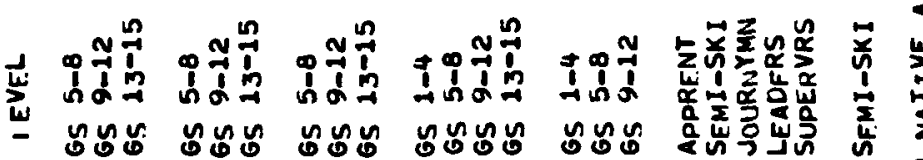

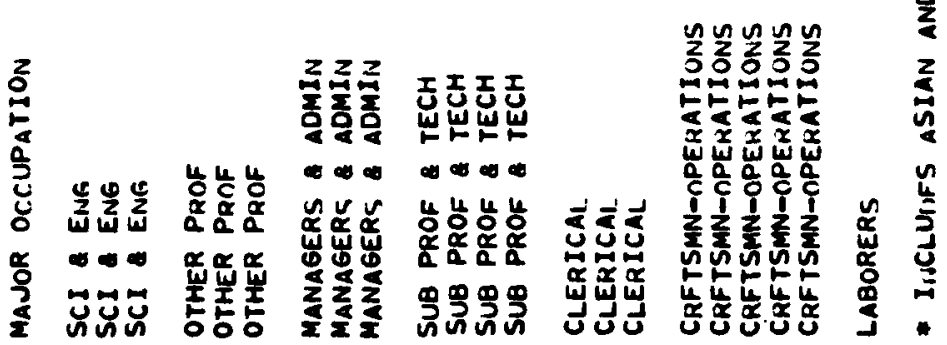




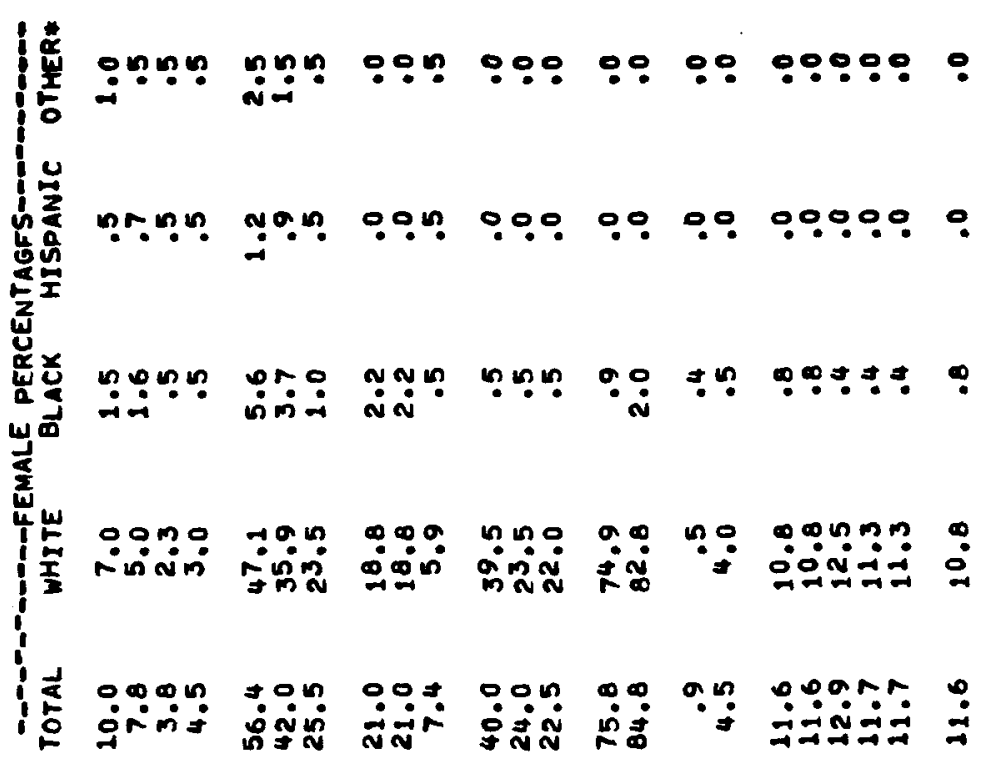

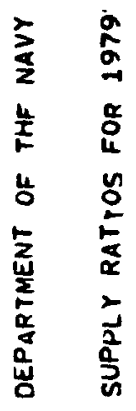

|

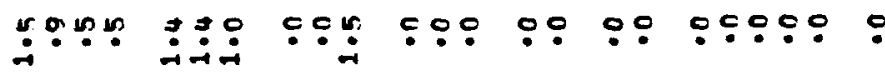

岁㫮

密

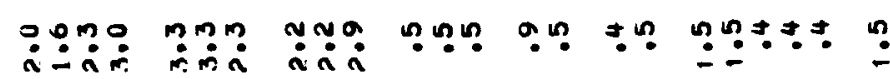

a

山

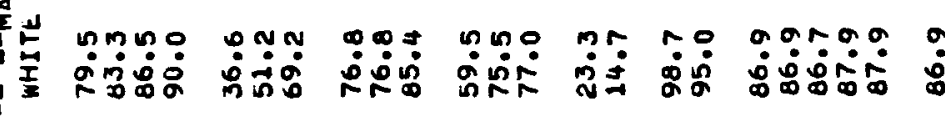

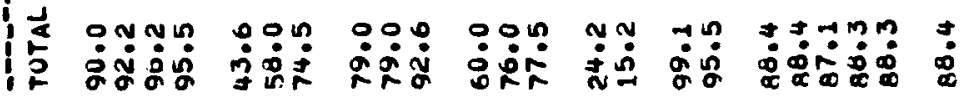

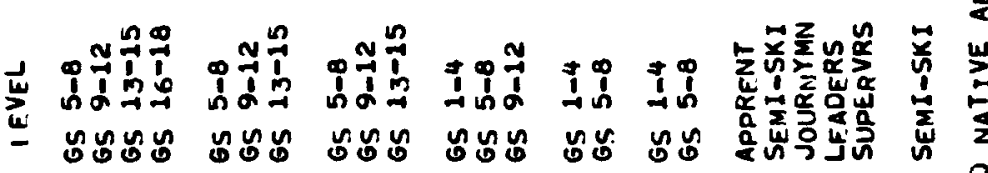

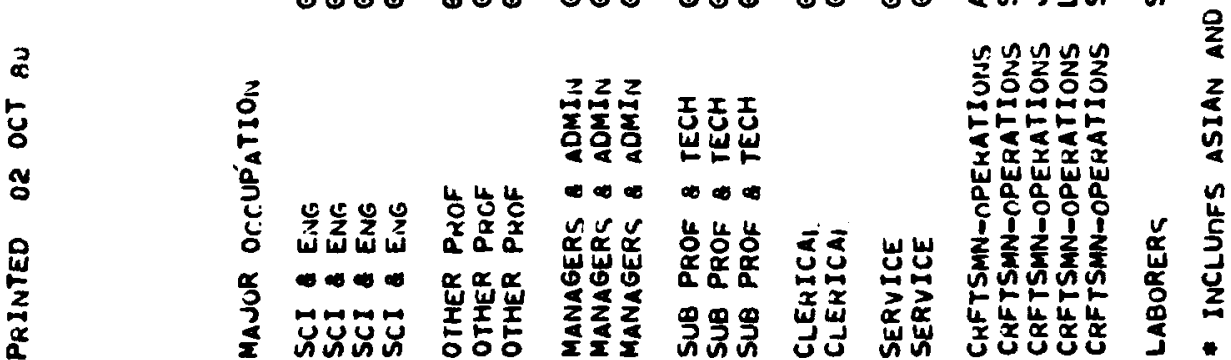



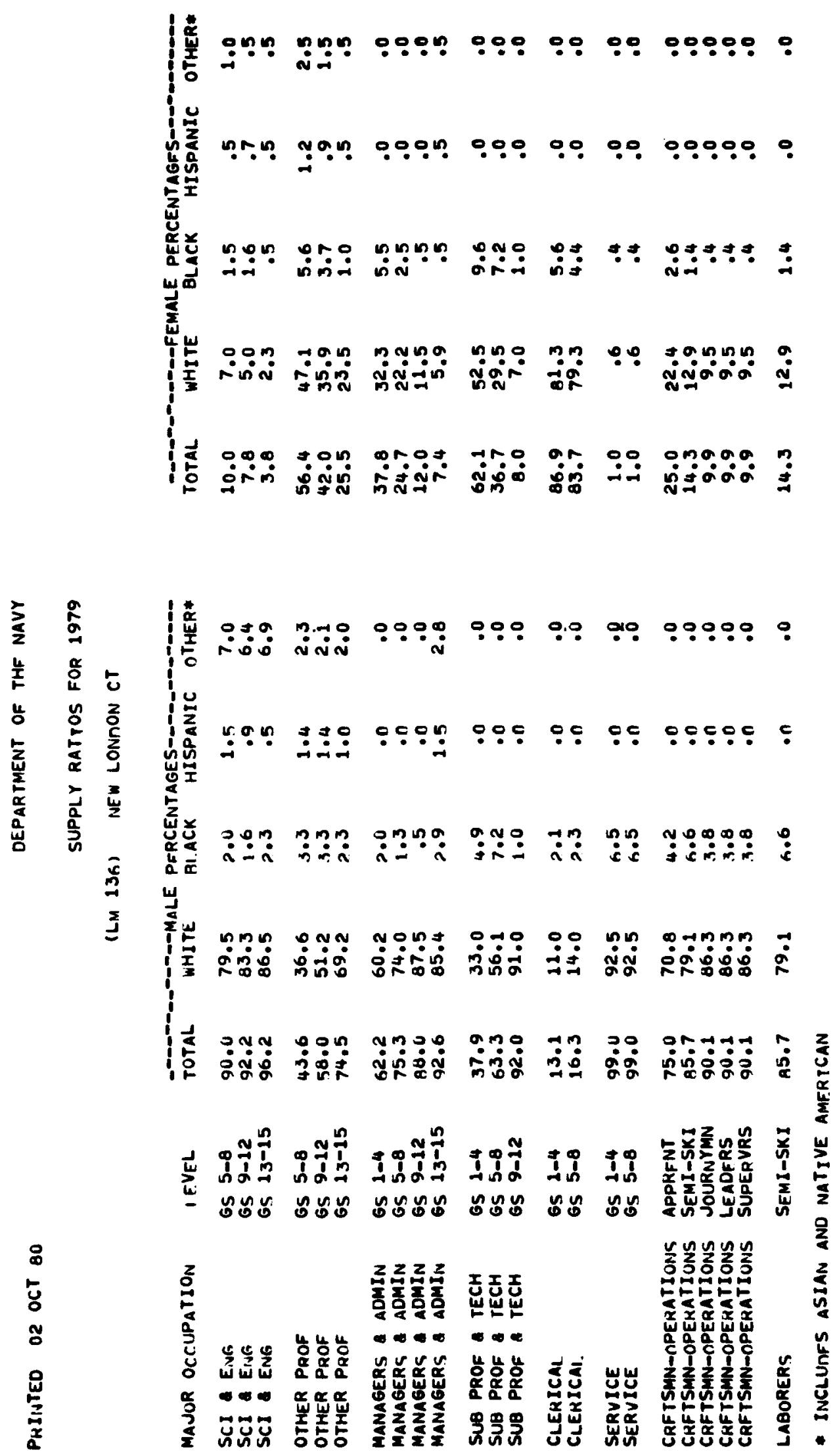


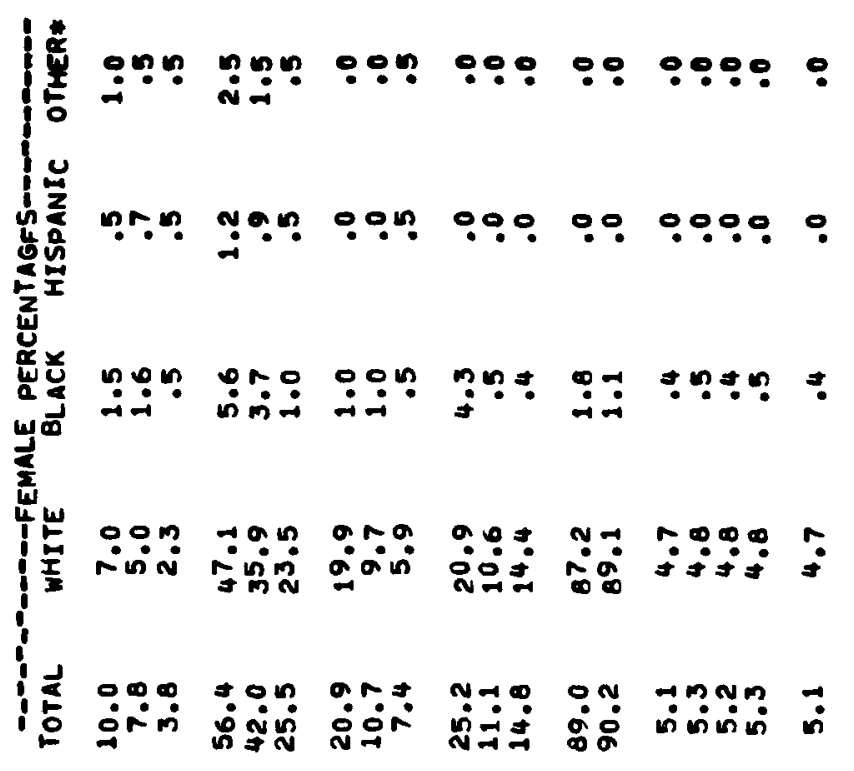

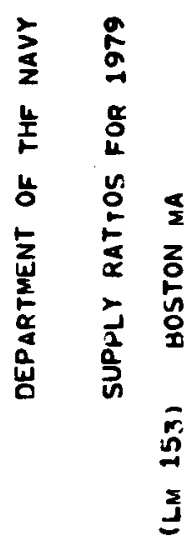

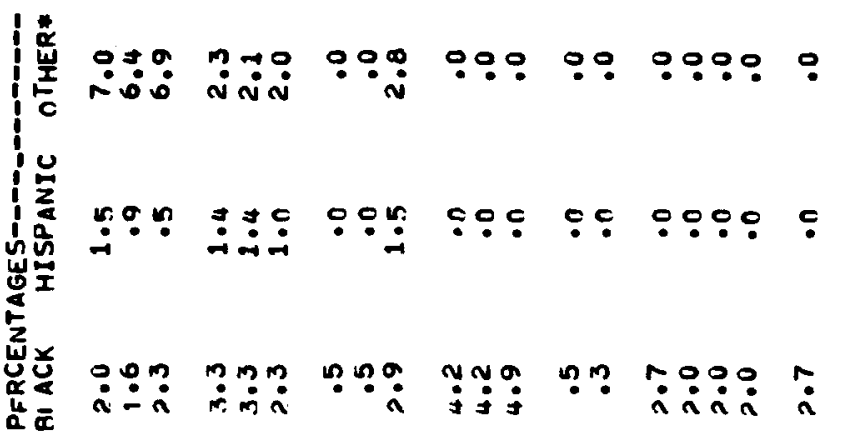

峁

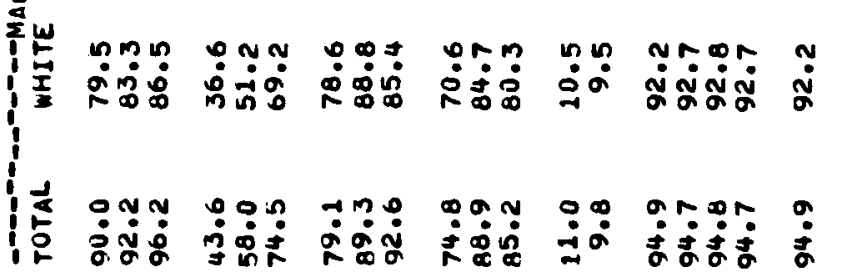

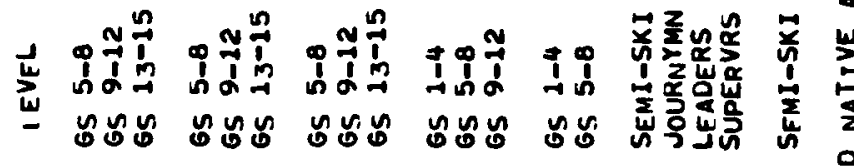

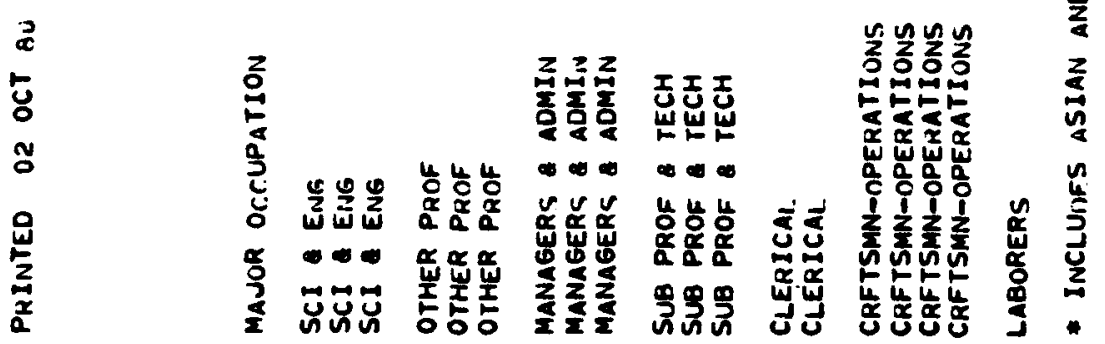




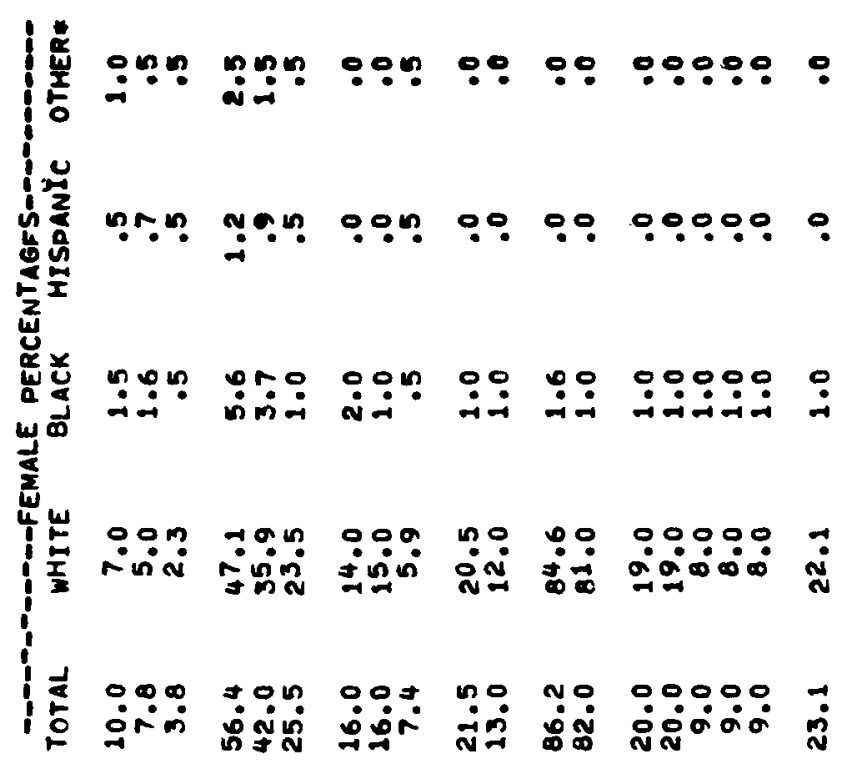

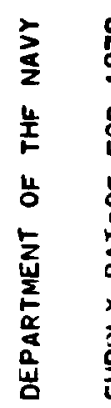

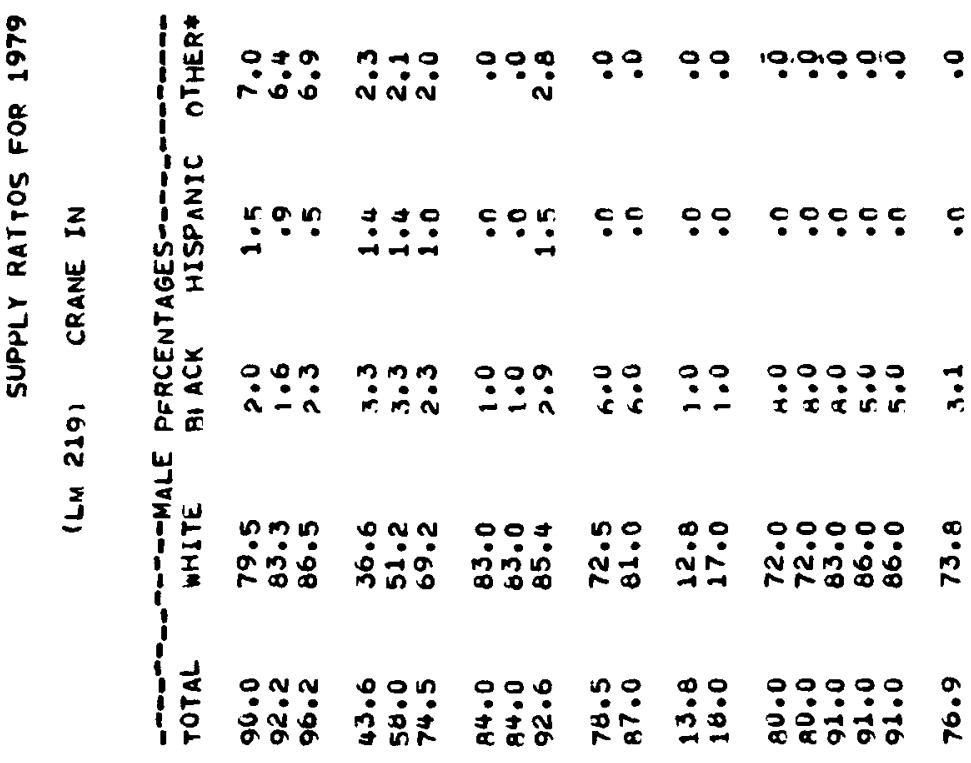

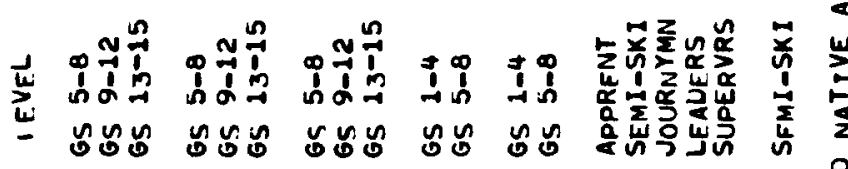

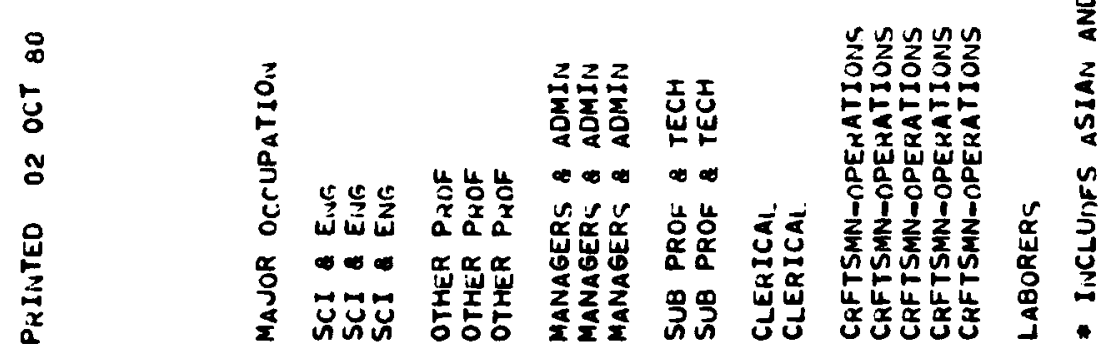



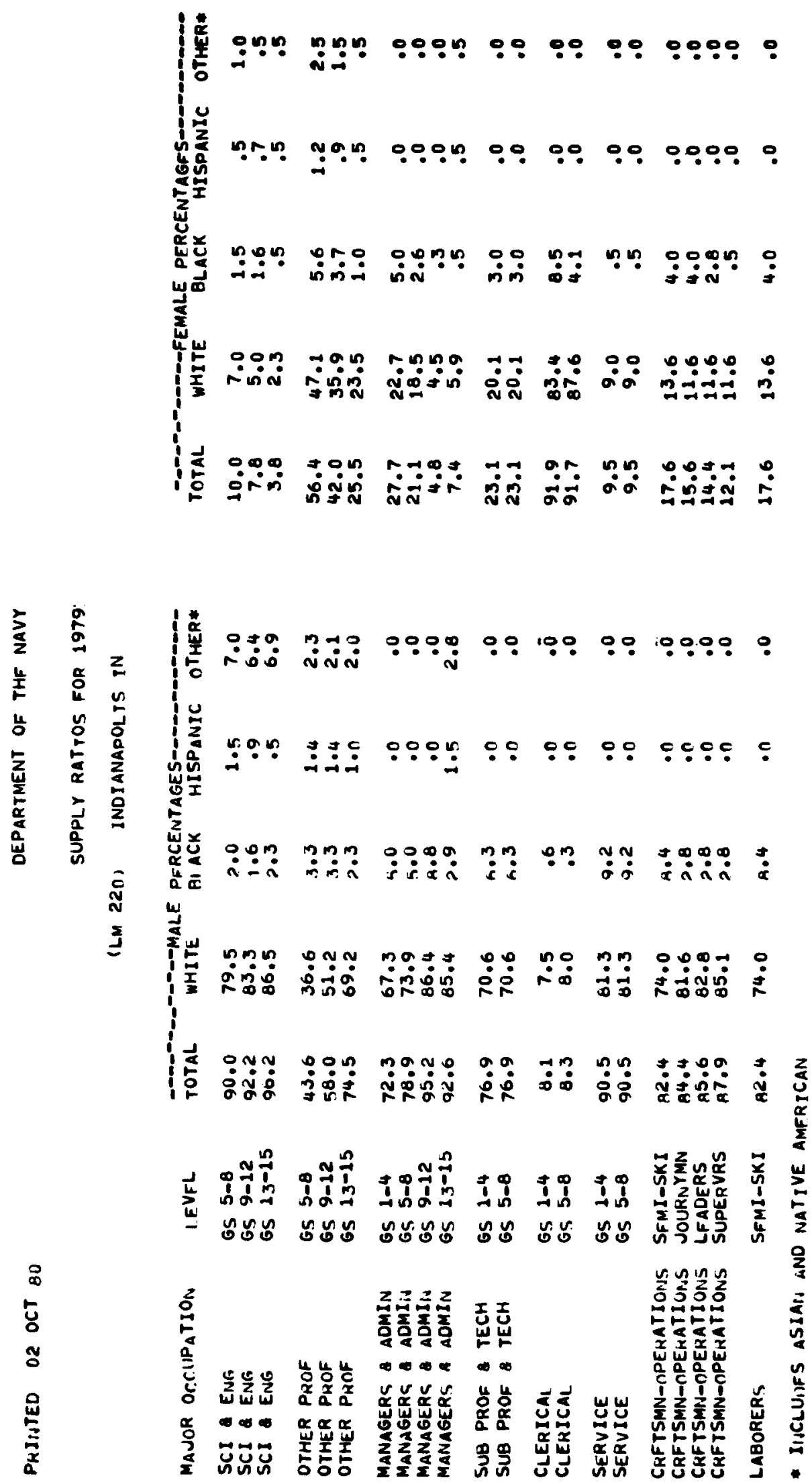

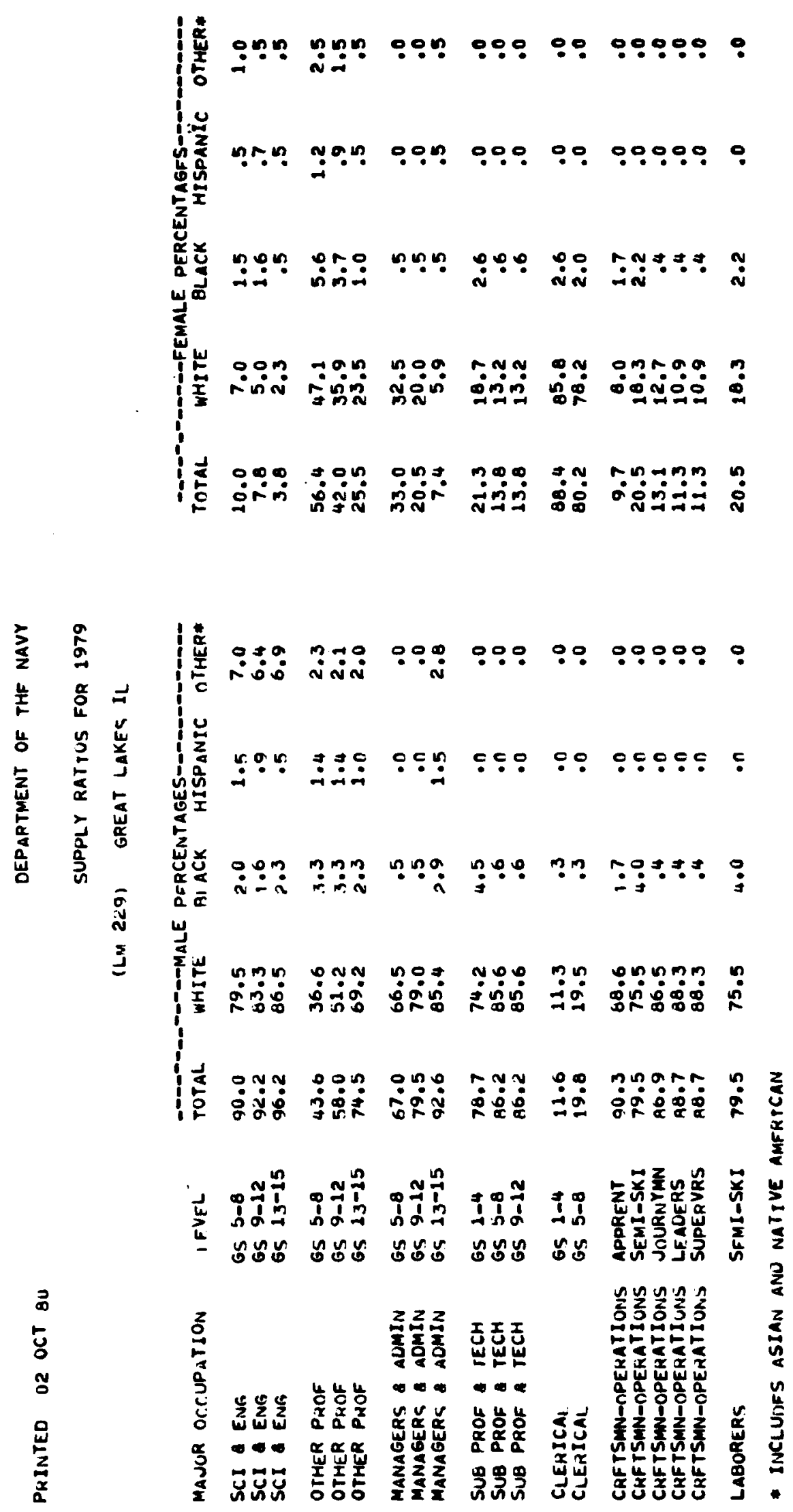


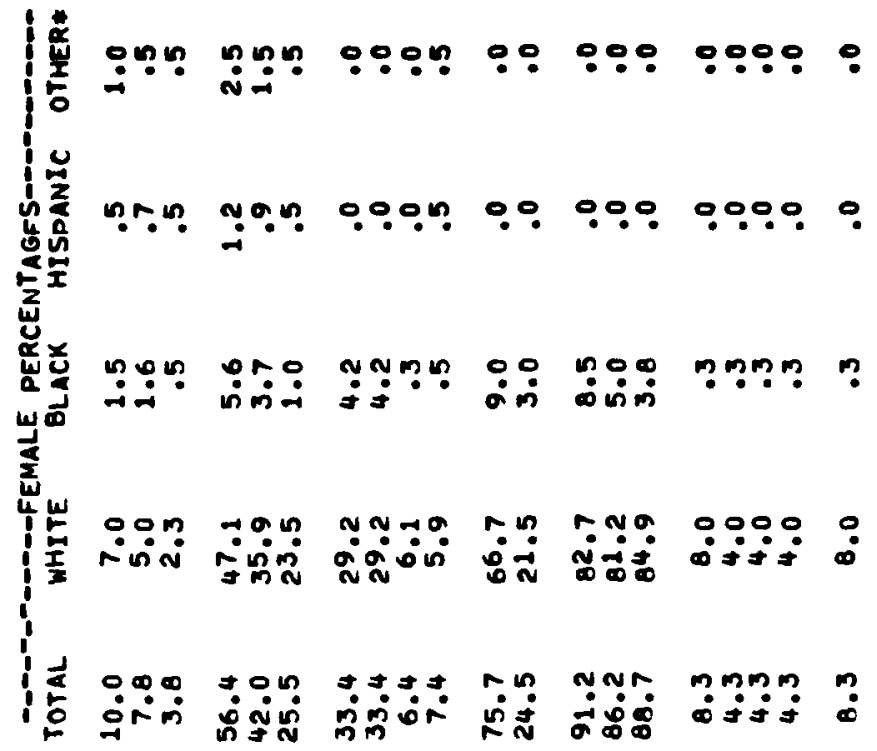

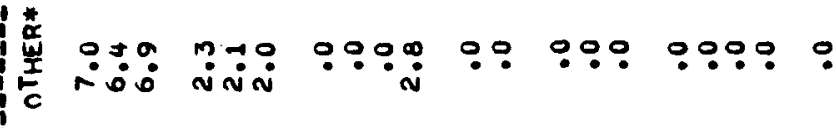

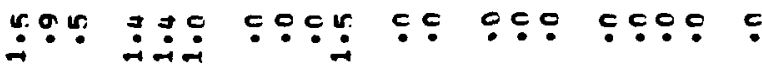

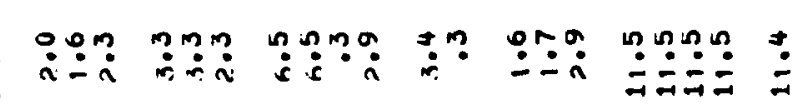

宸党

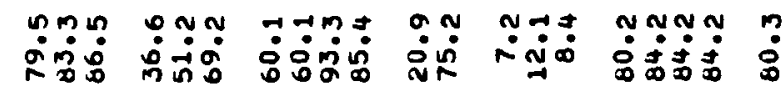

这

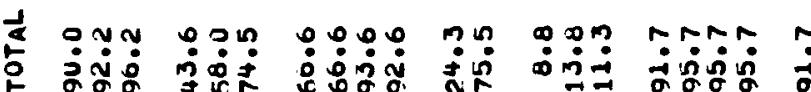

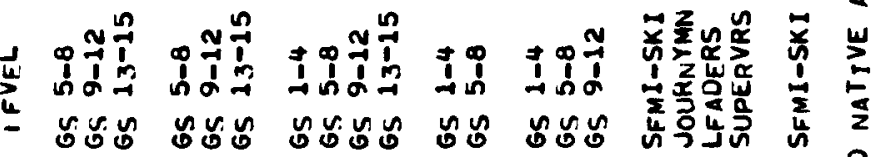

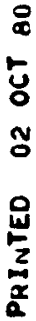

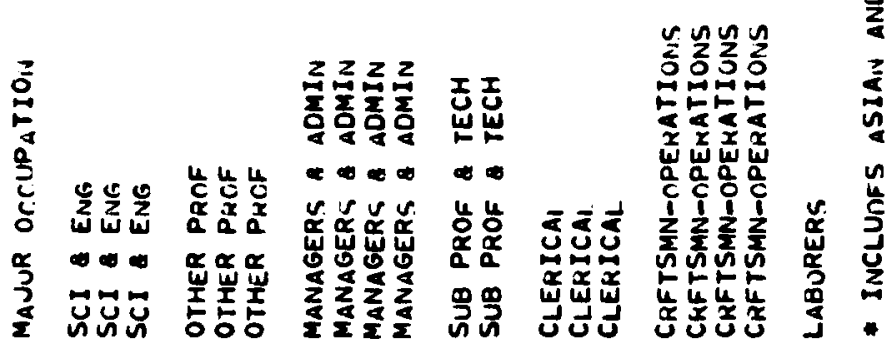




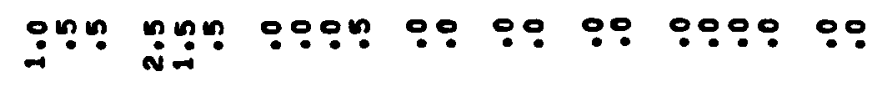

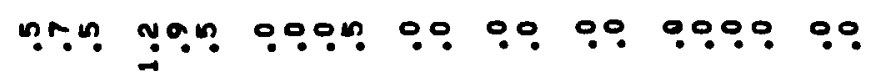

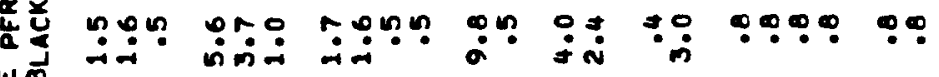
宸

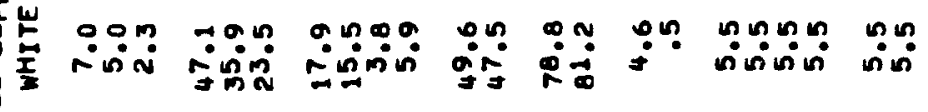

若

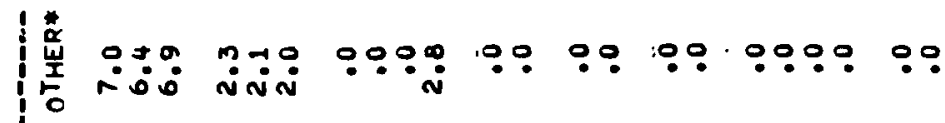

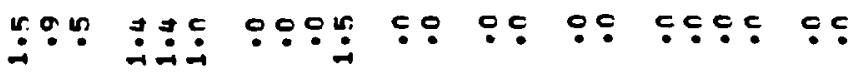

岁造

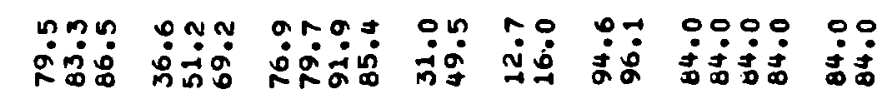
$i$

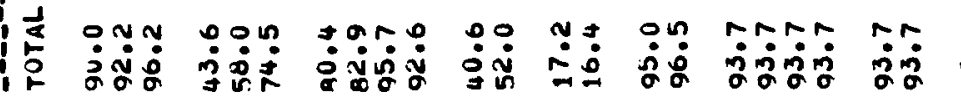

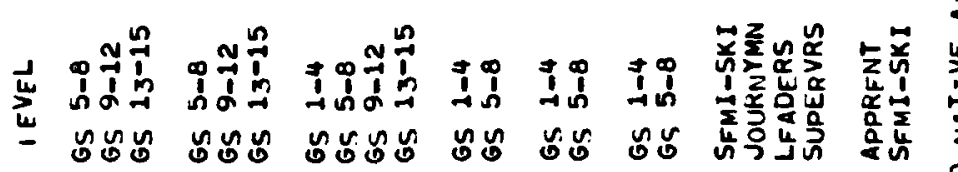

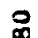

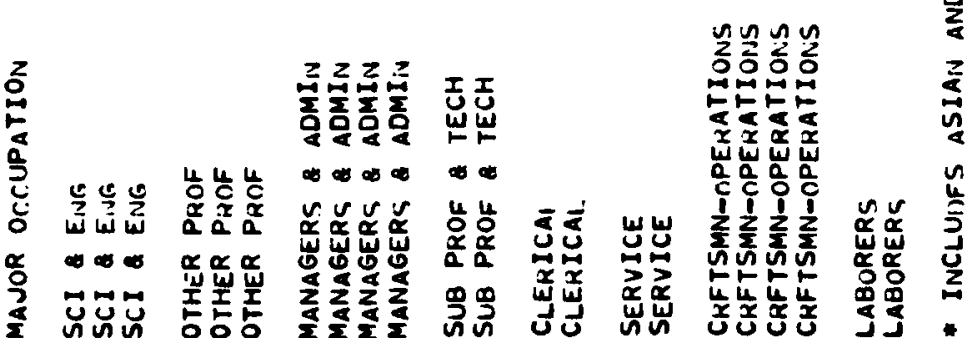




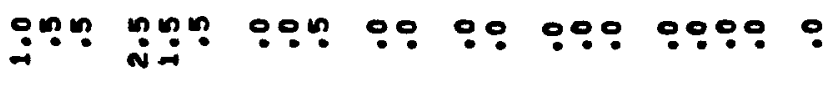

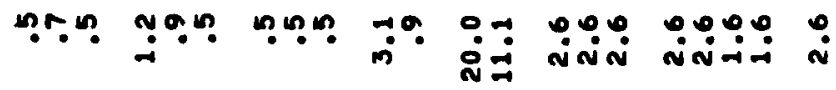

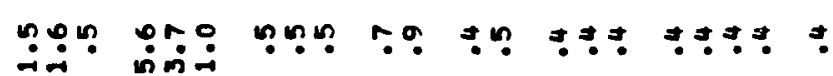

山क

章

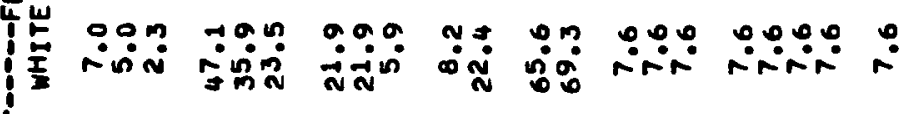

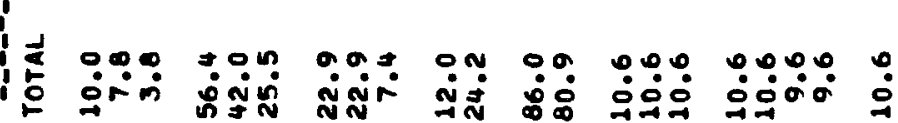

至

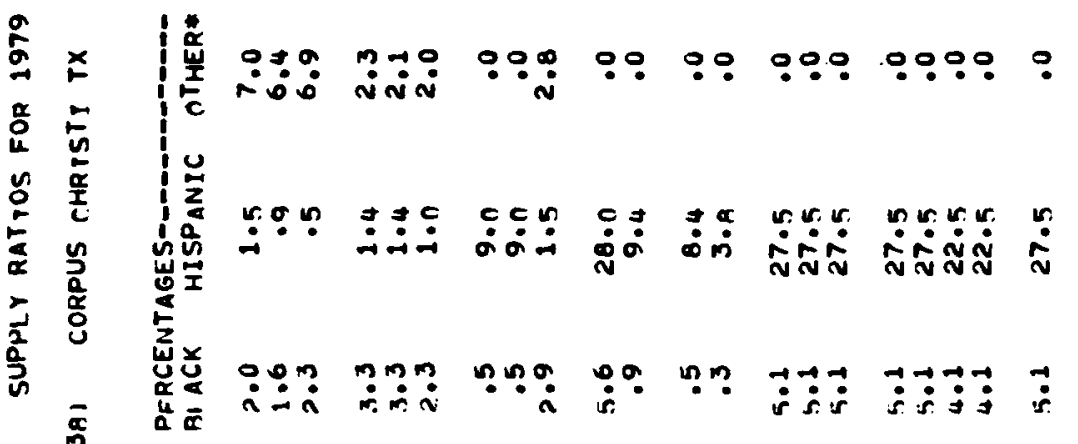

尉

$\stackrel{2}{2}$

لَّ.

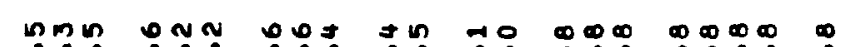

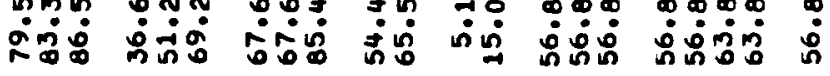

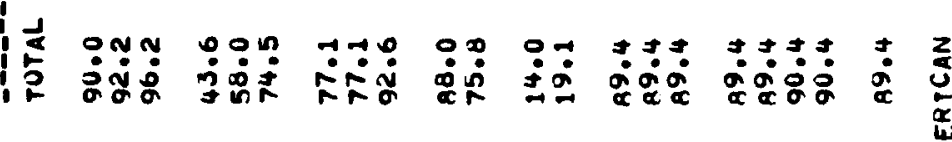

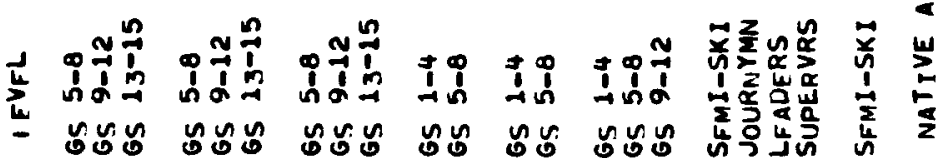

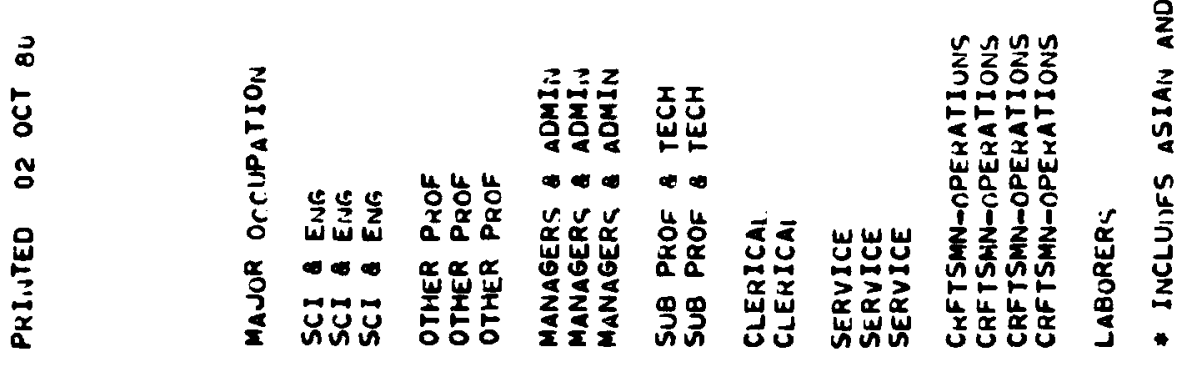




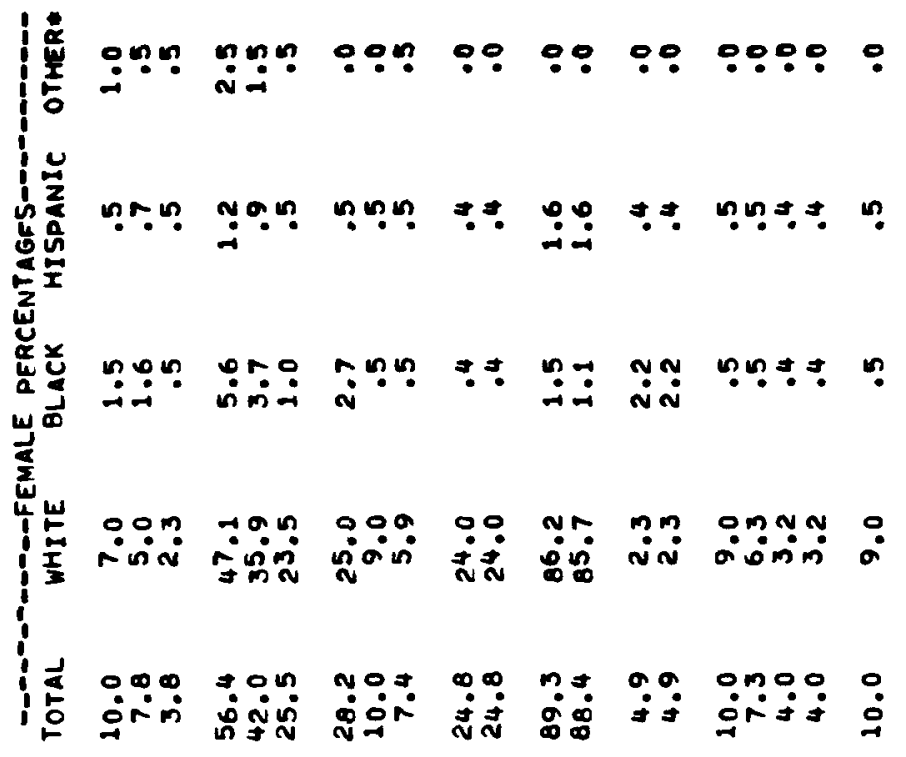

|

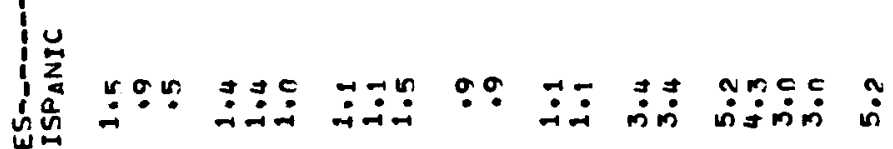
㬒宓 (

氙希 崖

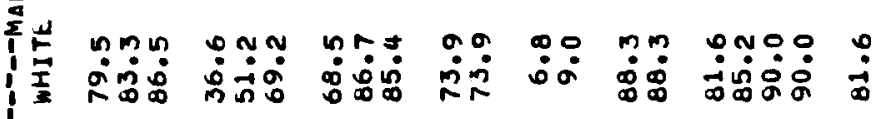
$\frac{1}{2}$

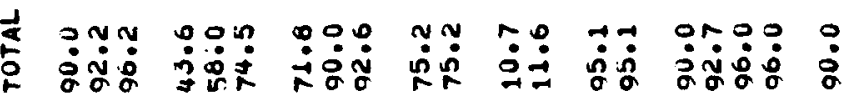

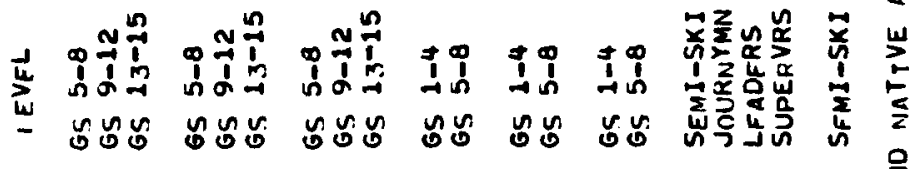

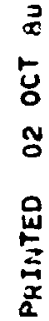

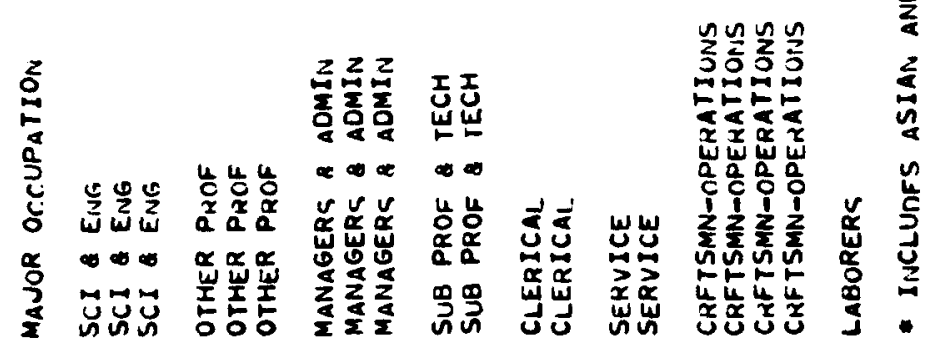



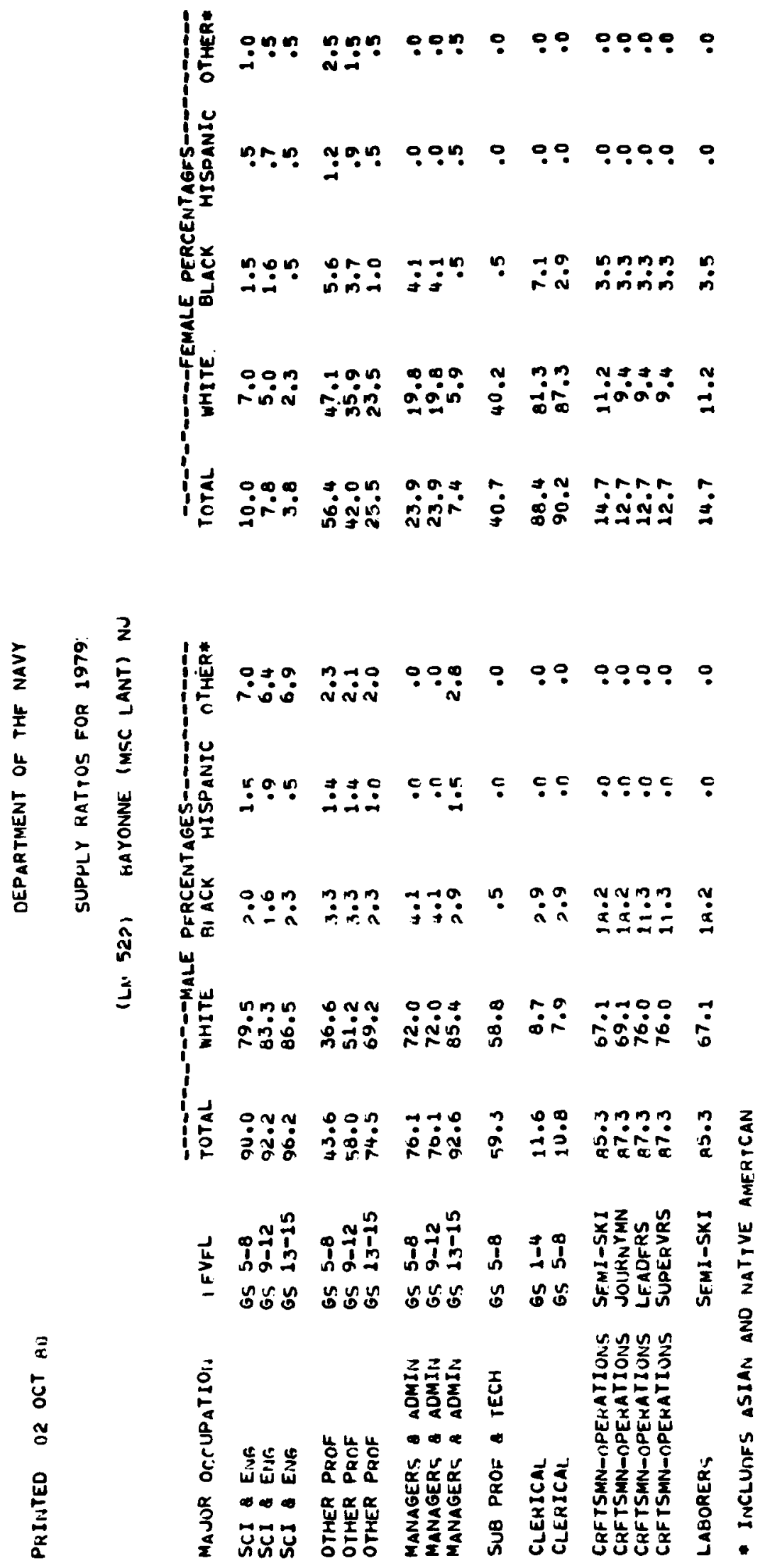

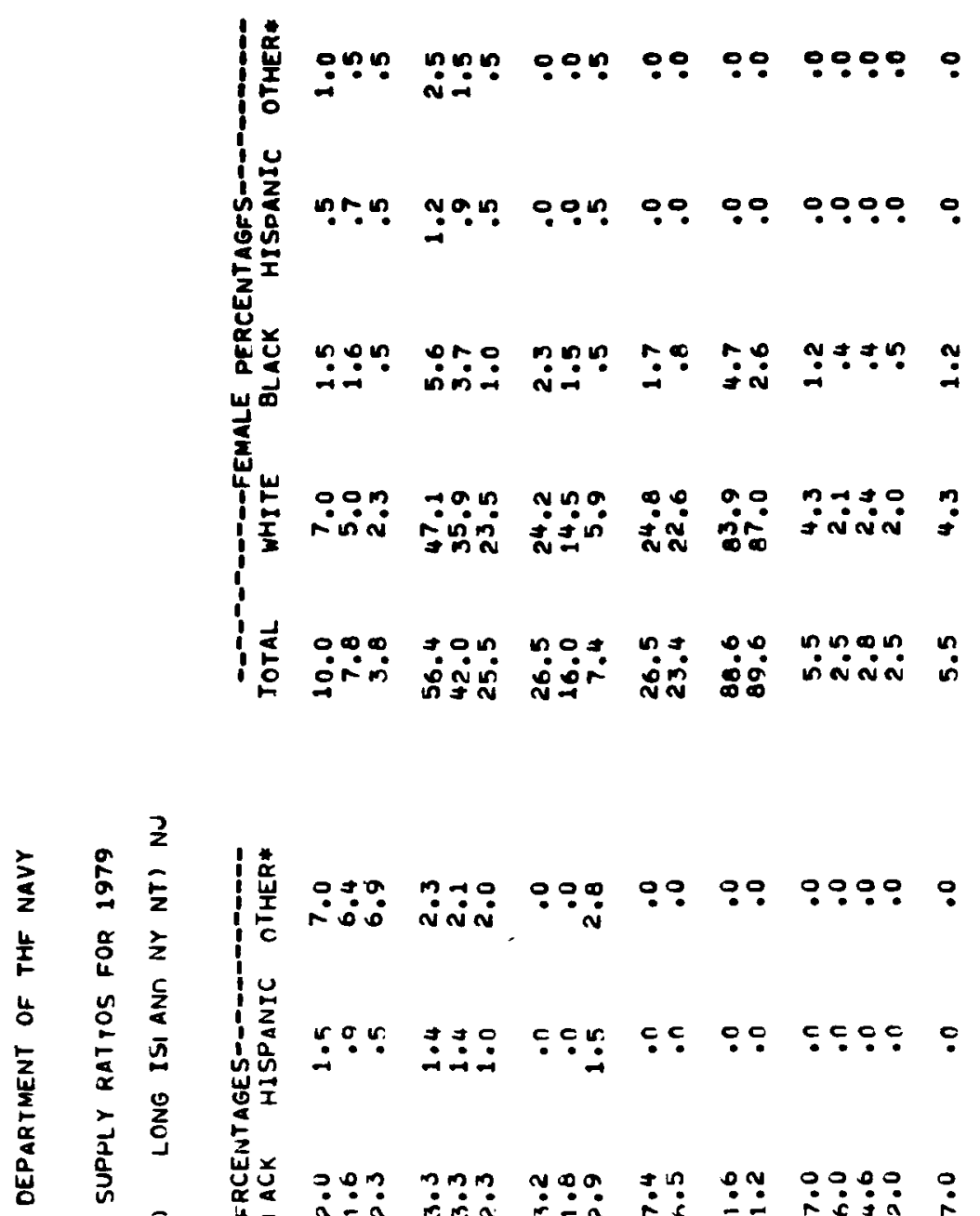

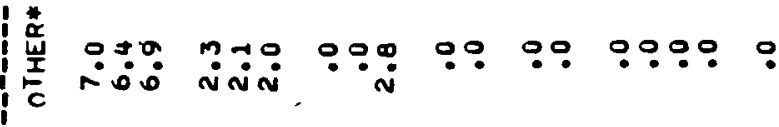

美

密

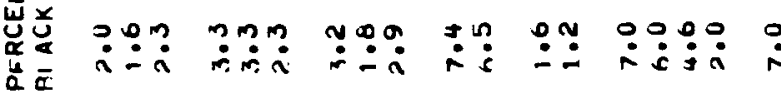

v

لـ

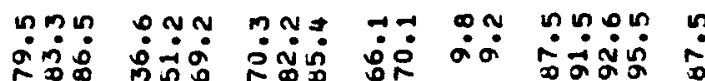

造

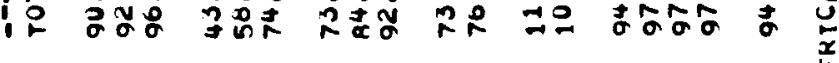

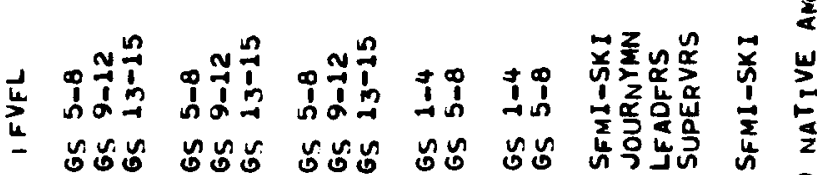

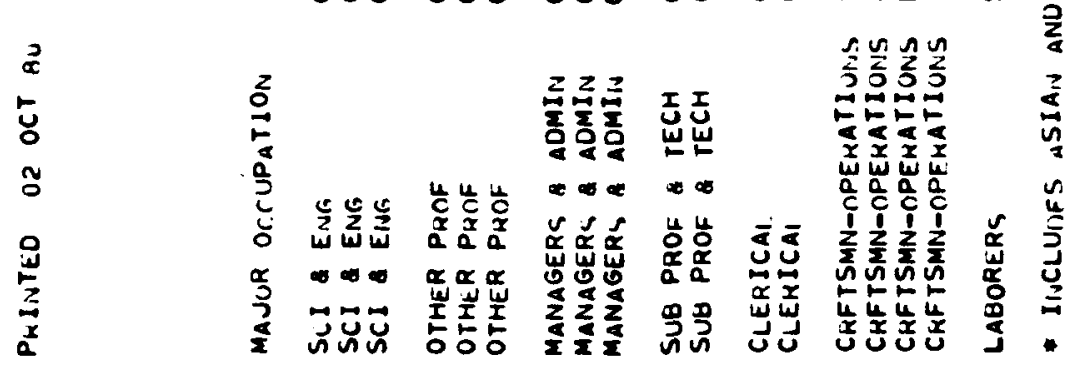




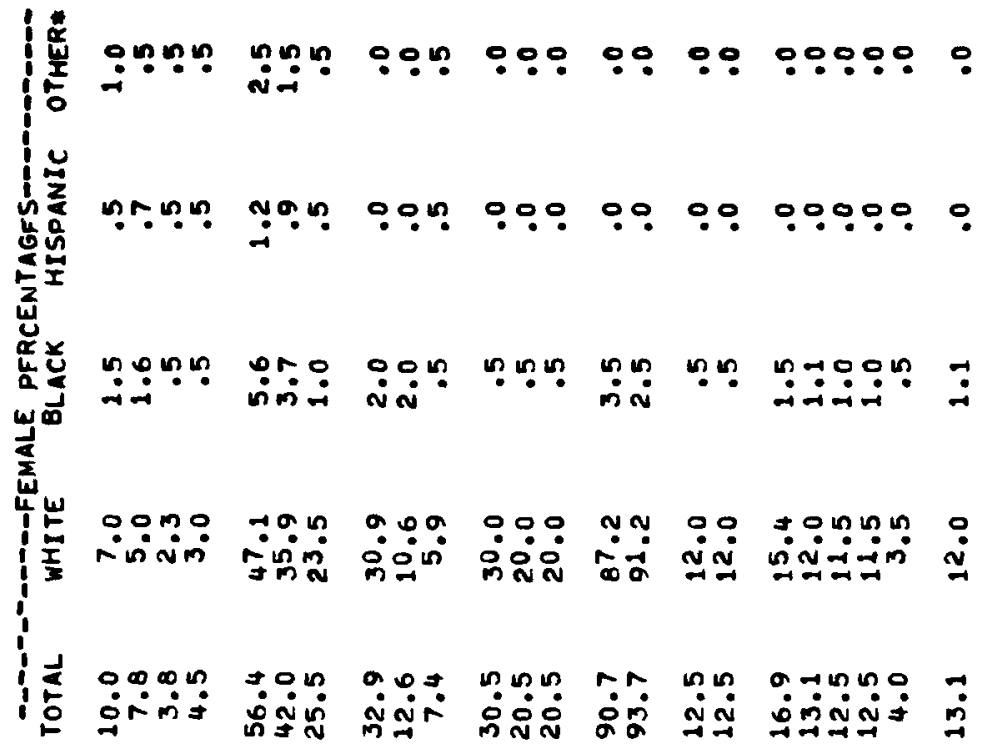

若

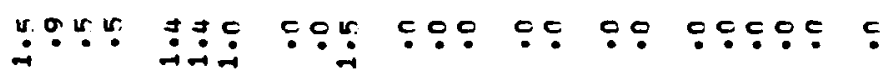

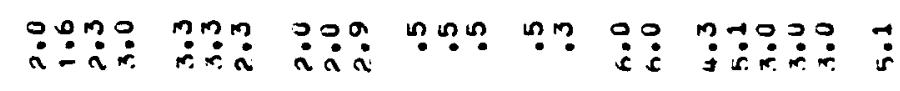
ب. 崖 :

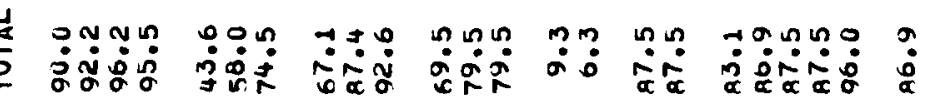

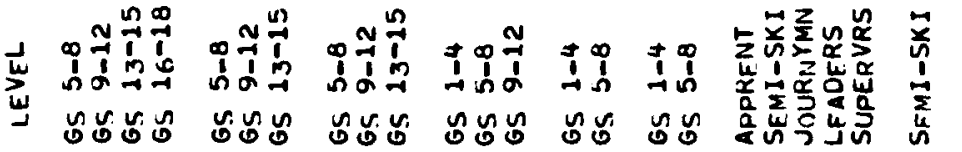

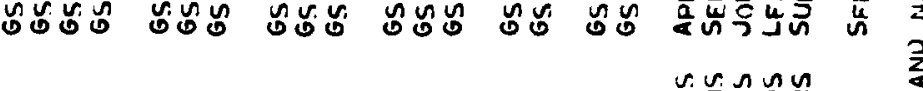

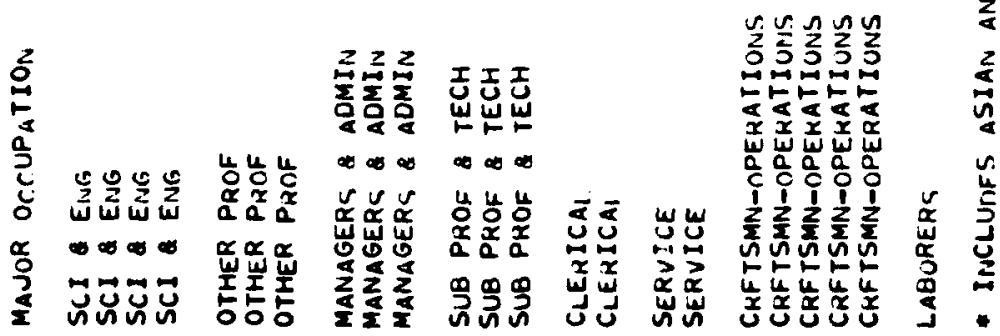




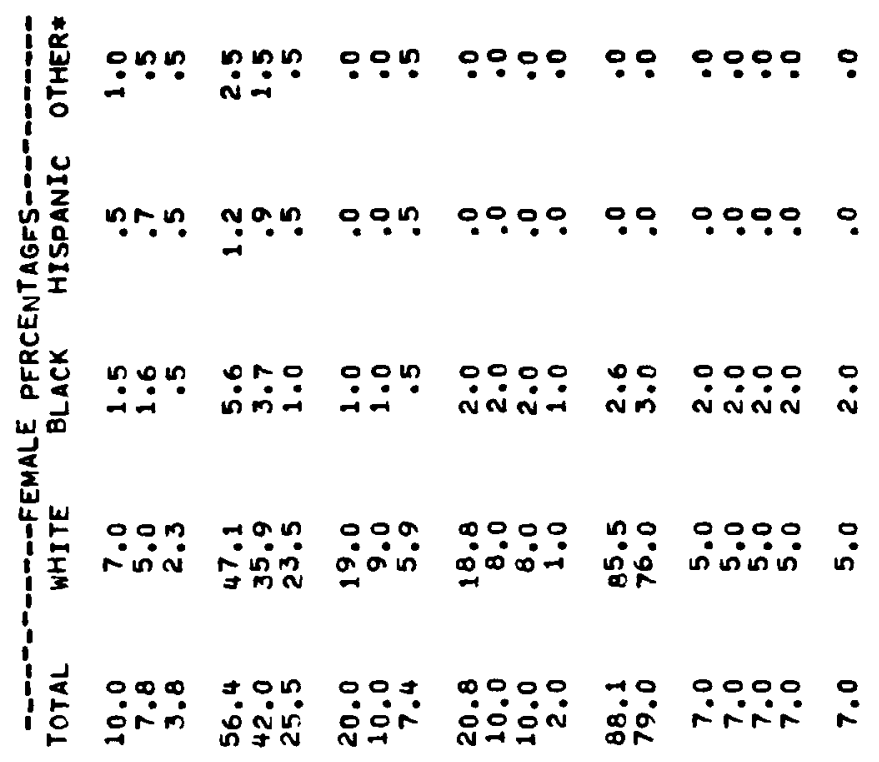

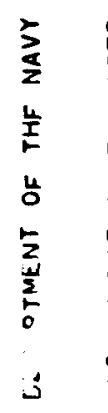

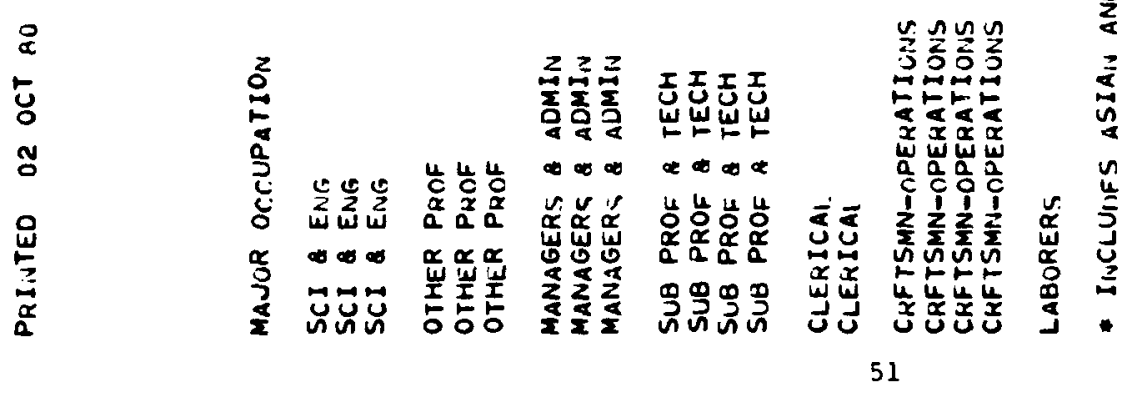




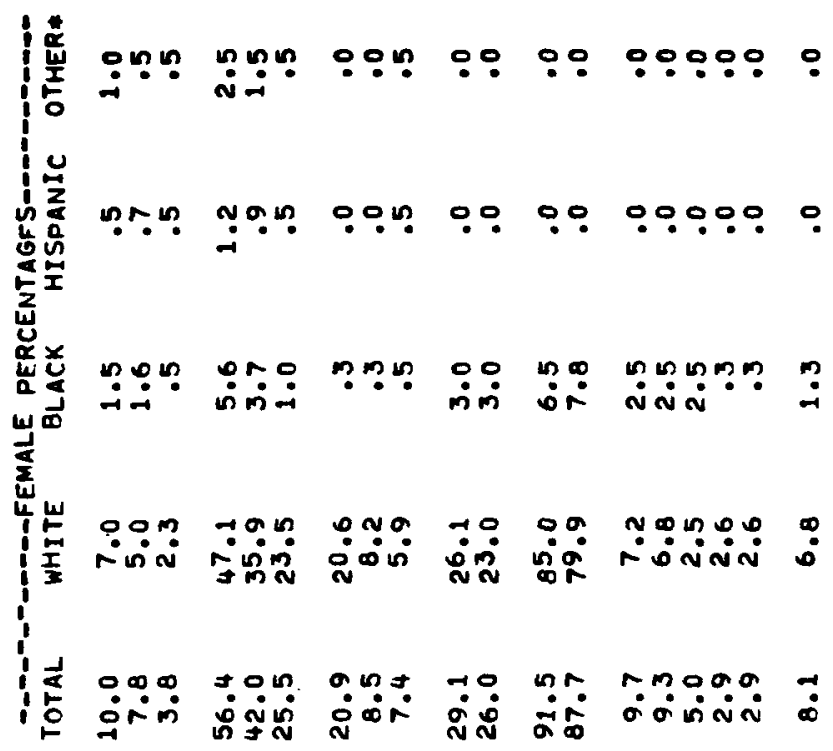

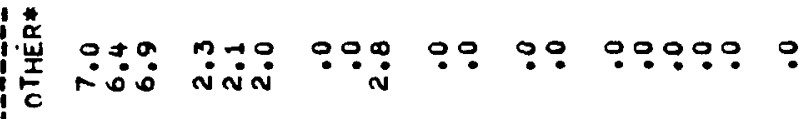

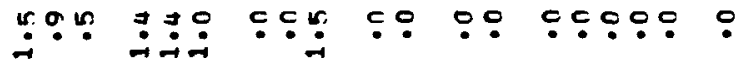

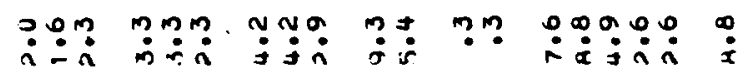
崖

造

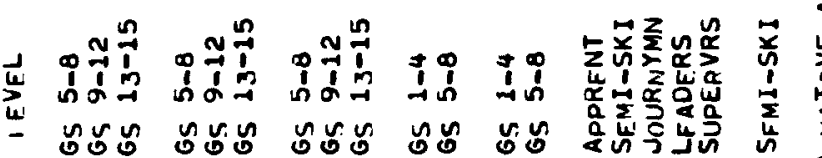

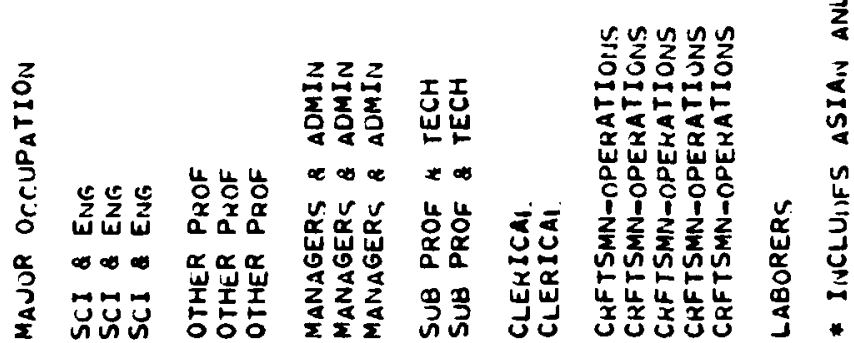



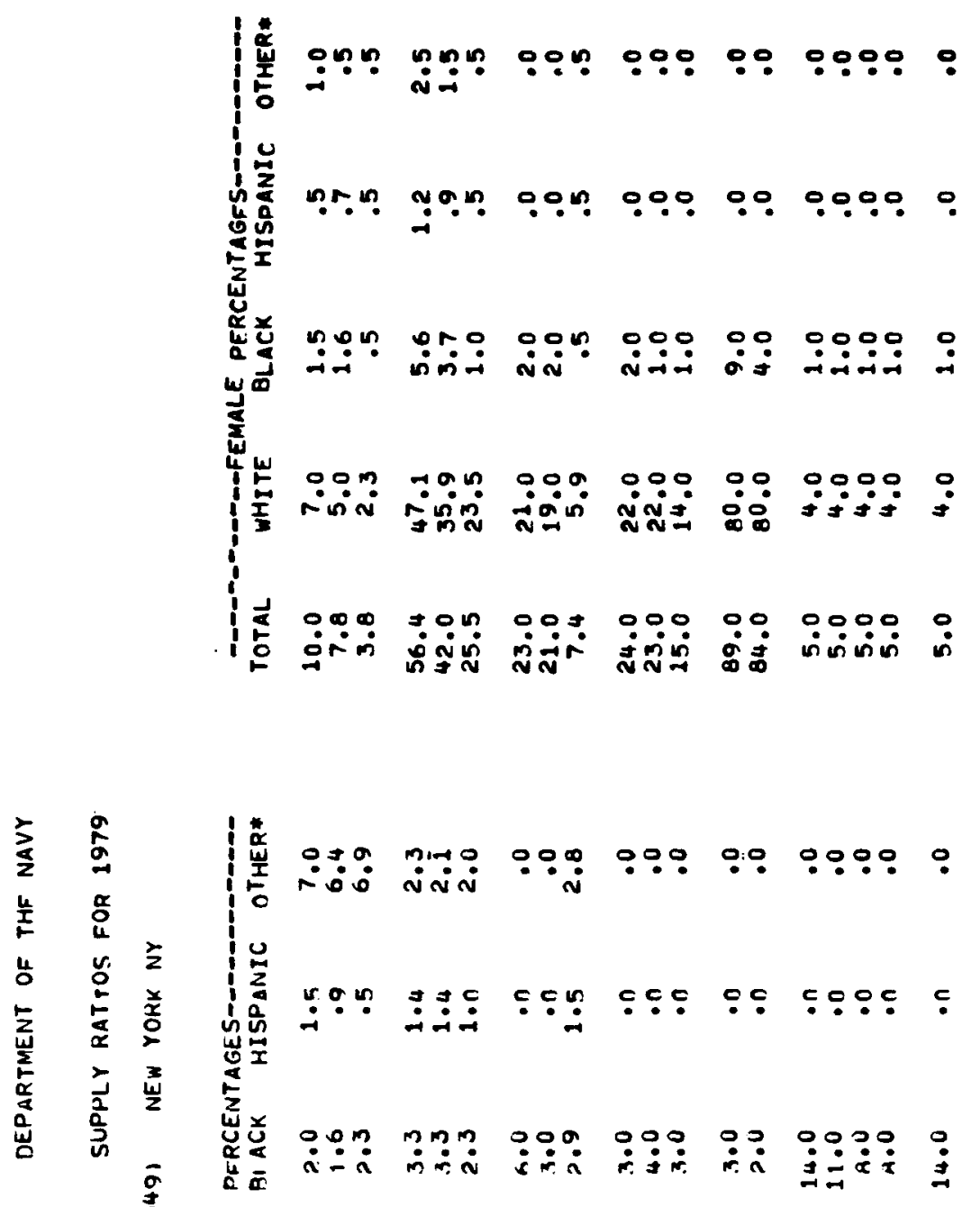

崖 I

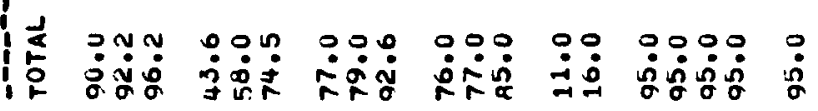

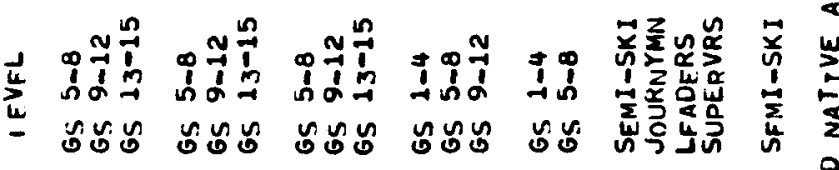

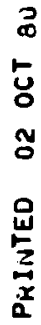

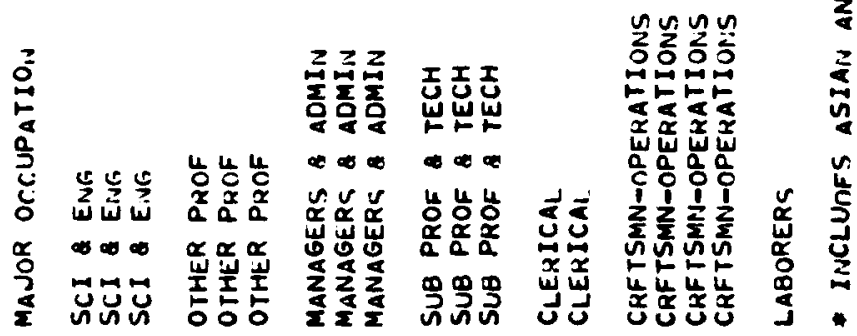




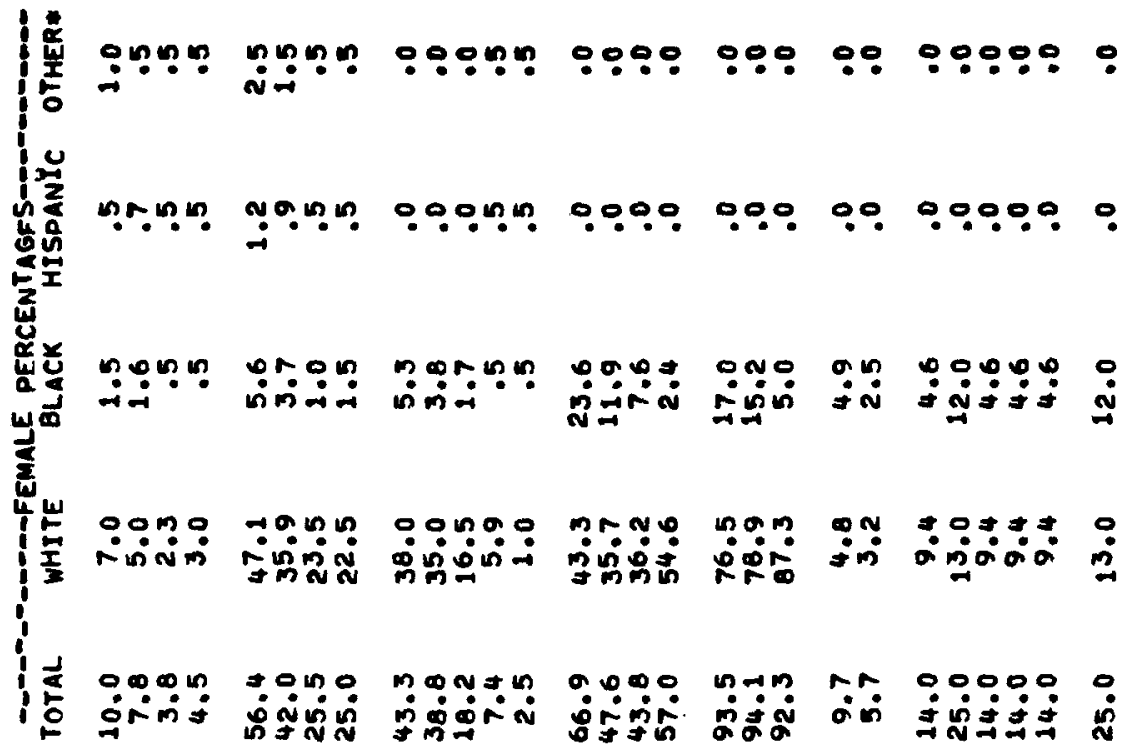

崖

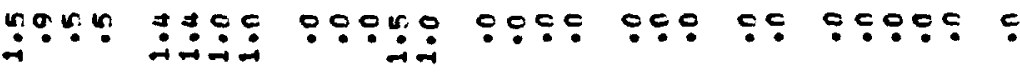

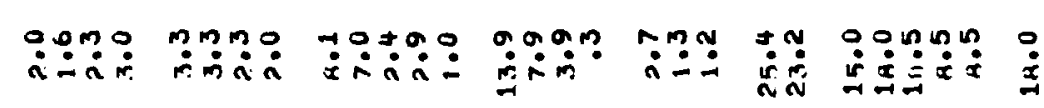
w

落 :

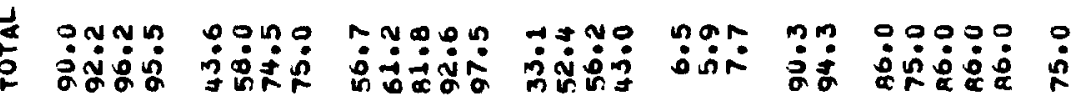

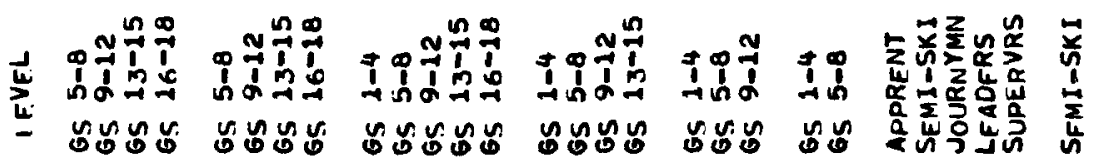

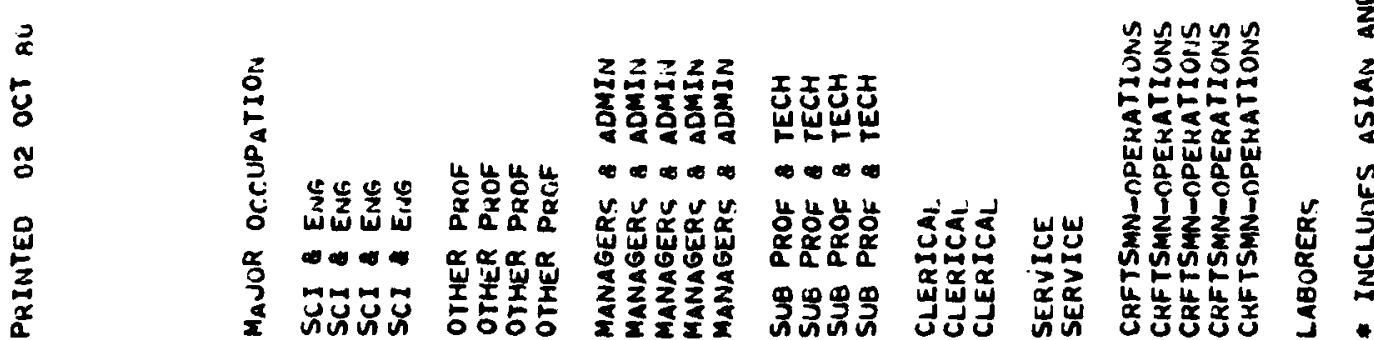




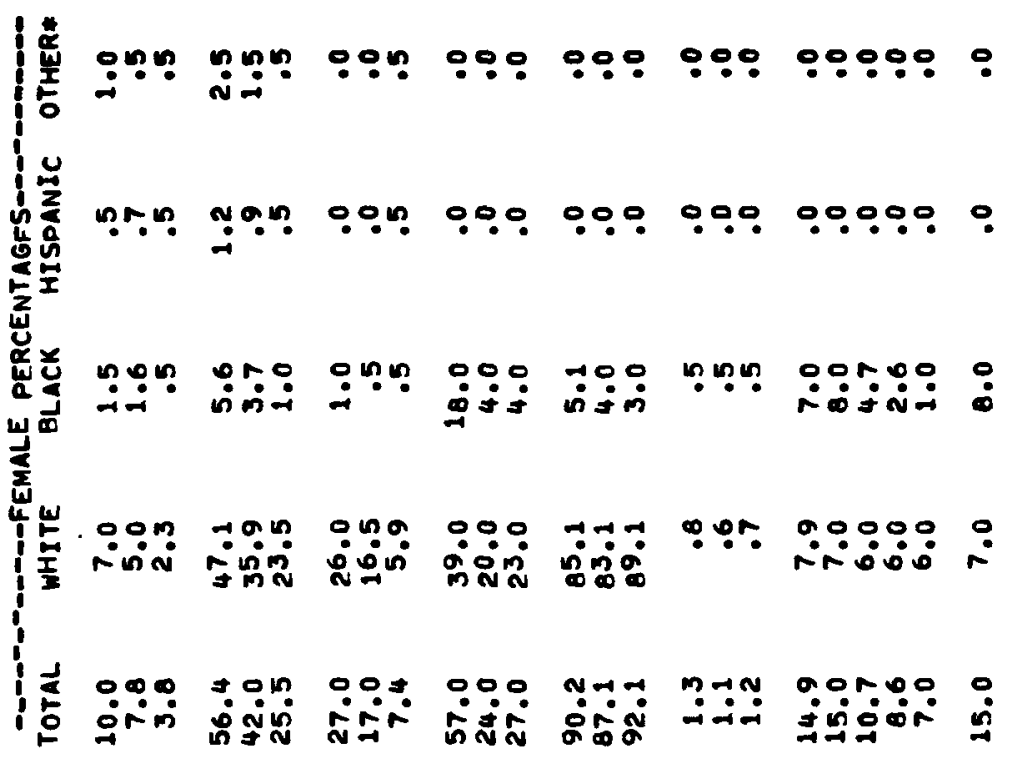

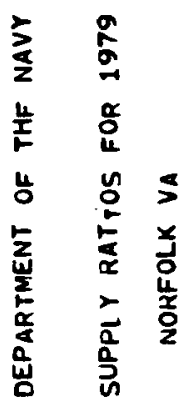

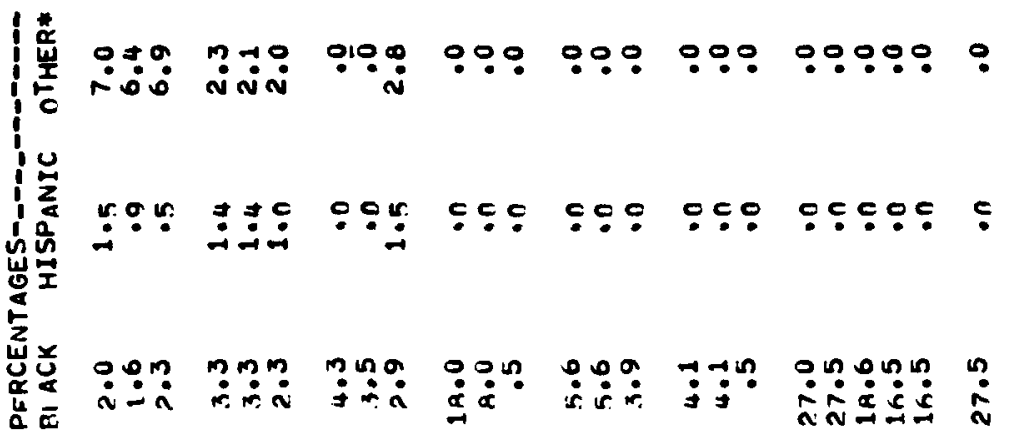
号

岁

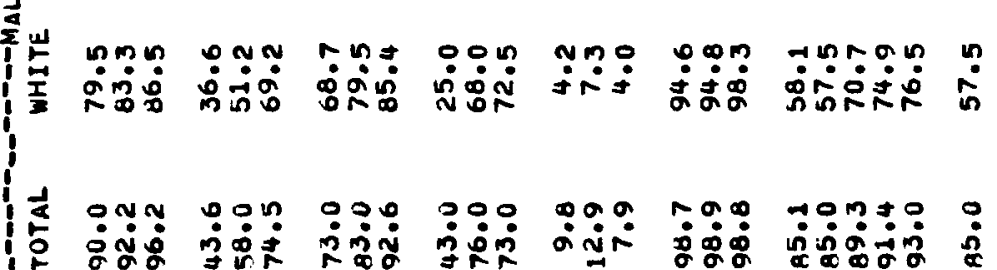

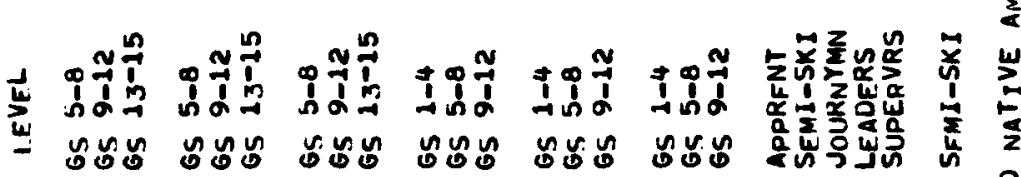

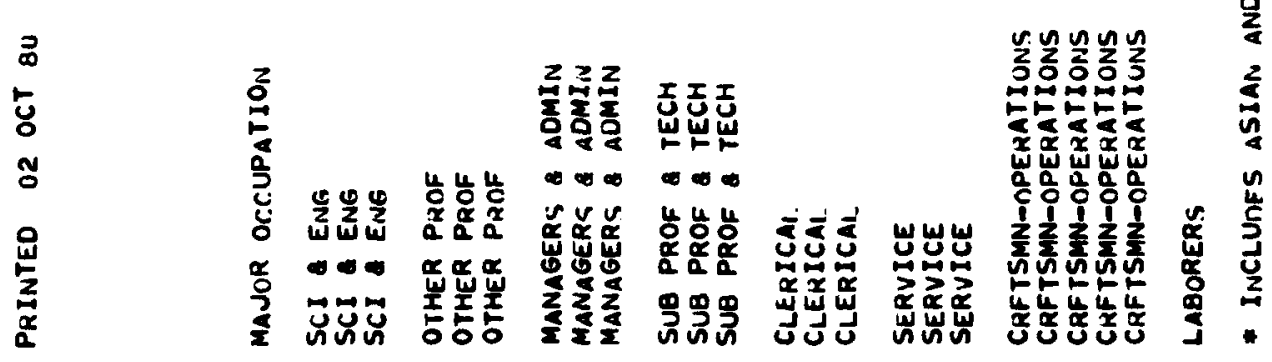




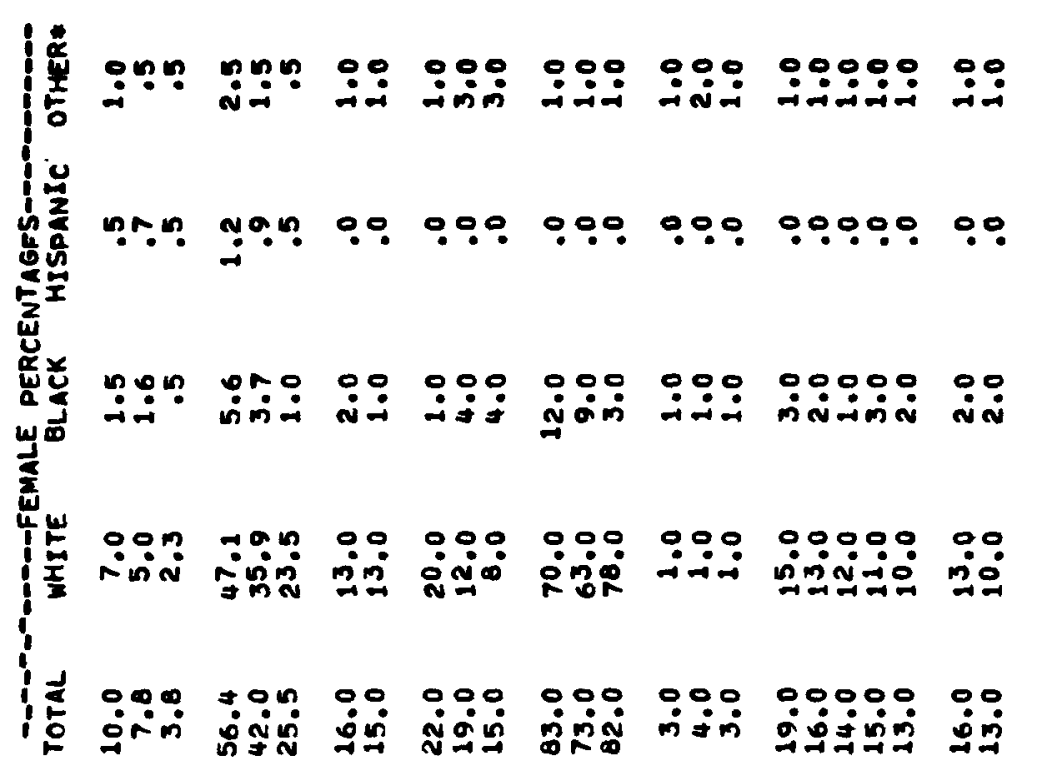

| 若 焉通

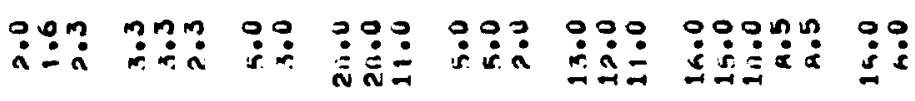
宸

mmn onn $00000000000000 n n 00$

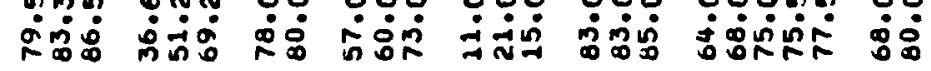
范

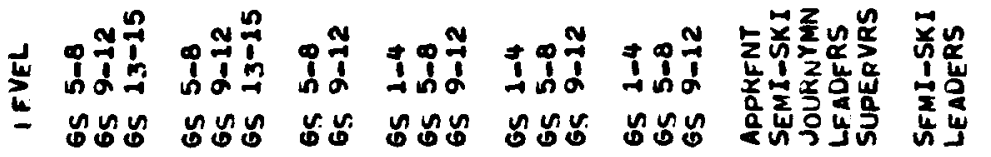

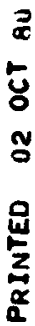

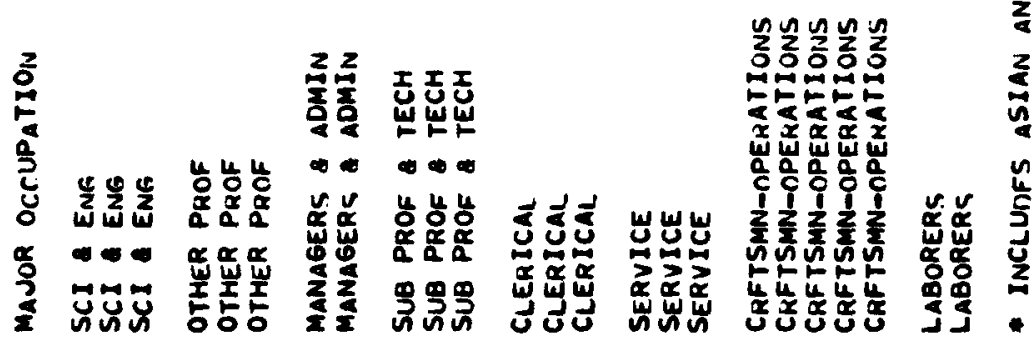



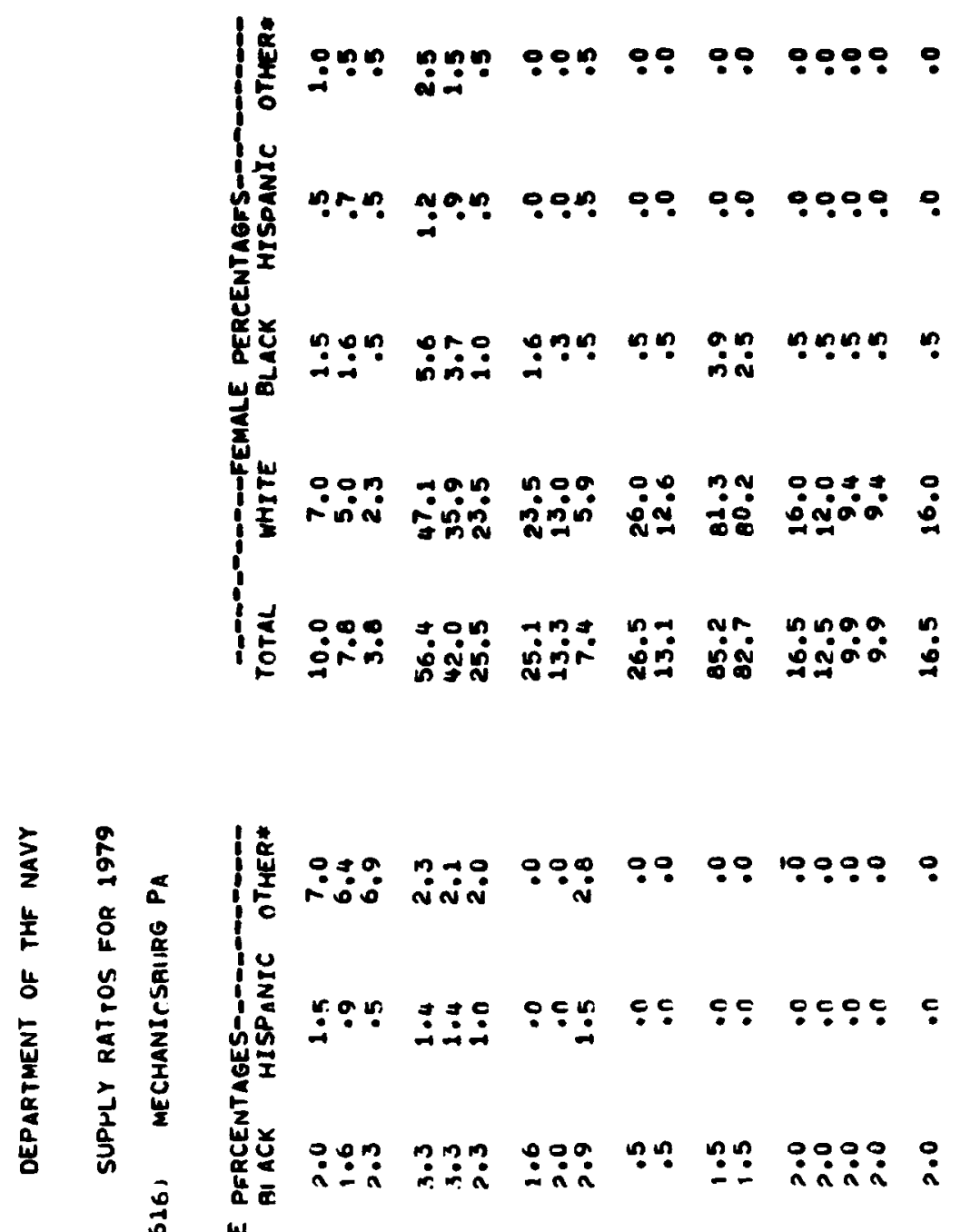

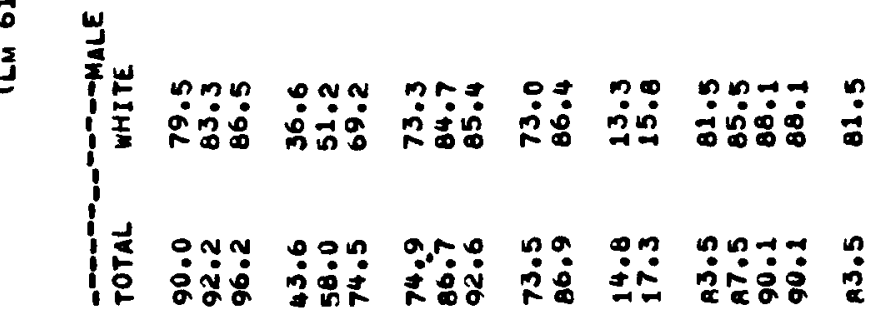

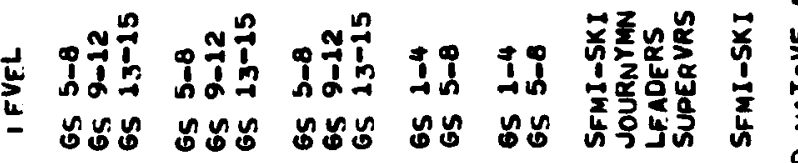

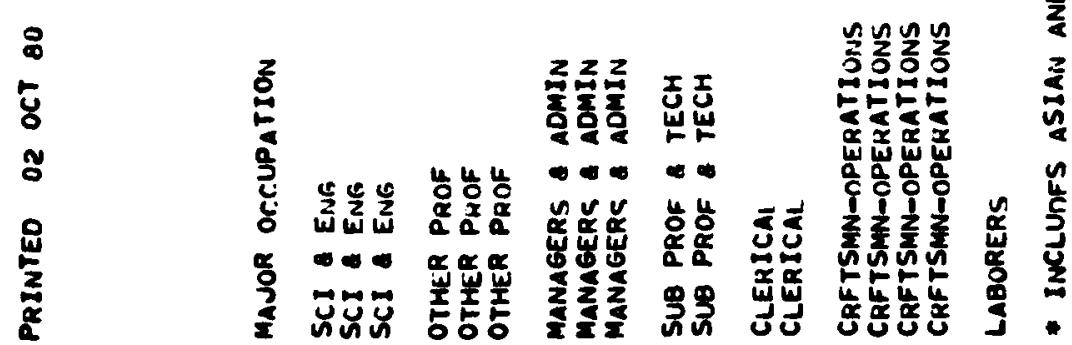



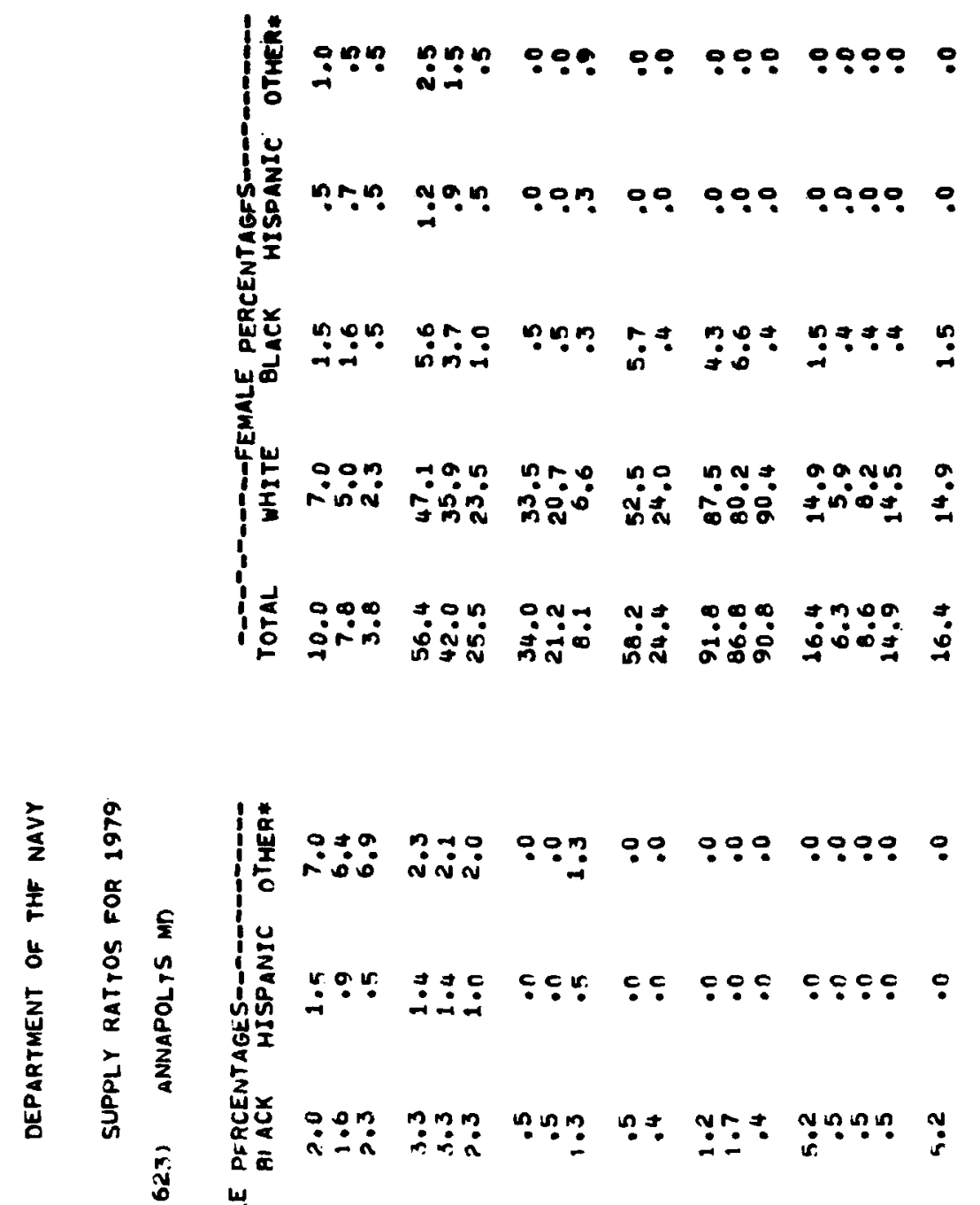

等

:

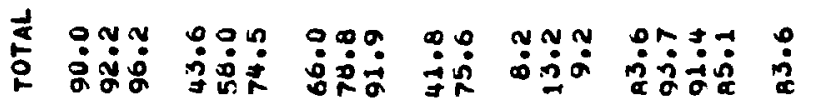

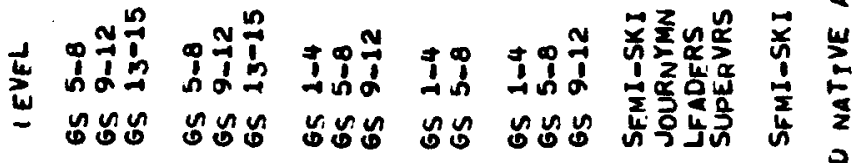

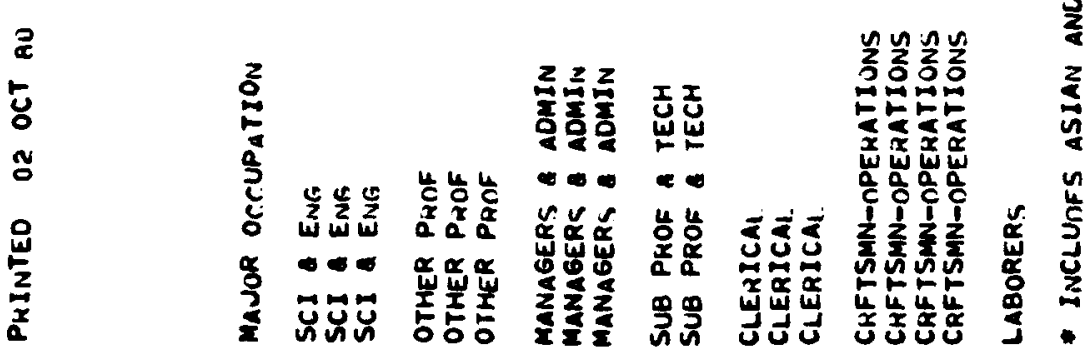



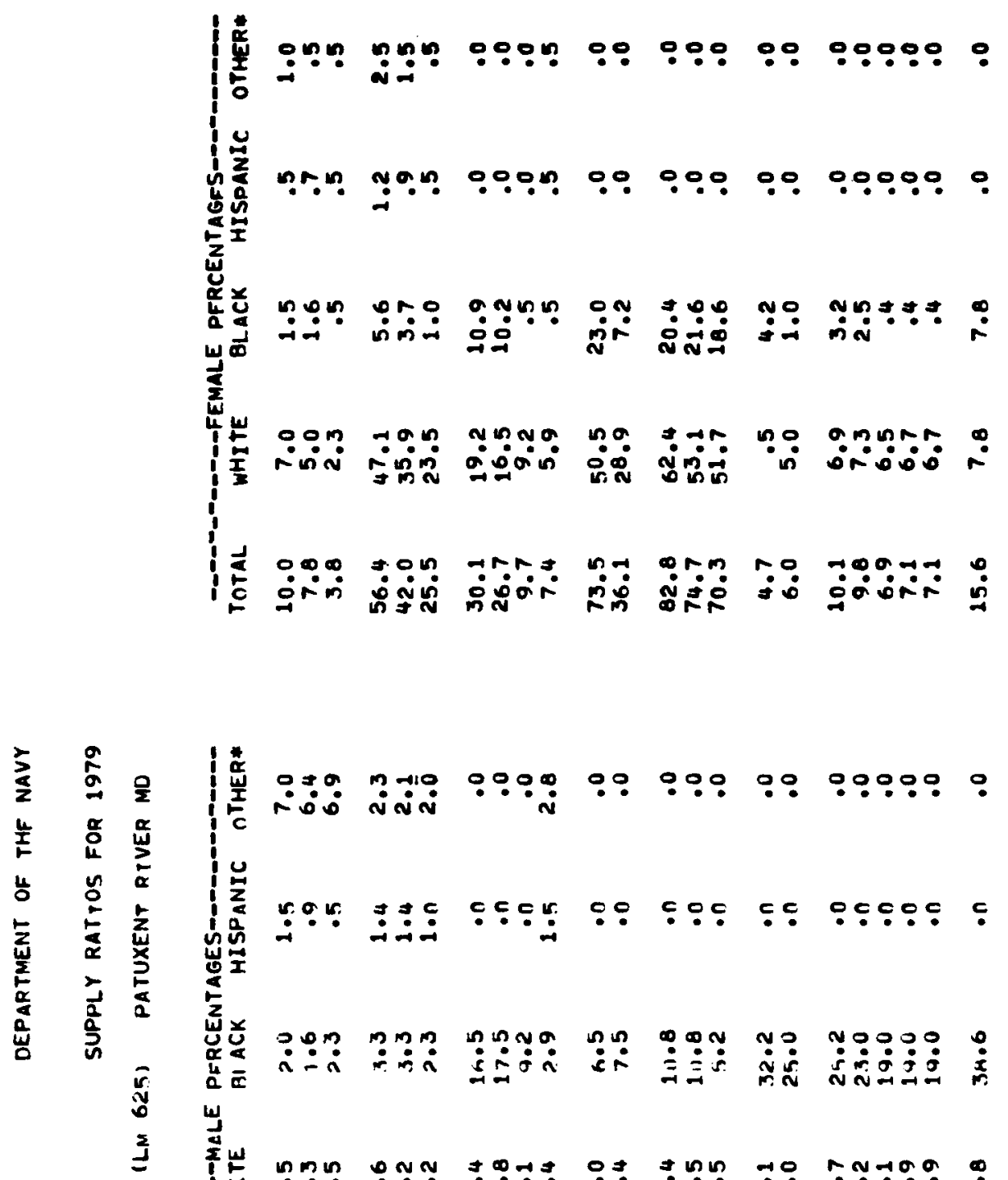

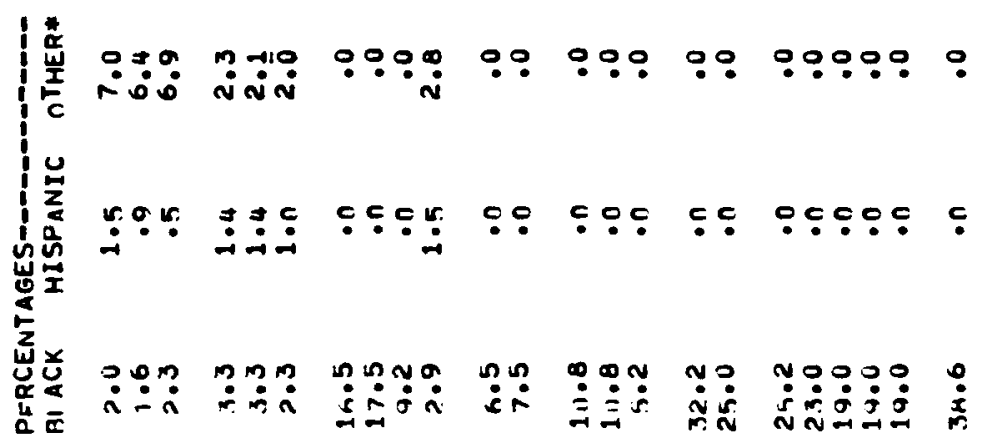

崖

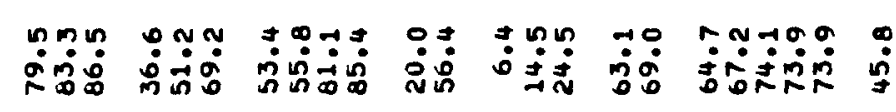

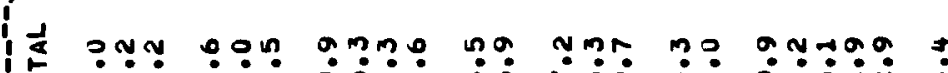

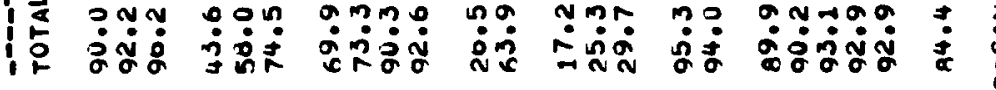

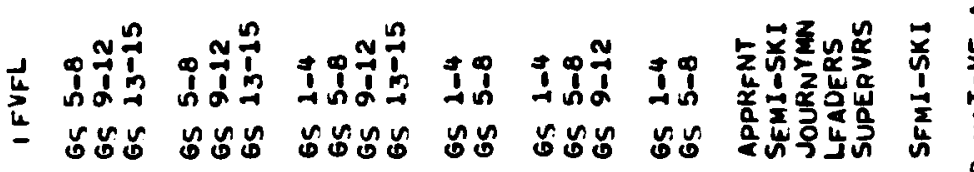

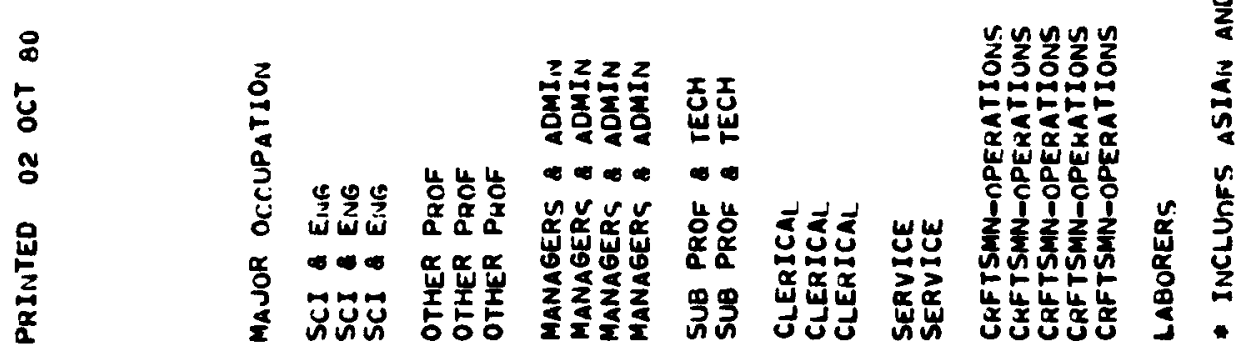




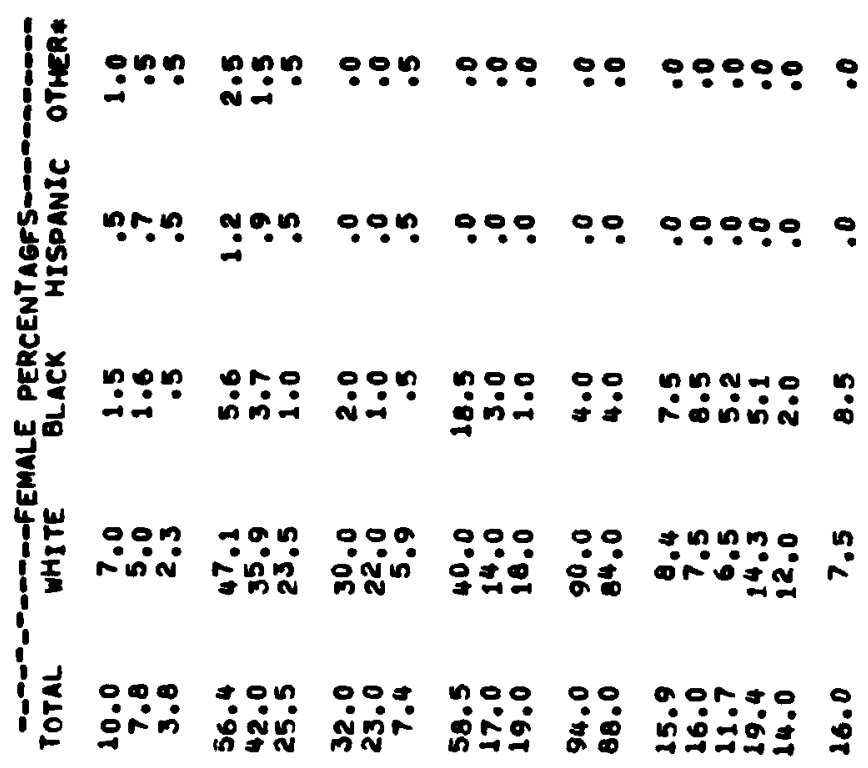

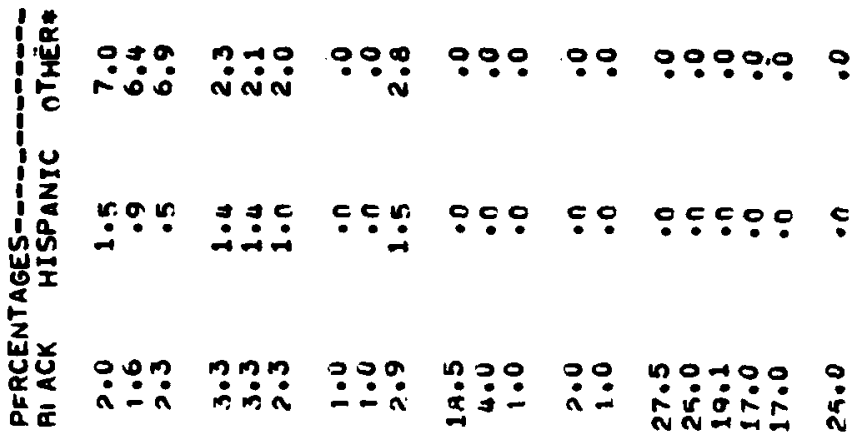

بु.

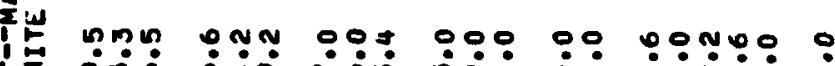

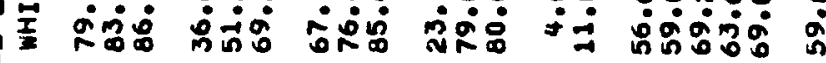

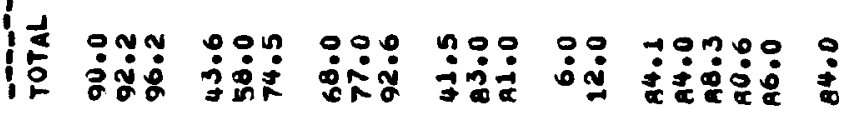

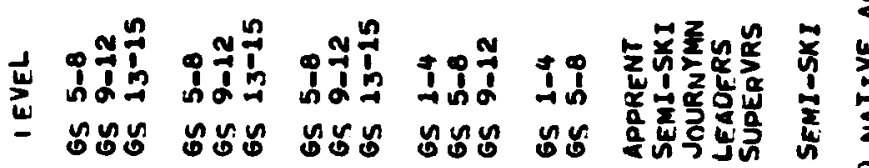

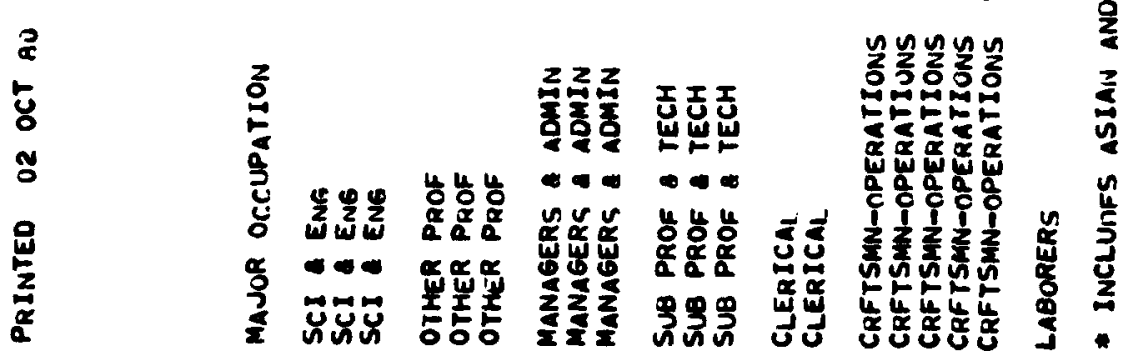




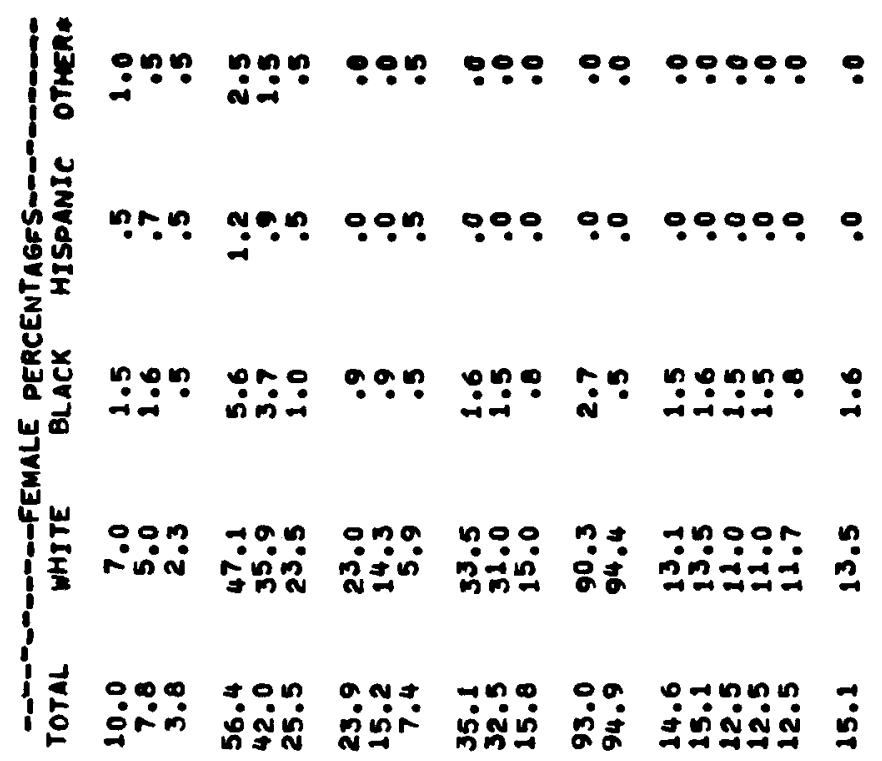

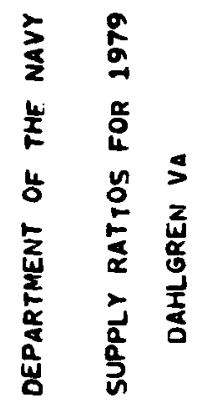

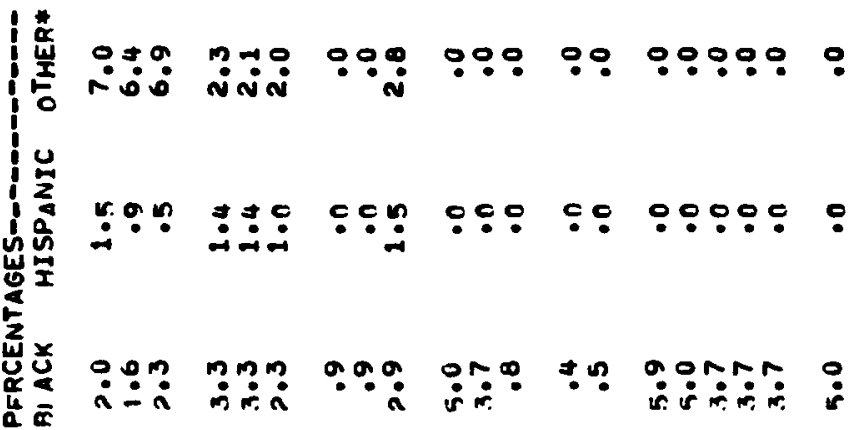

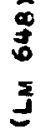

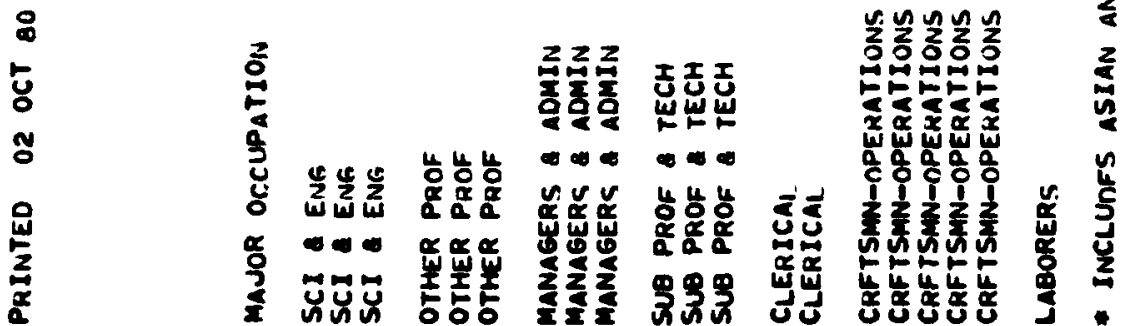

I

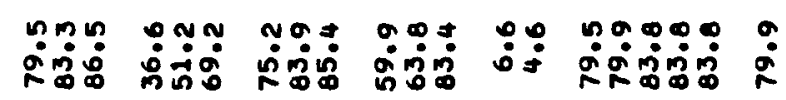

$\frac{1}{2}$

占

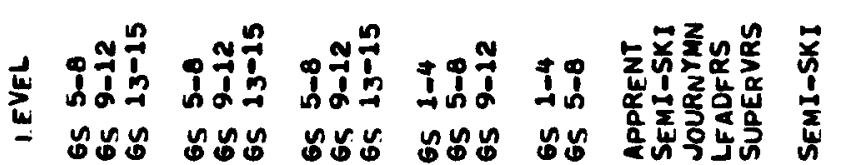

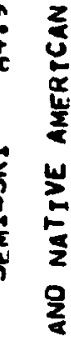



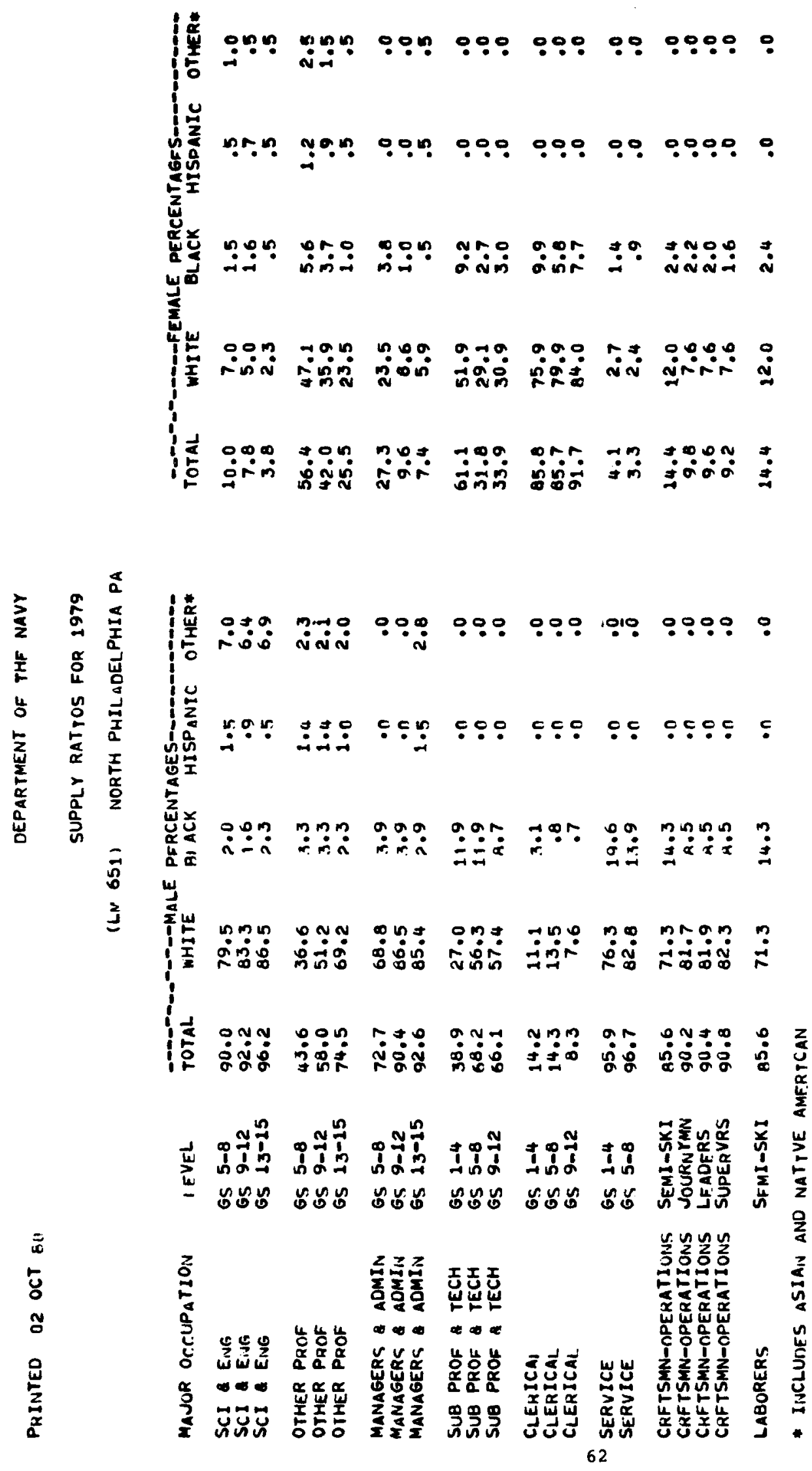


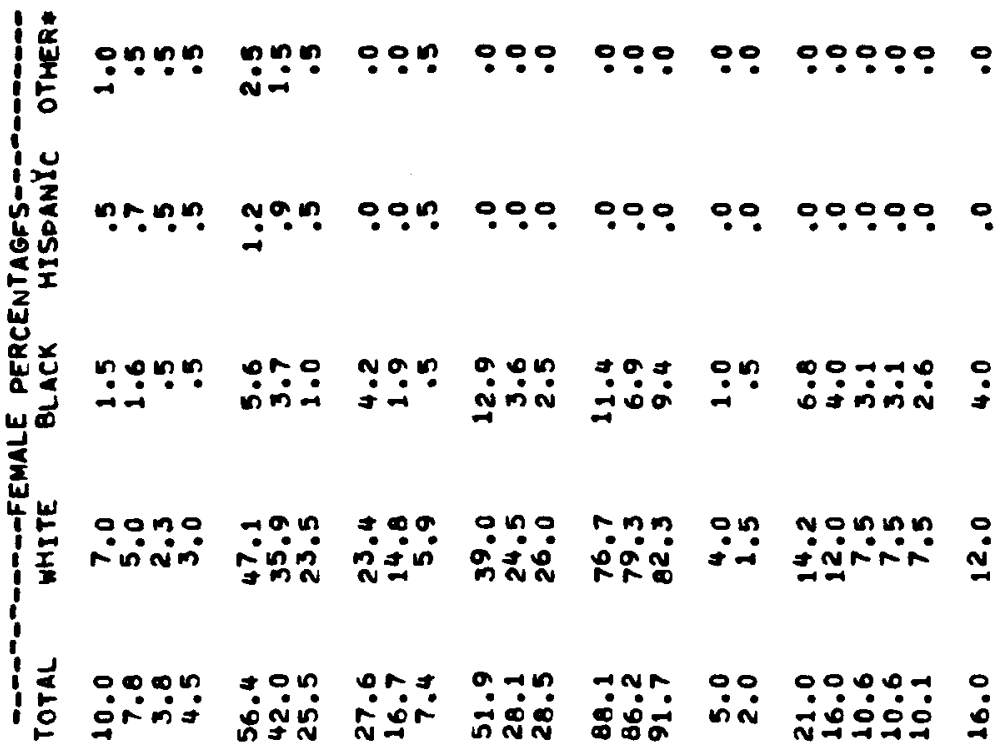

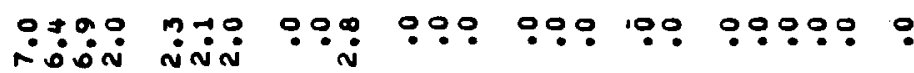

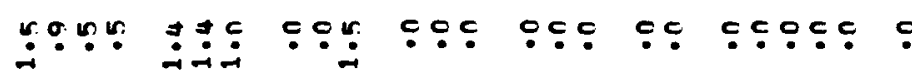

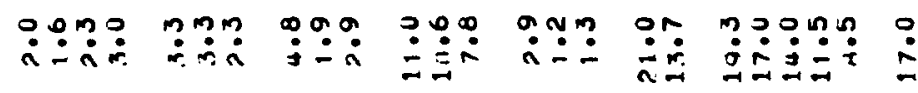

宸

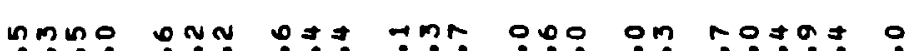

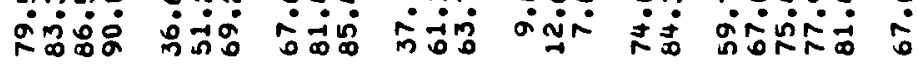

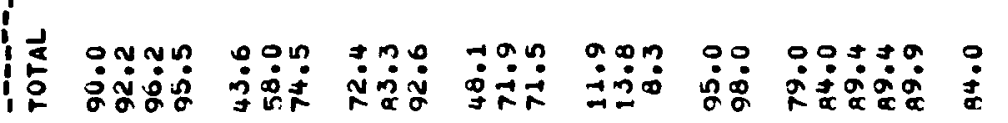

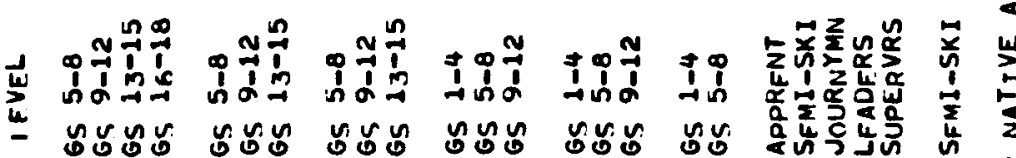




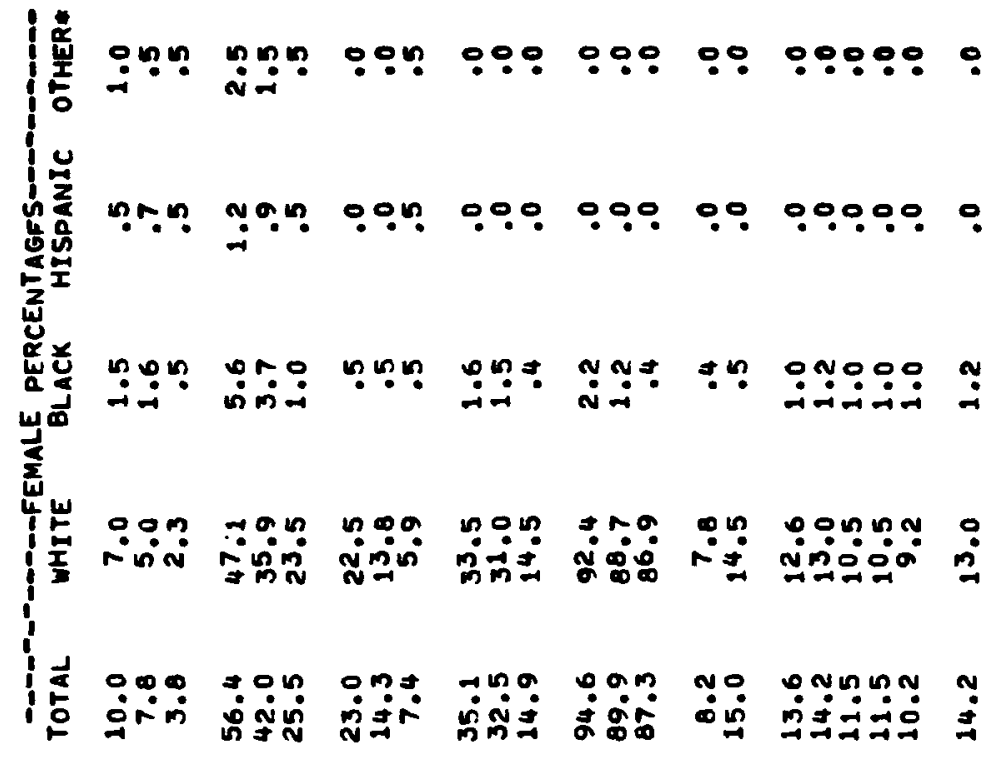

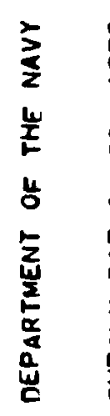

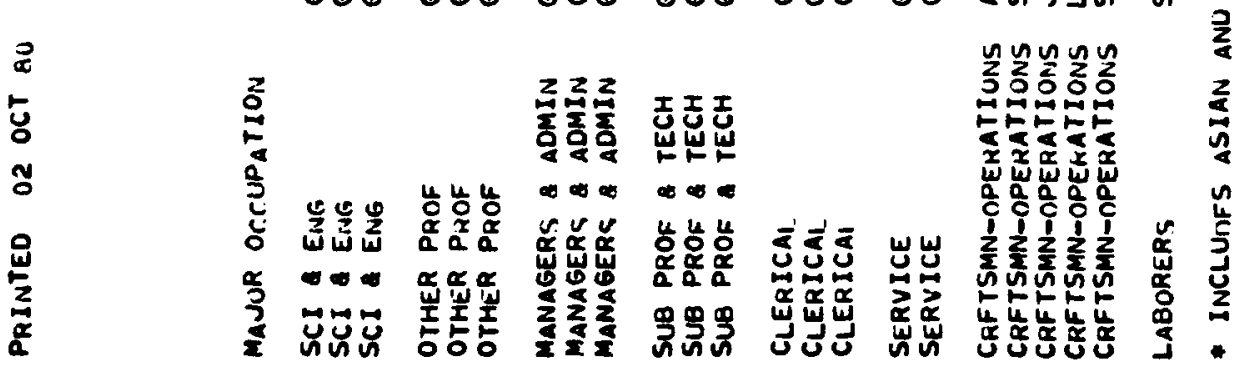



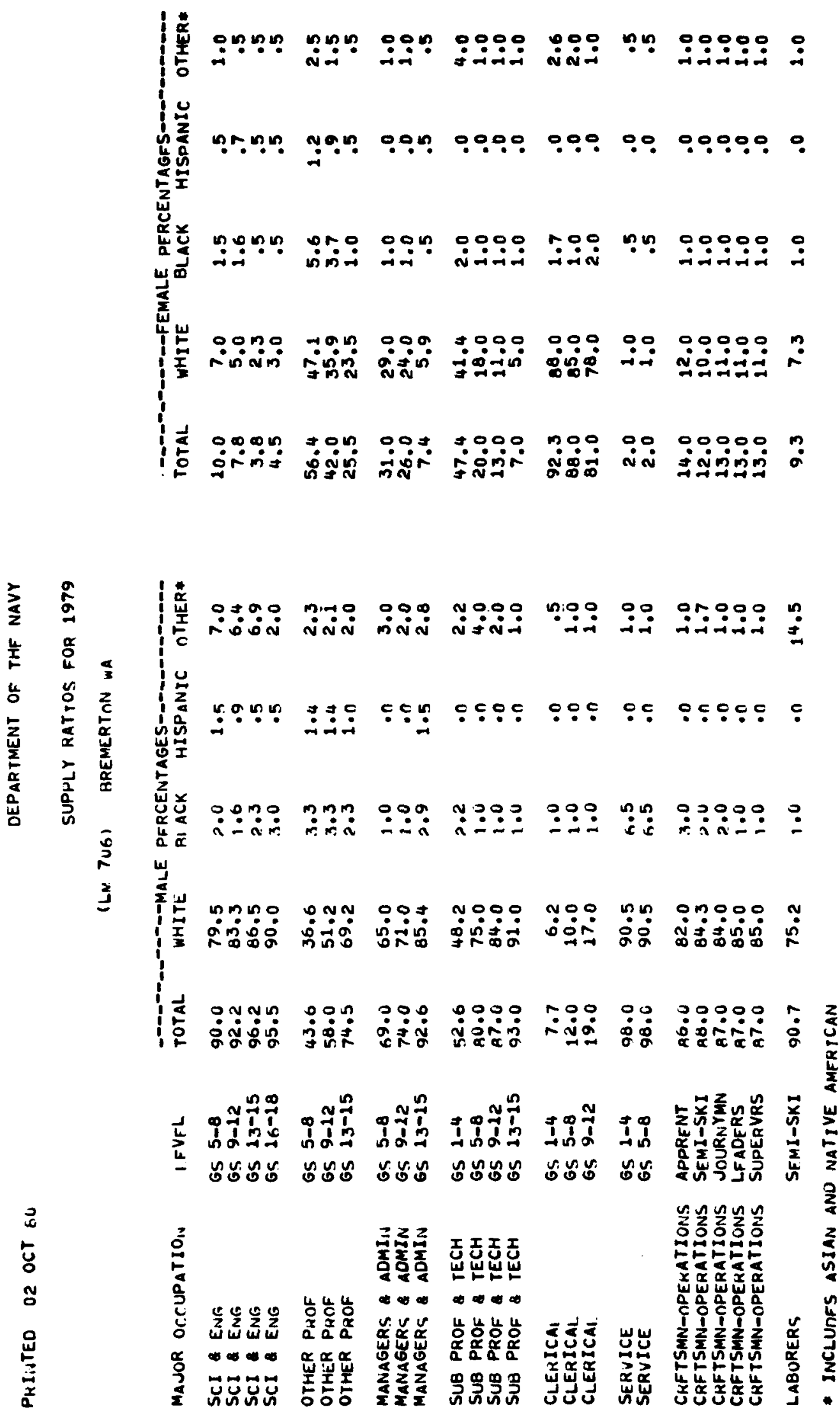


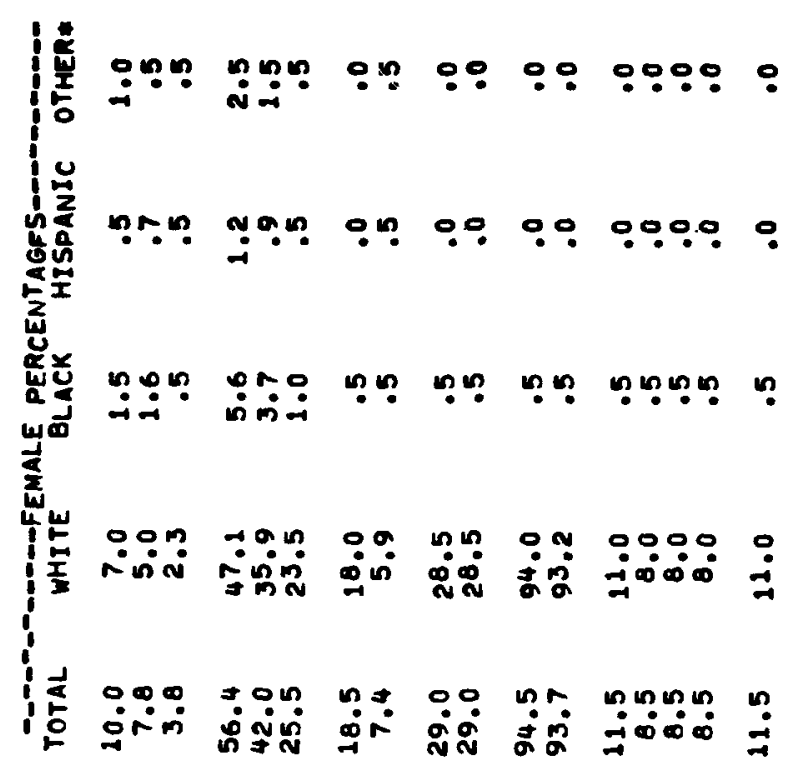

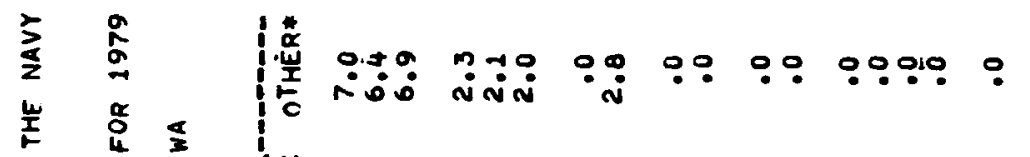

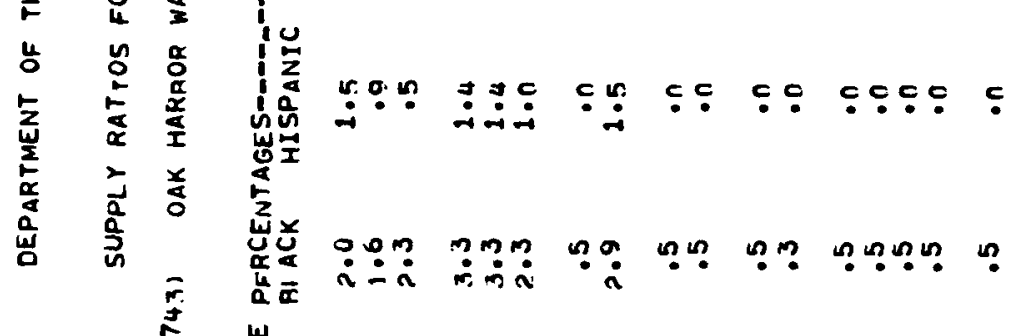

崖

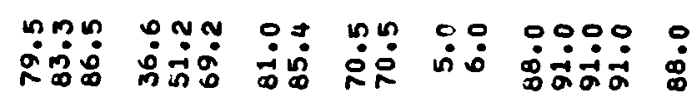

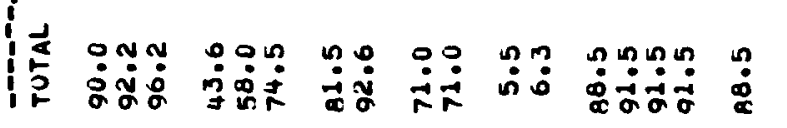

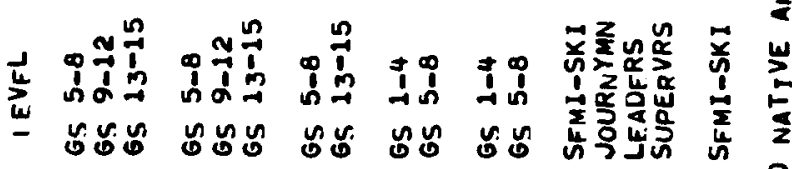

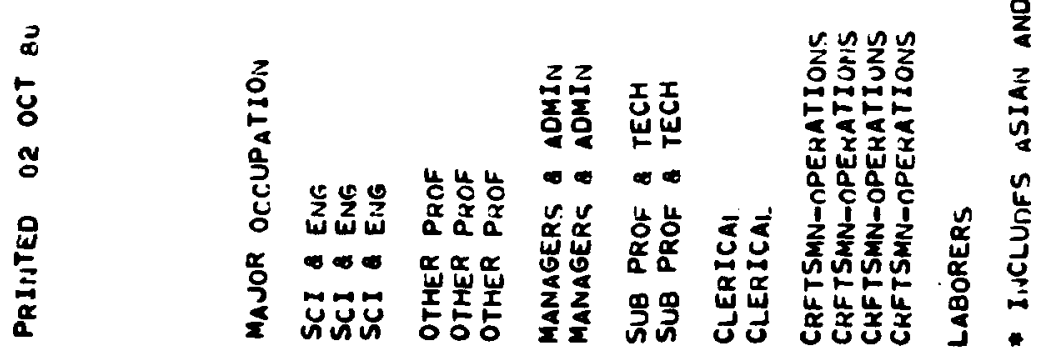



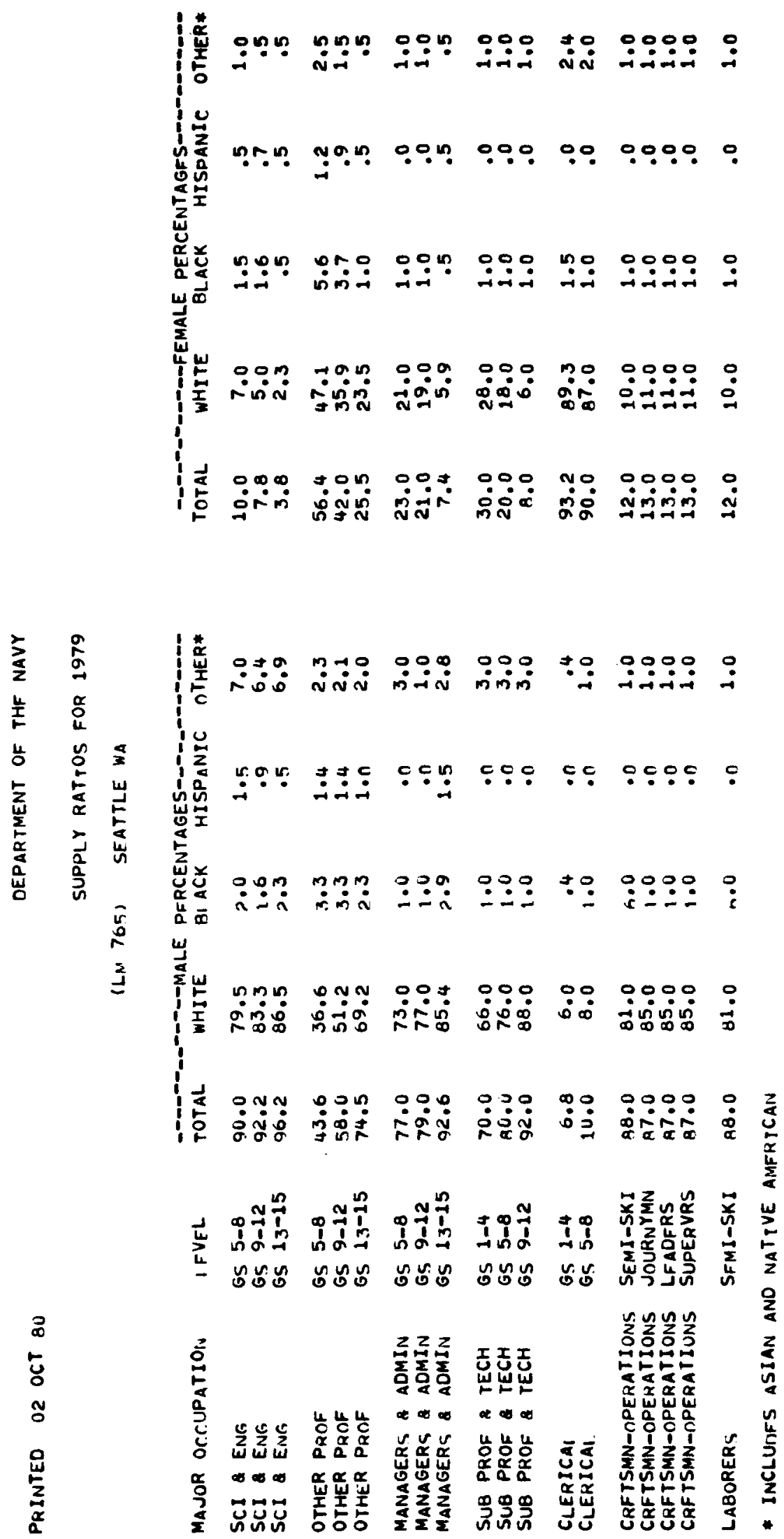

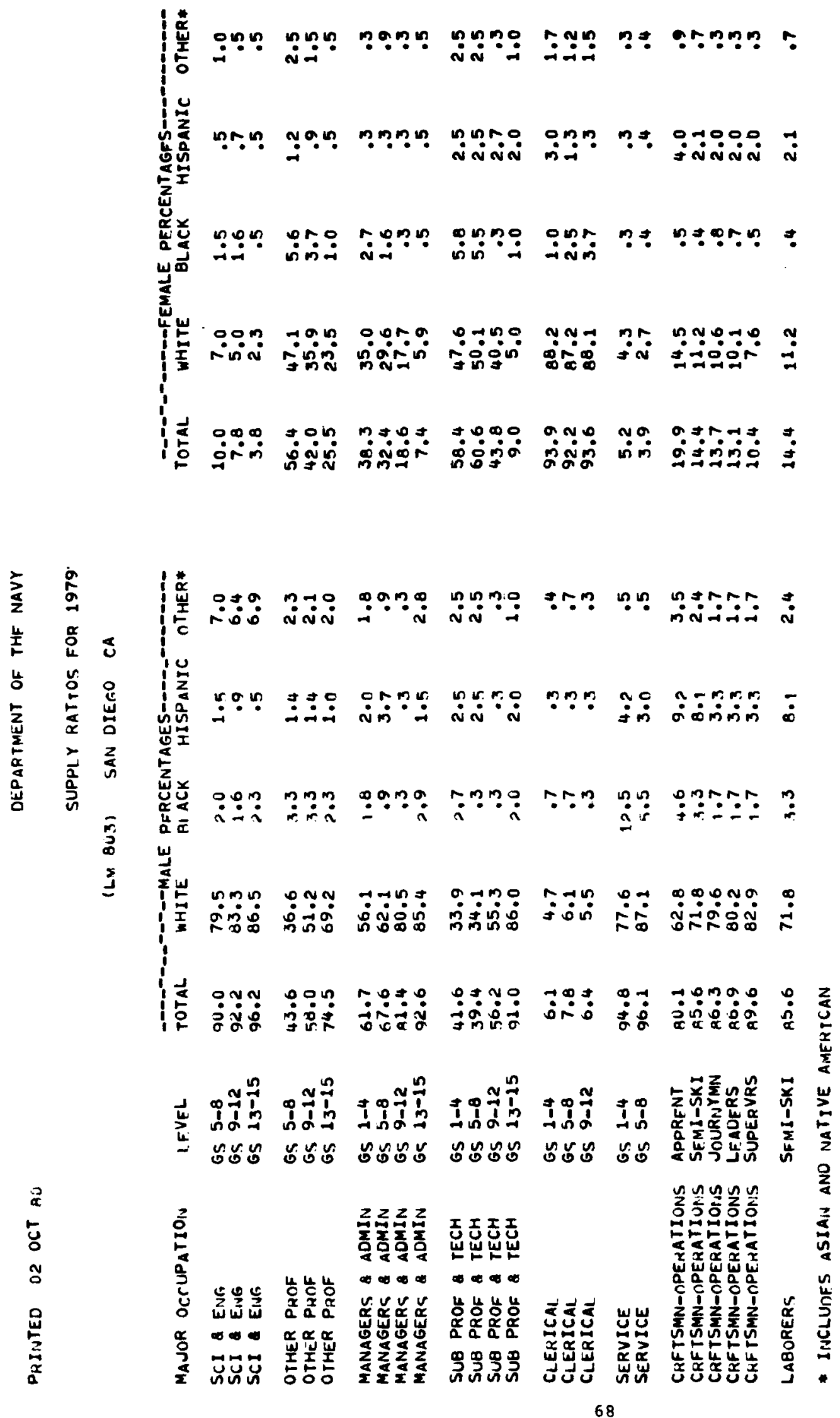

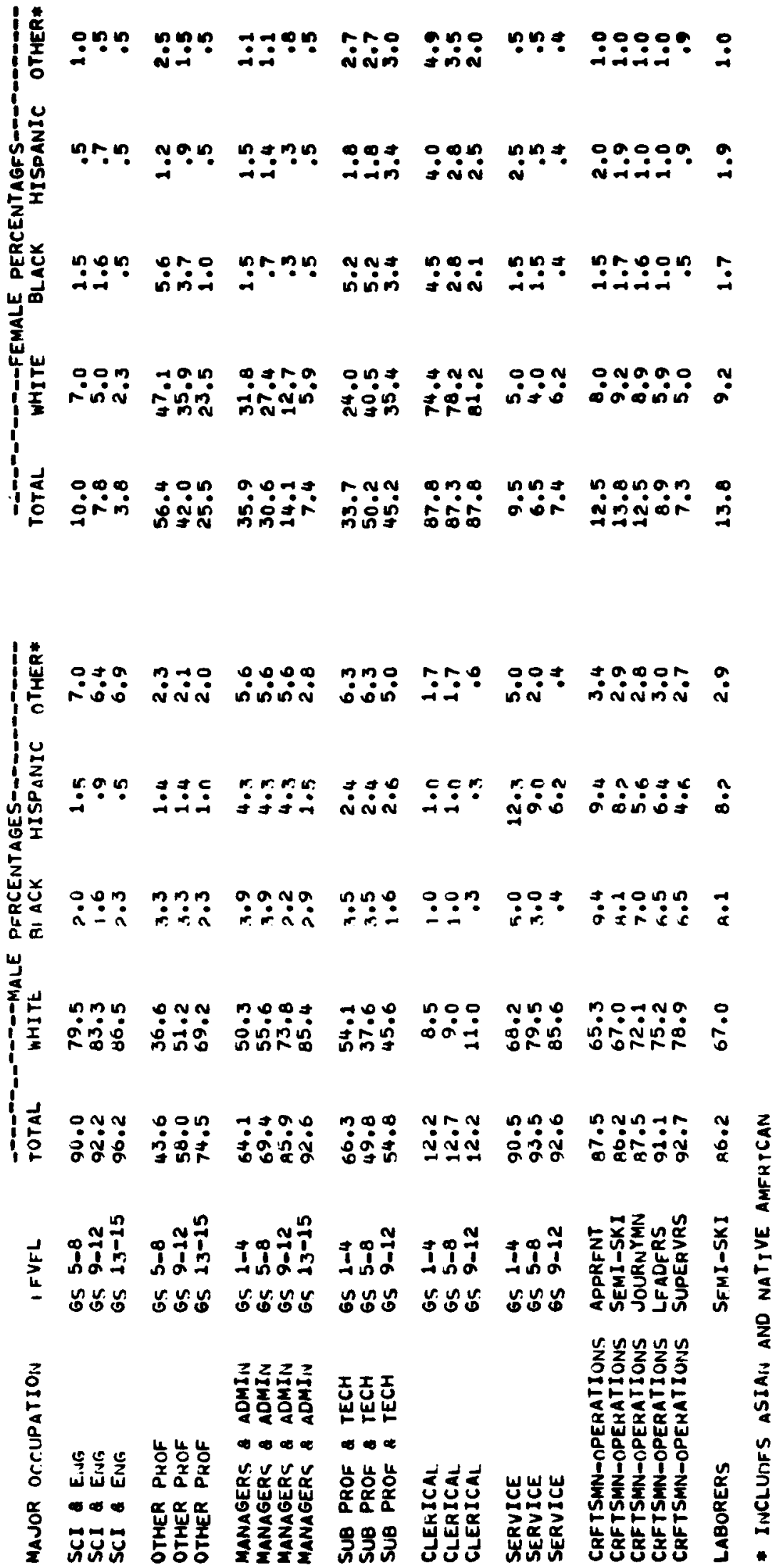


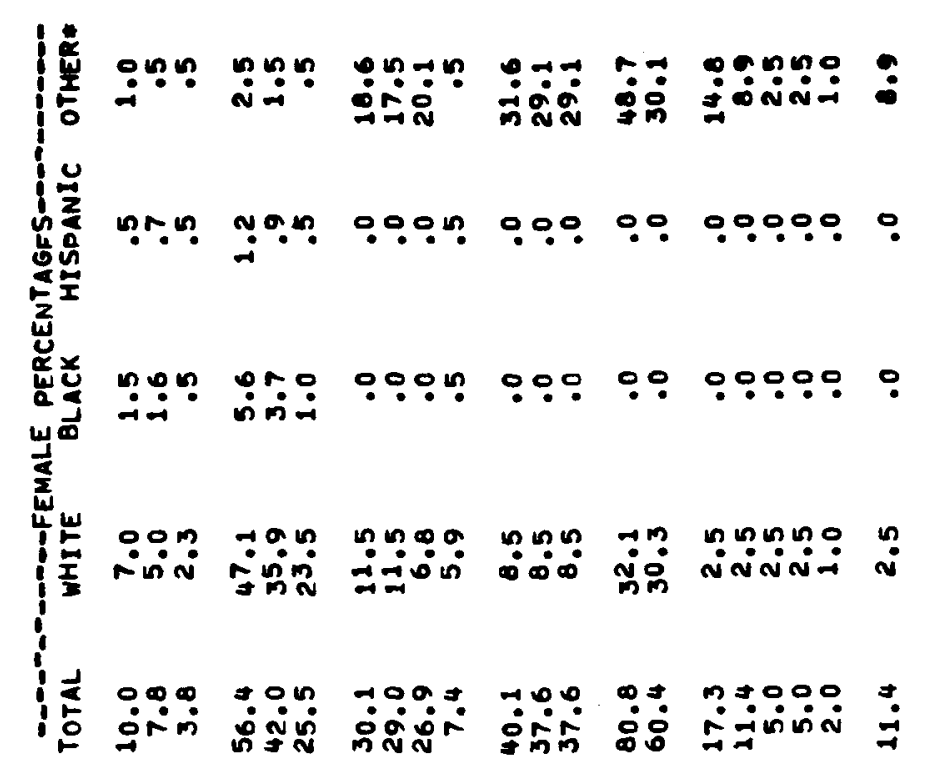

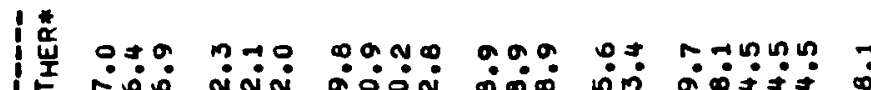

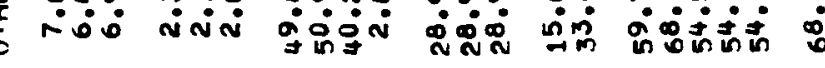

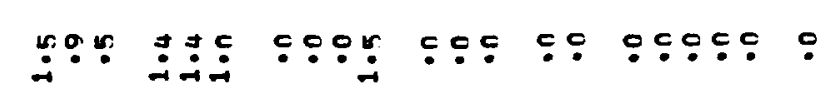
㟧

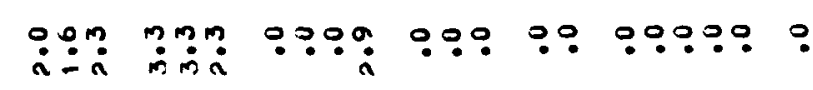

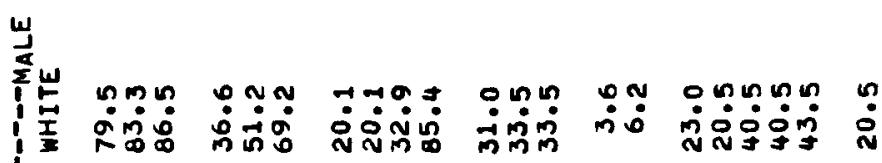
支

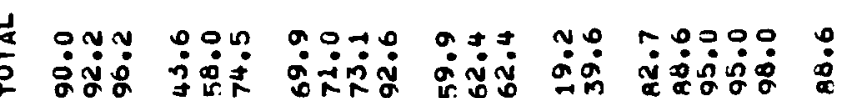

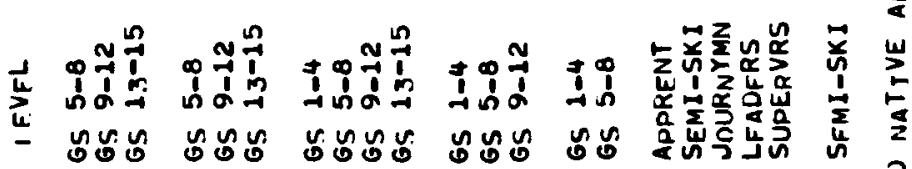

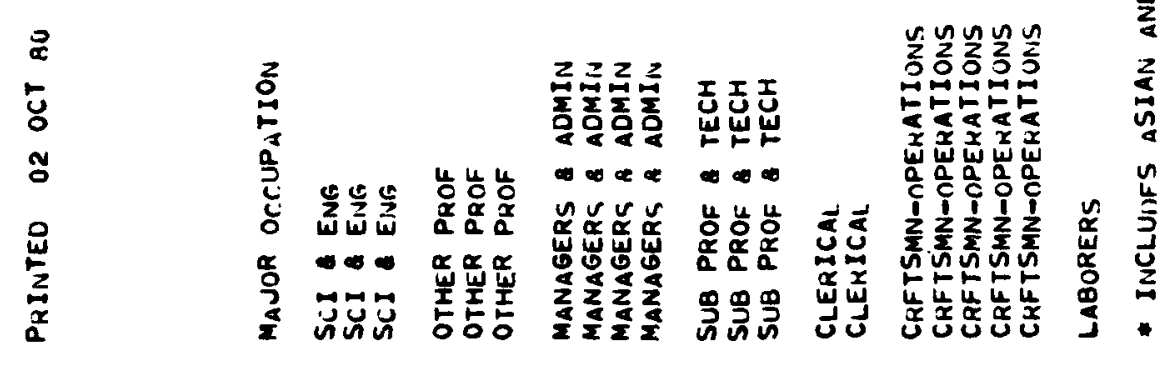




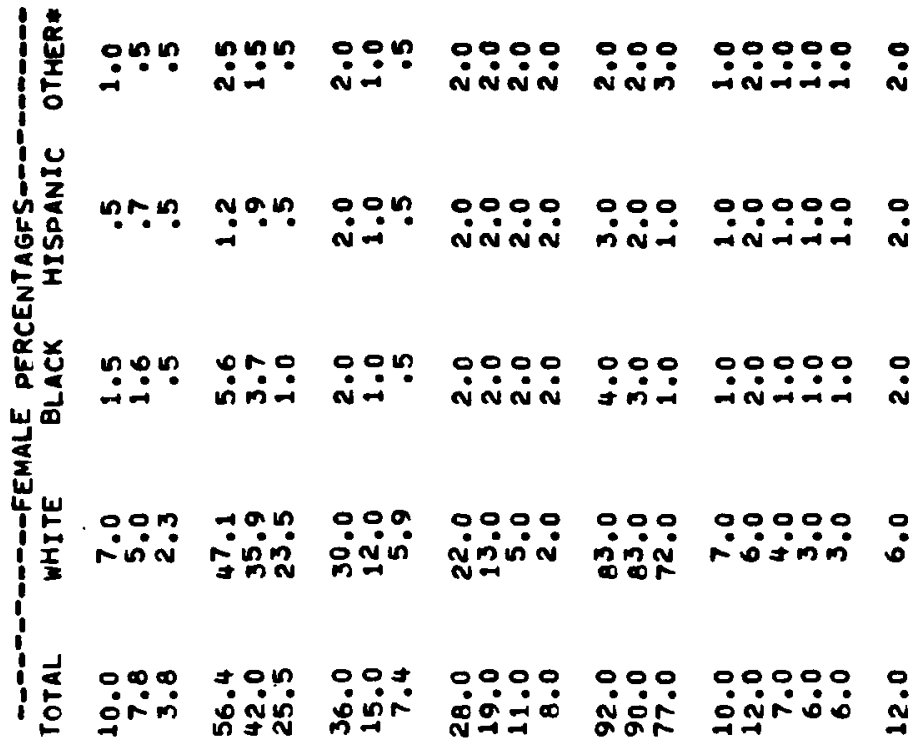

|

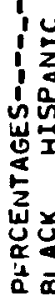

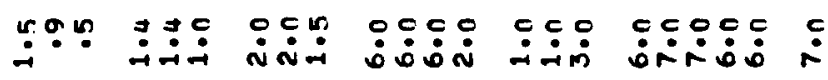
㝵 mmó 党

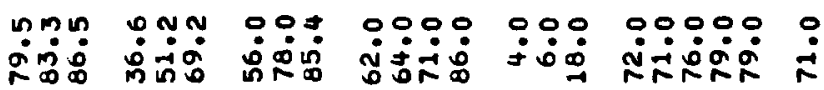
$\left\{\begin{array}{l}\frac{5}{5} \\ \frac{1}{2}\end{array}\right.$

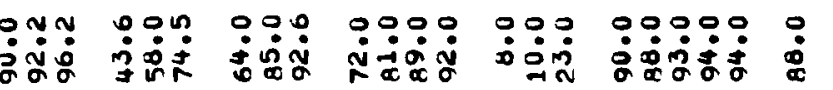

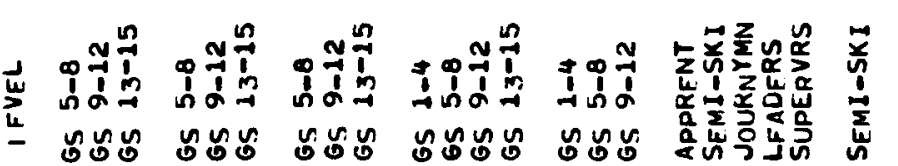

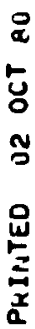

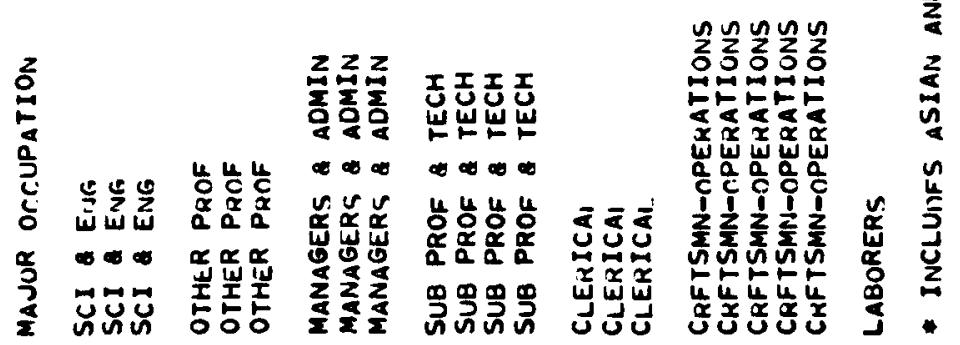



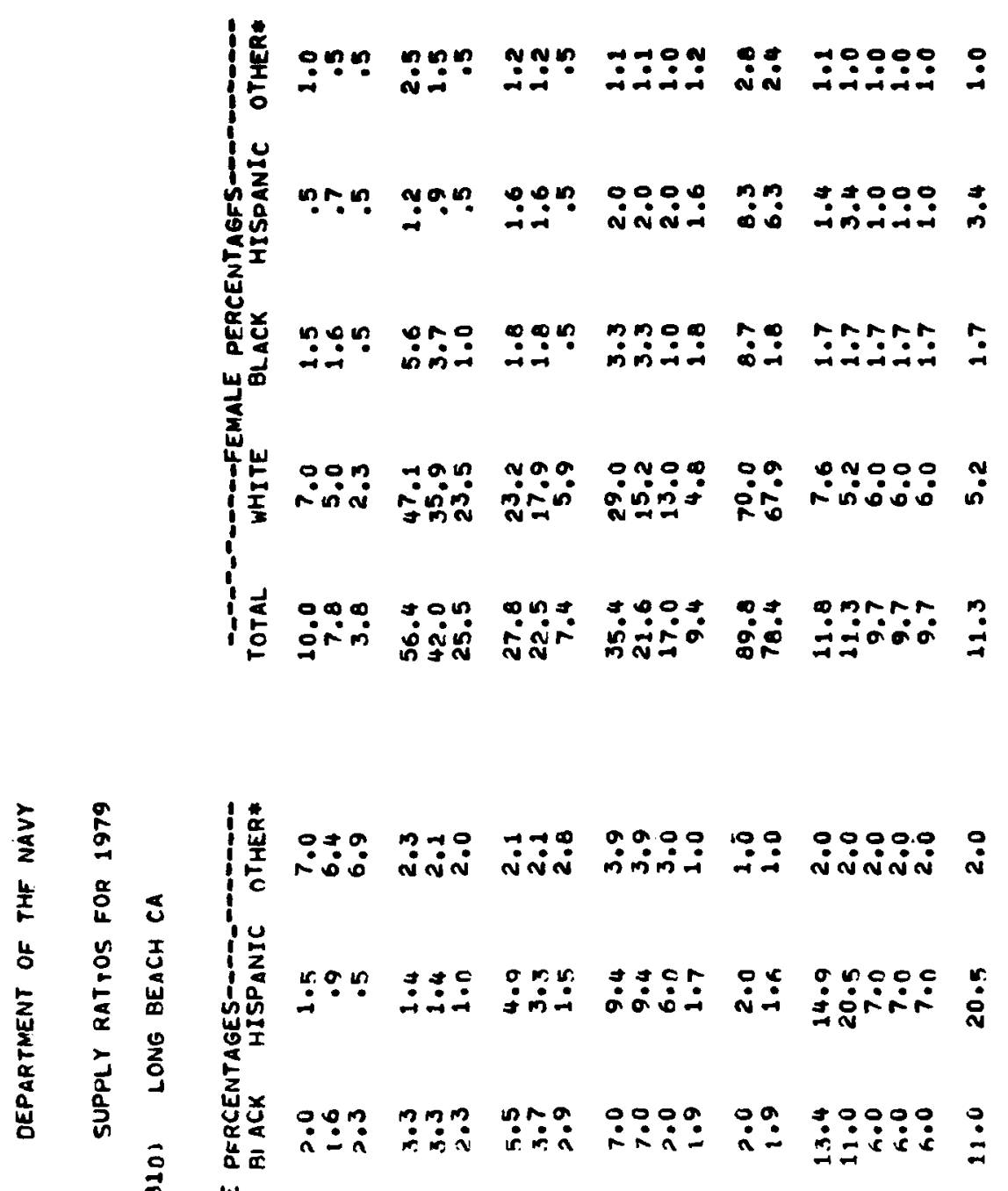
更

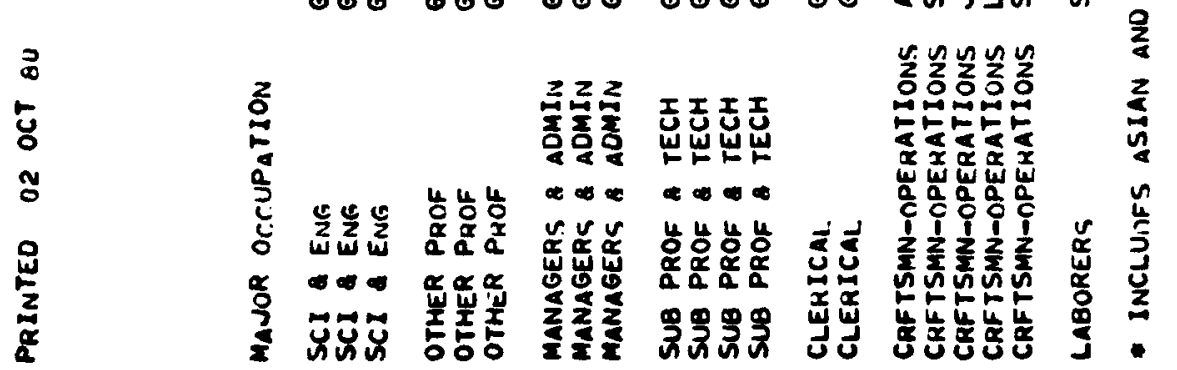



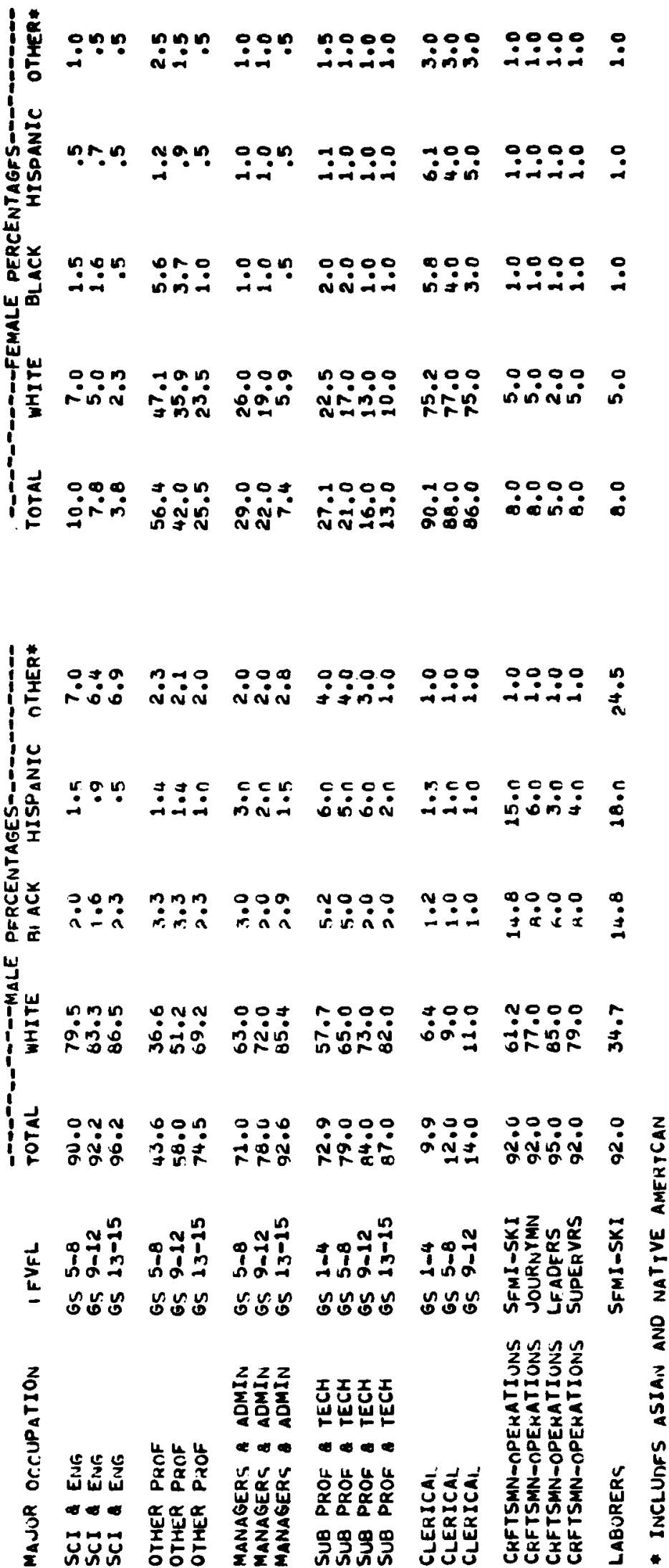

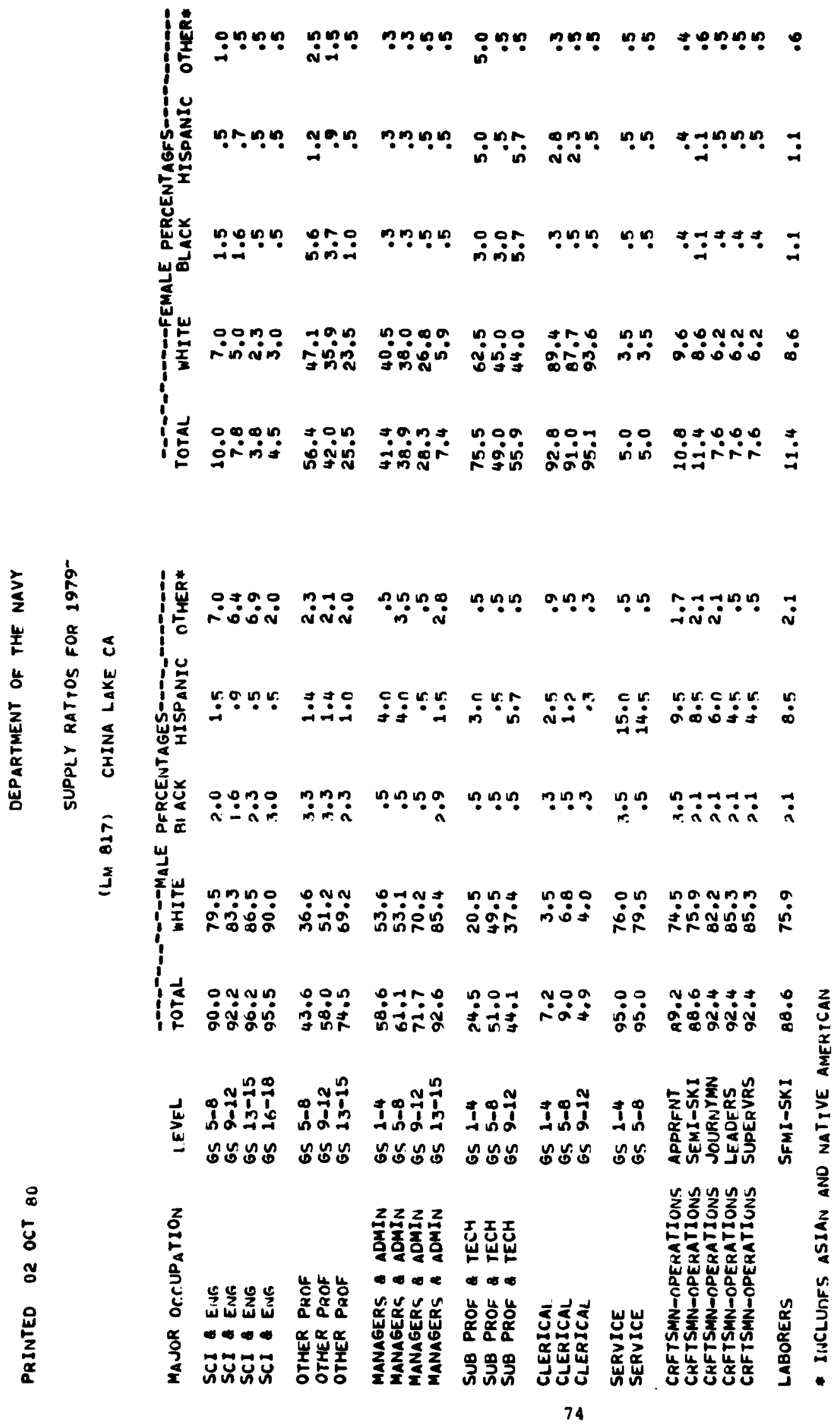

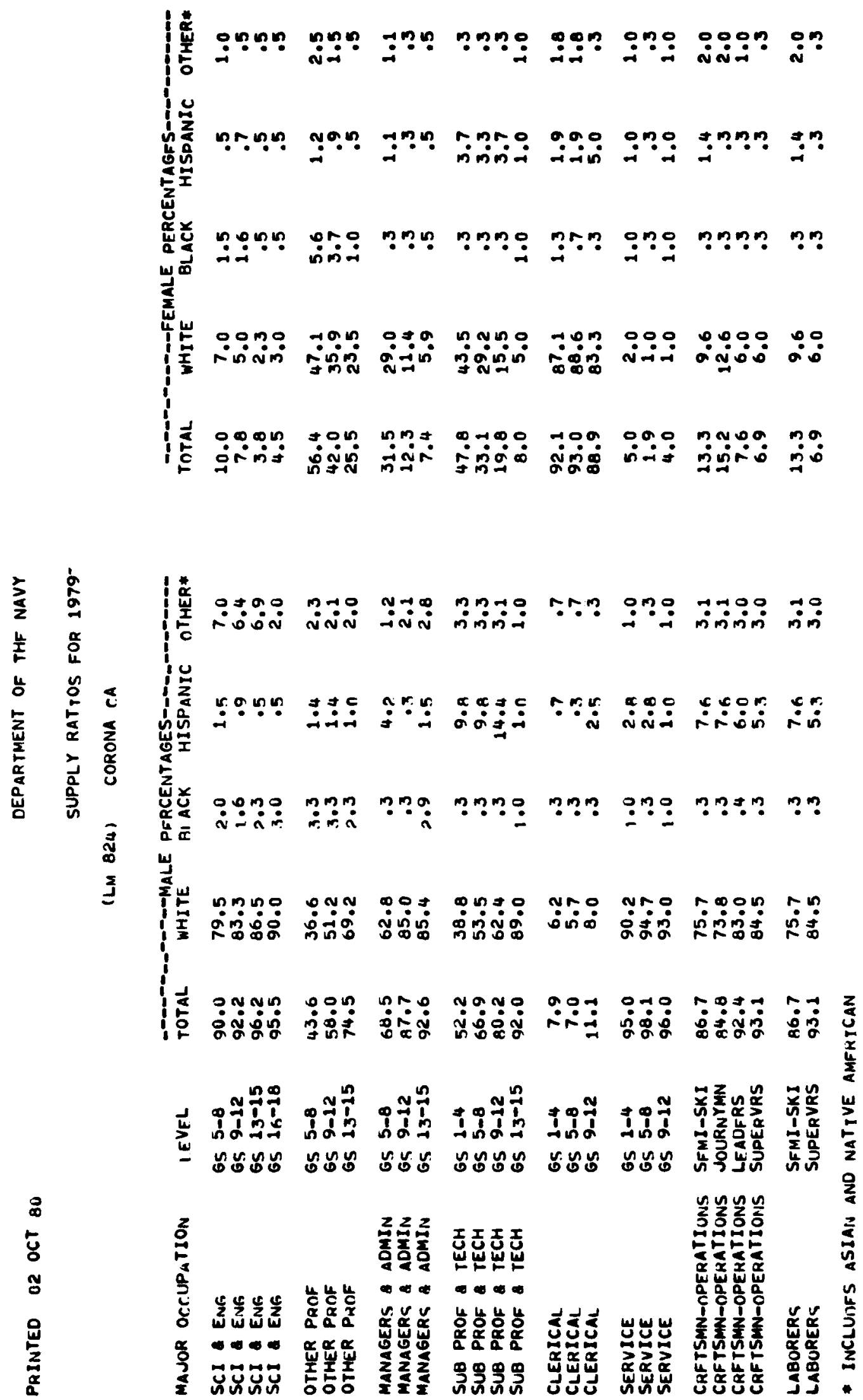


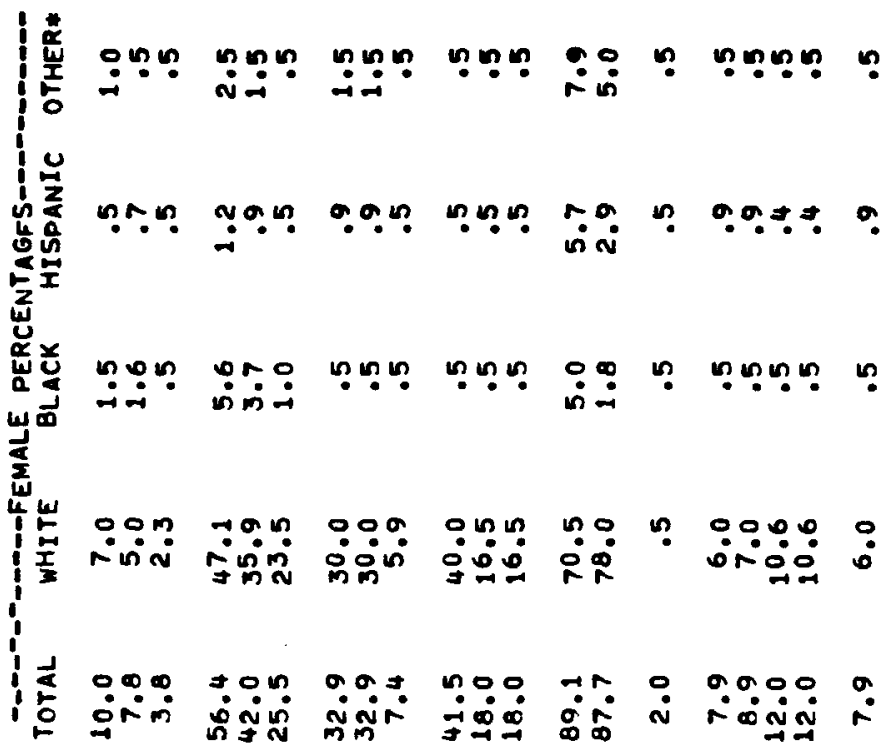

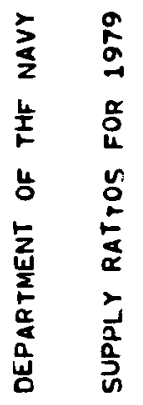

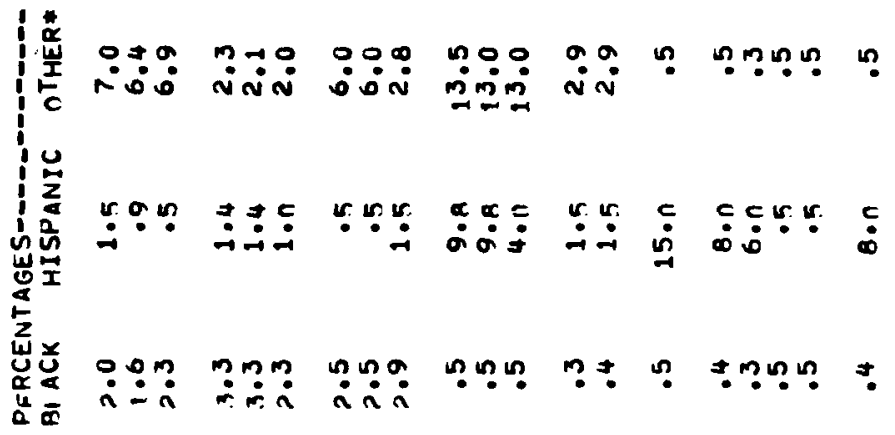

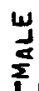

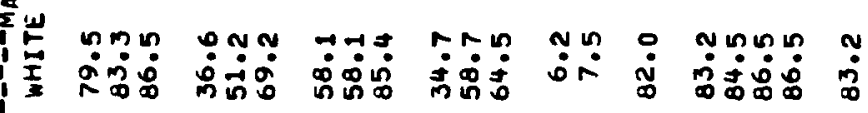

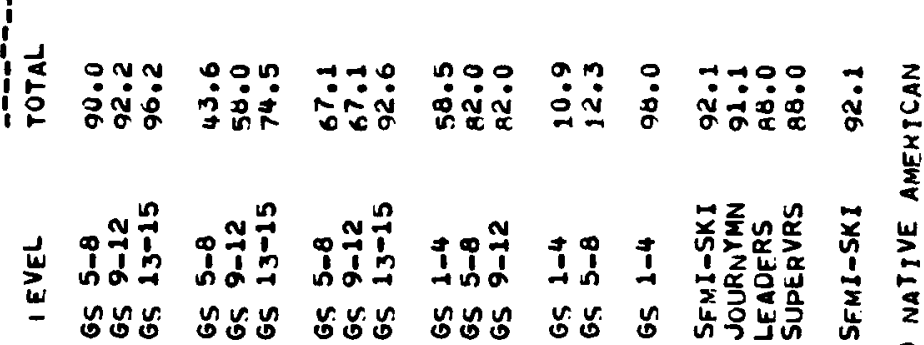

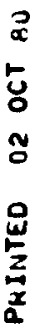

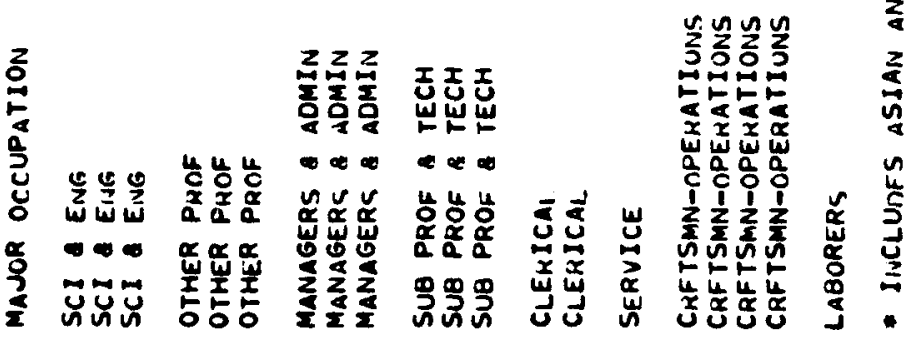



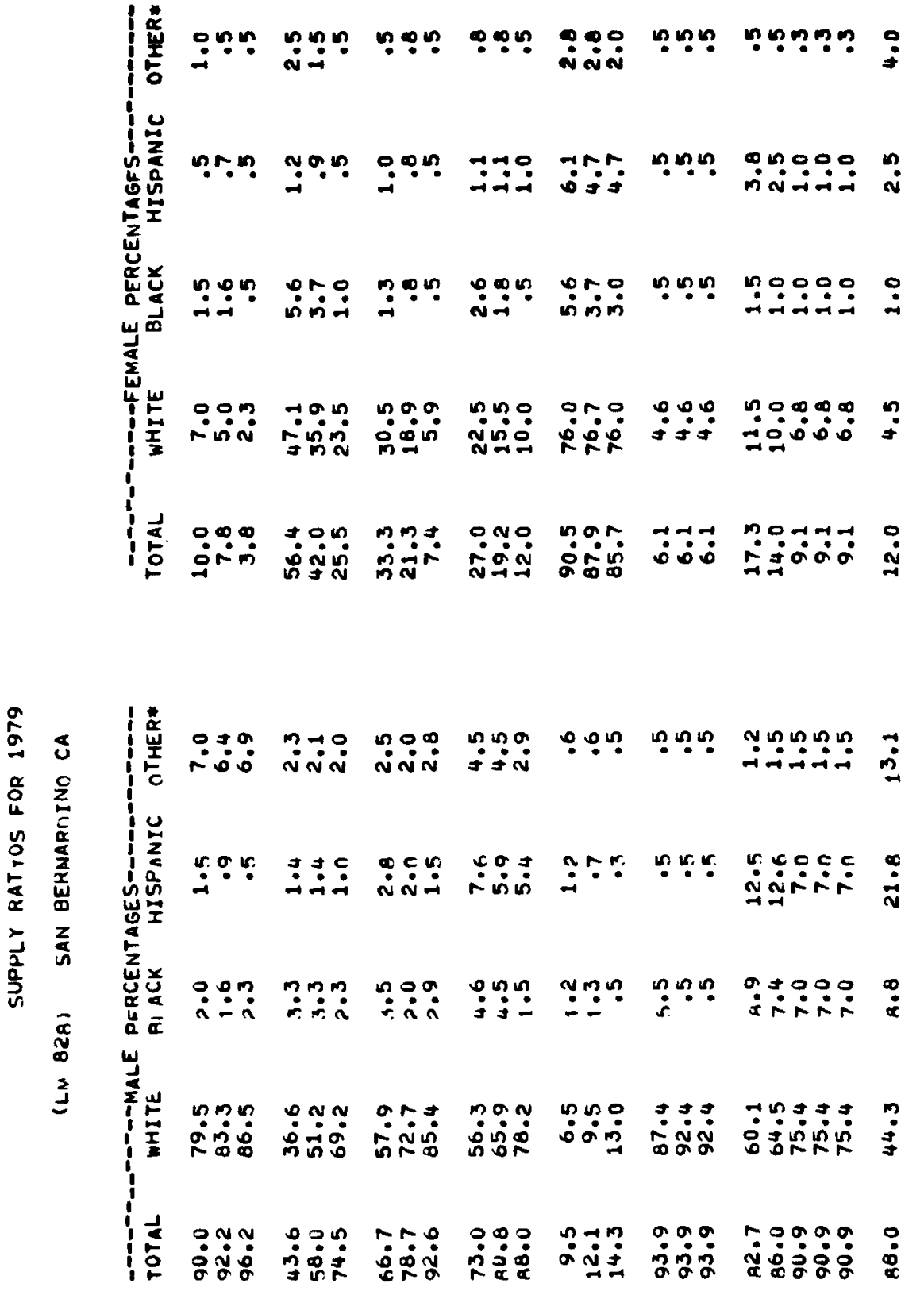

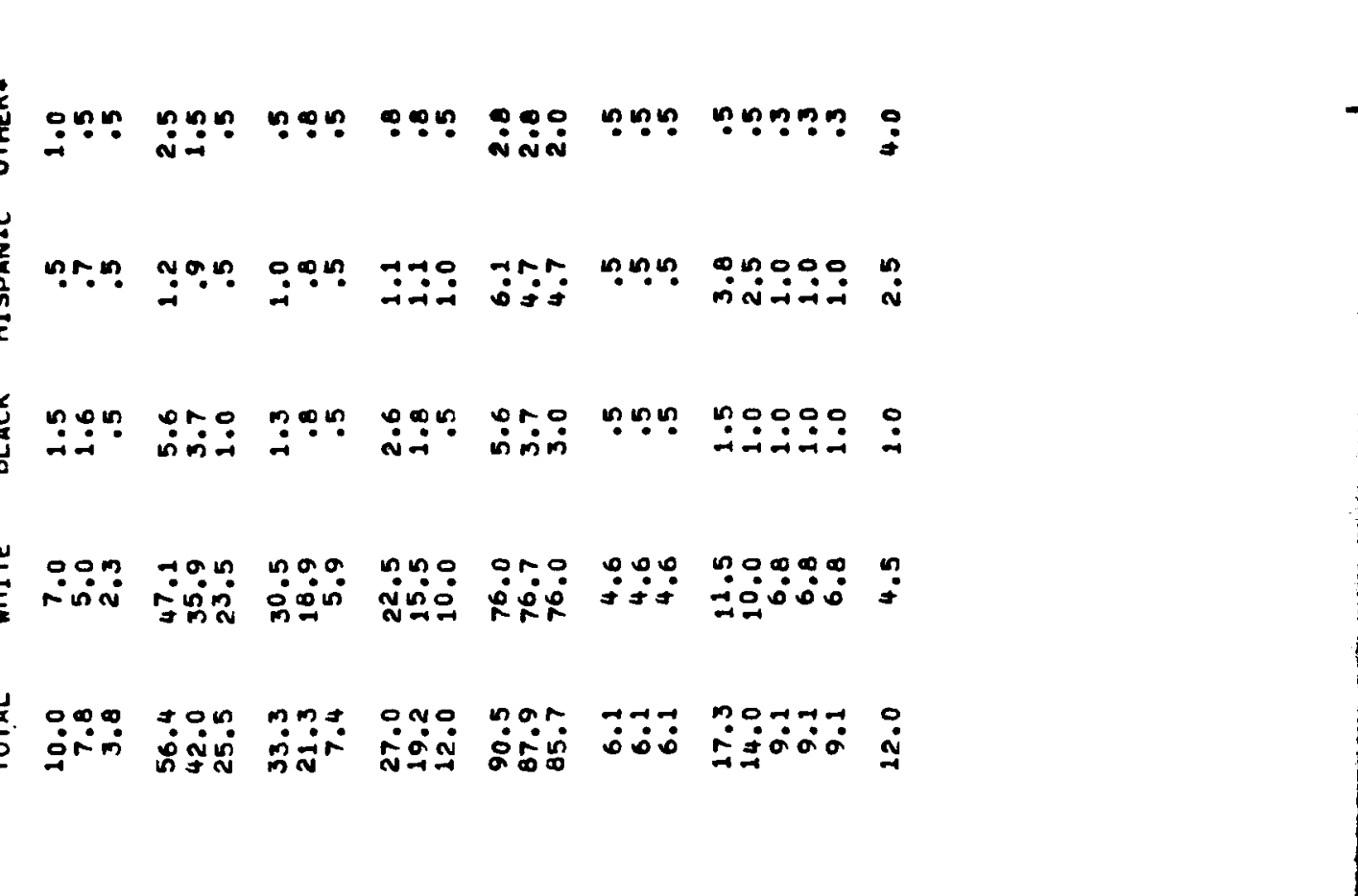

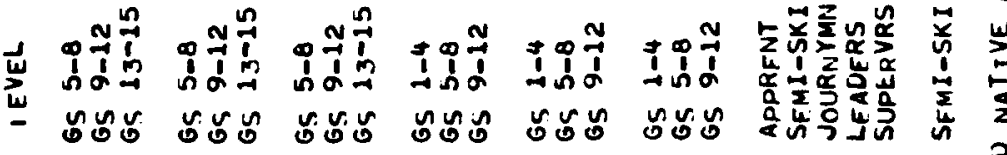

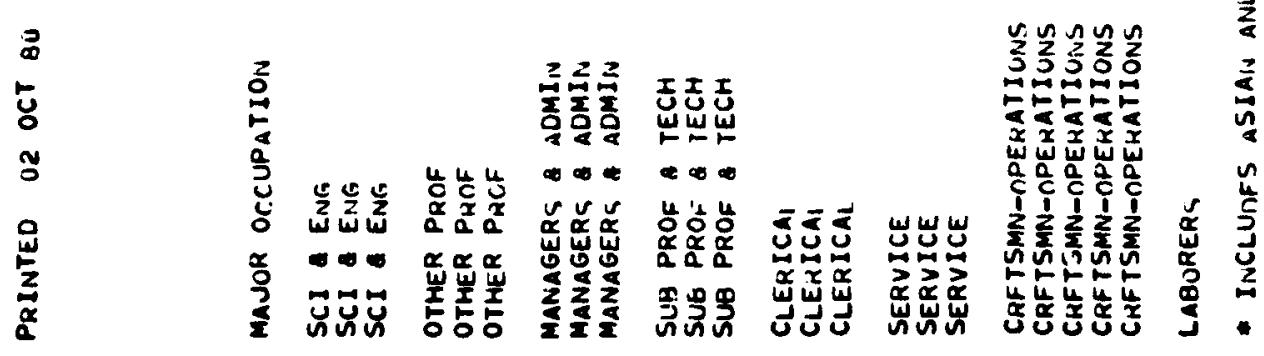




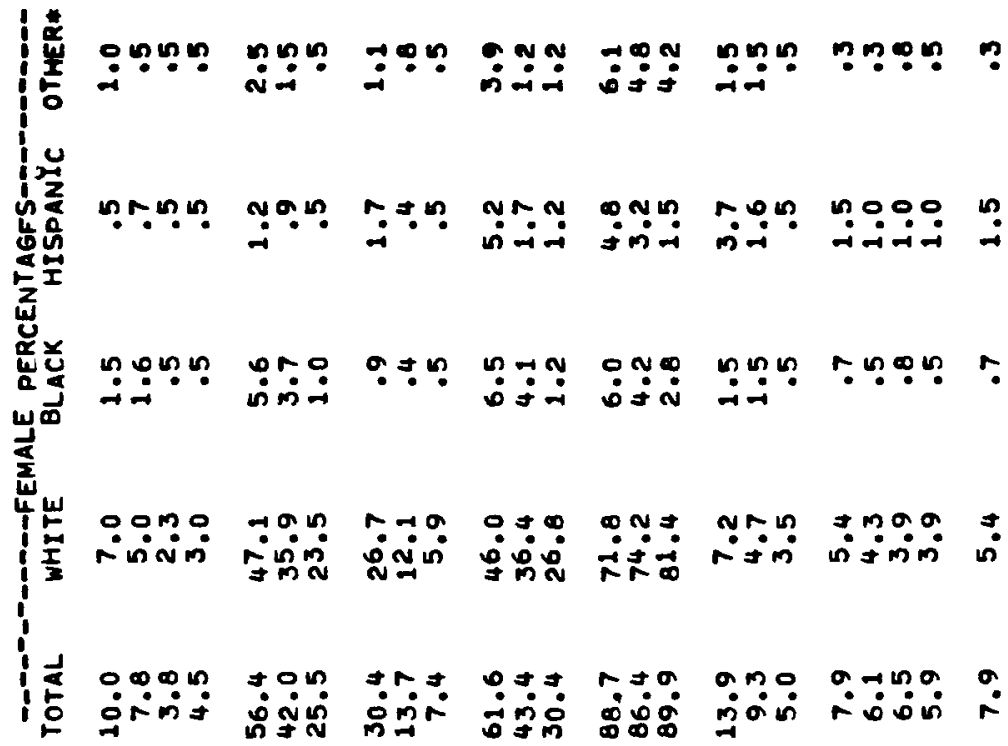

n.

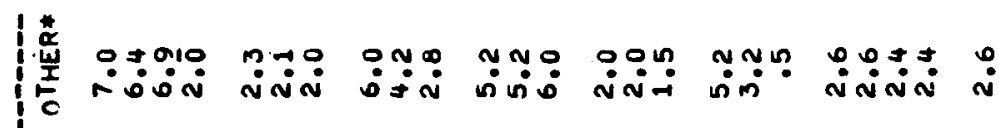
告

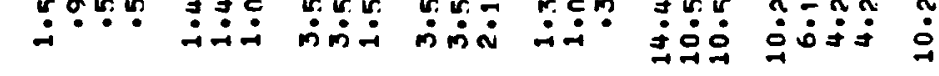

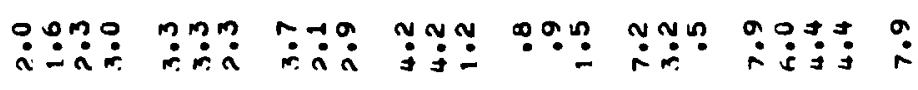
岁

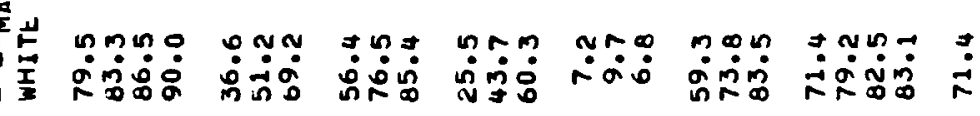
:

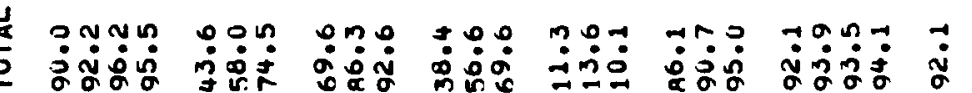

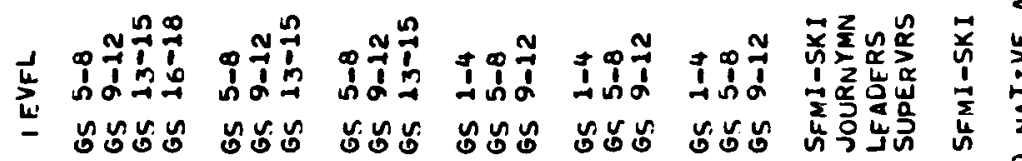

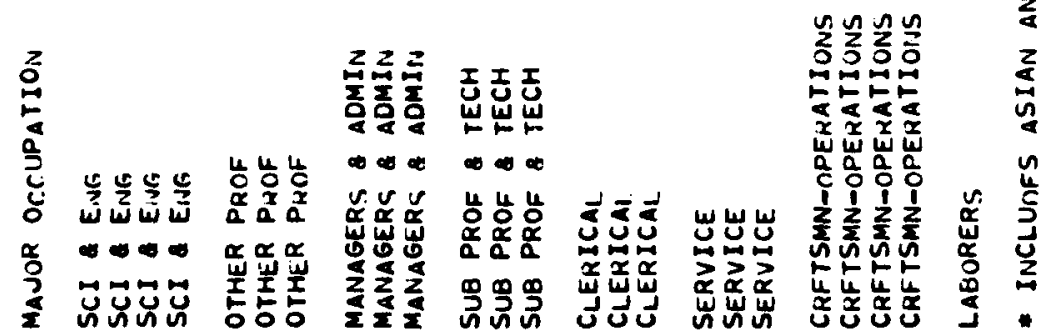



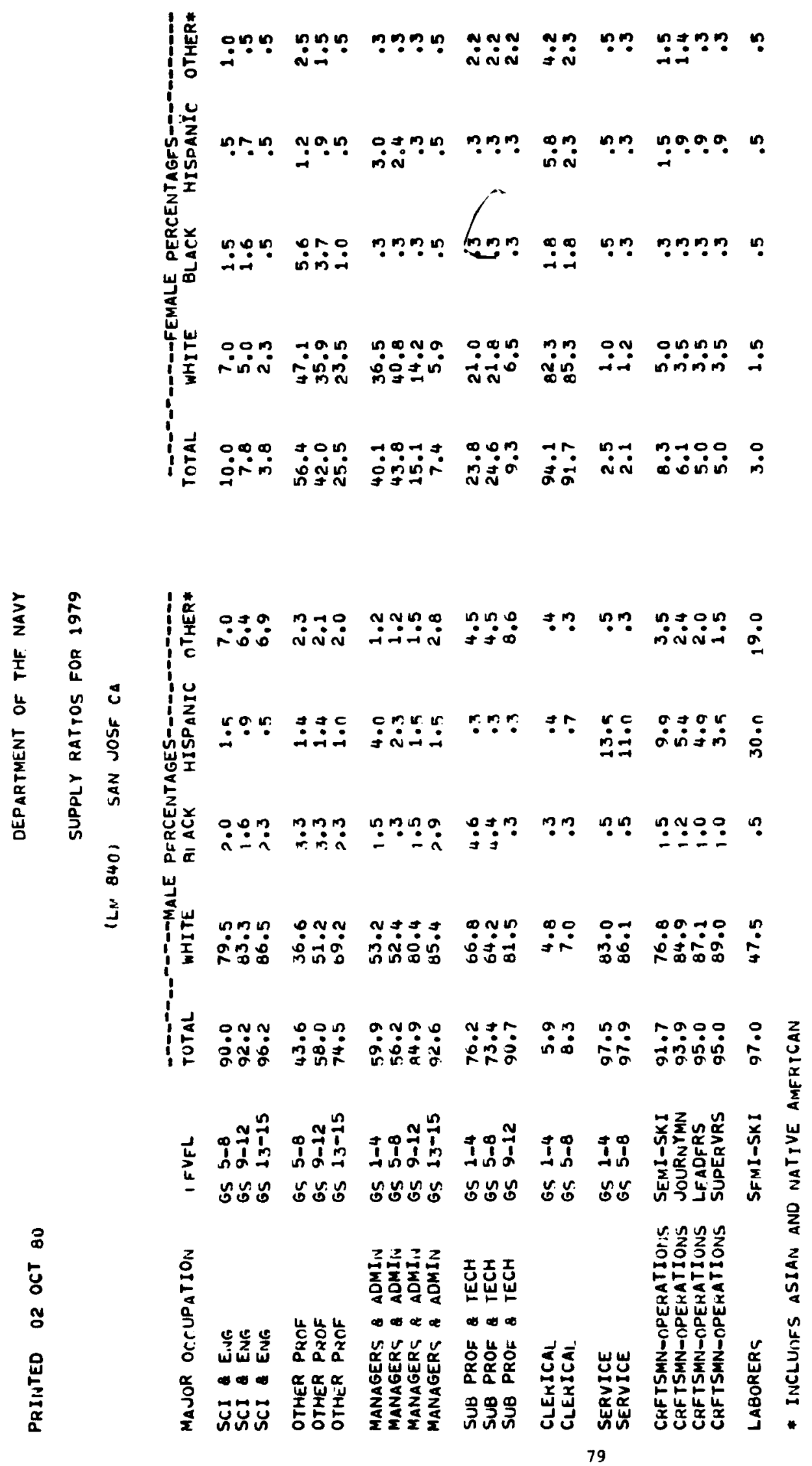

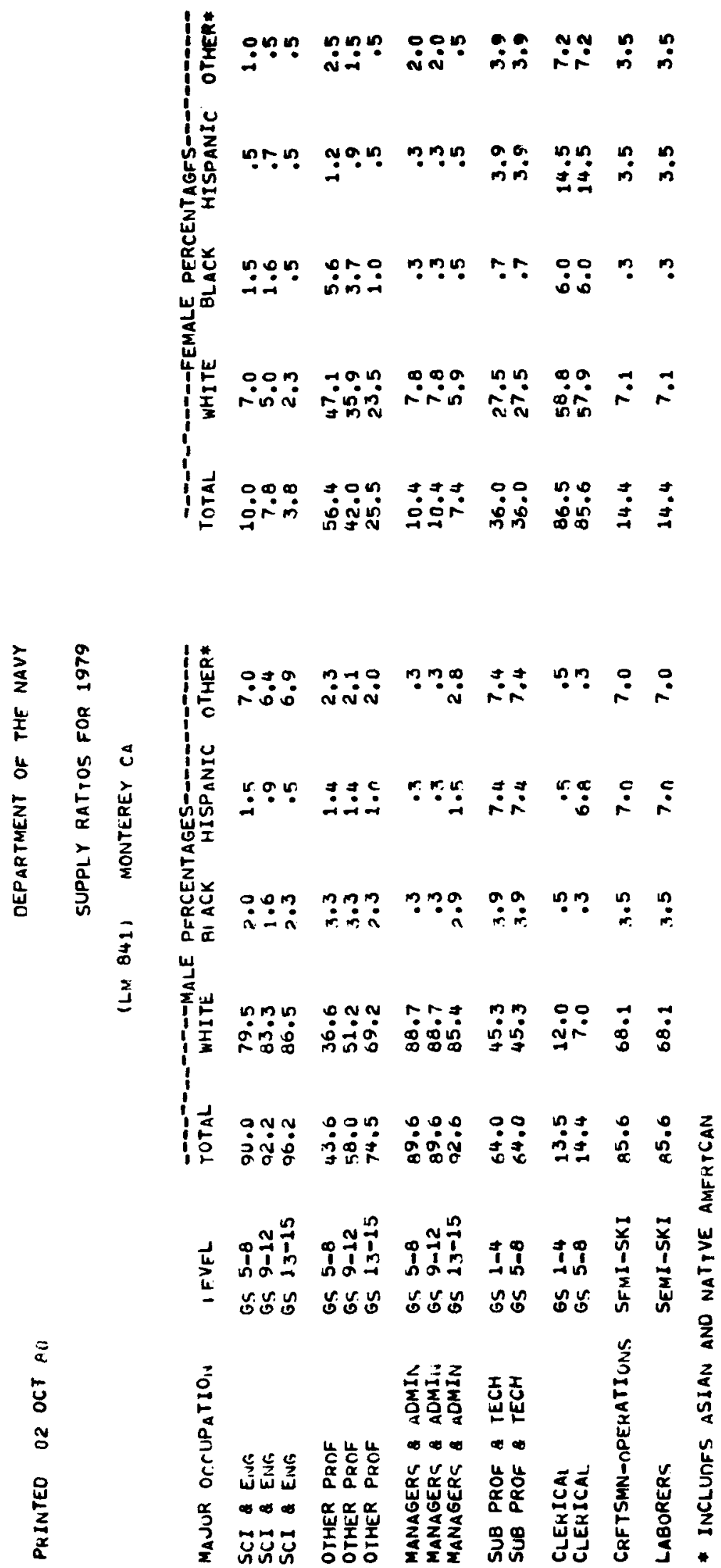


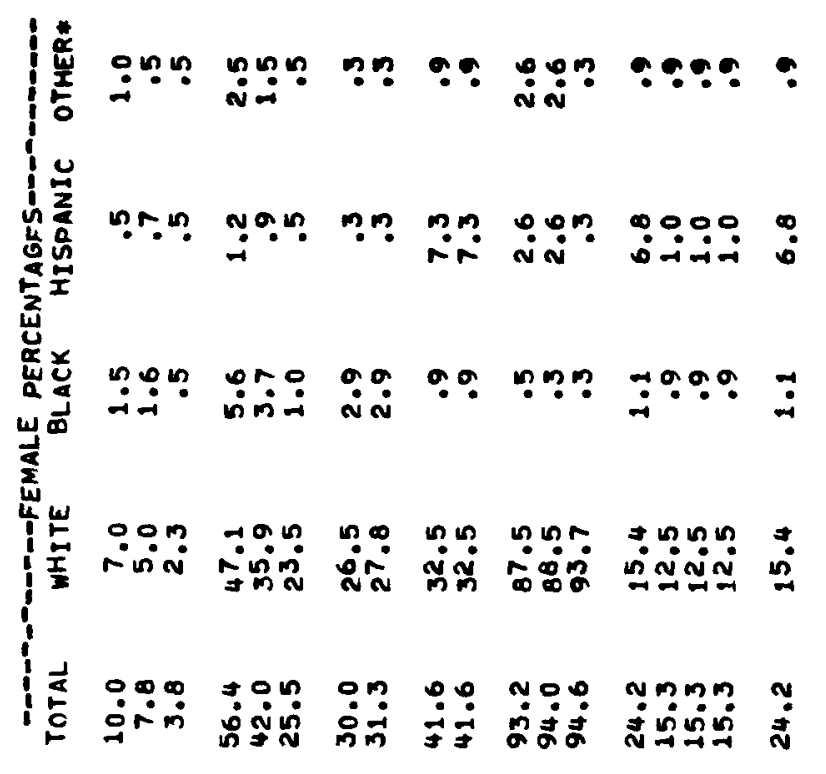

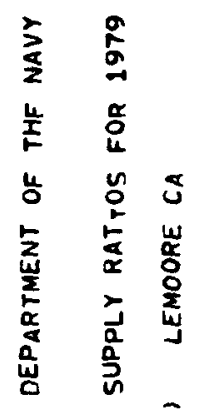

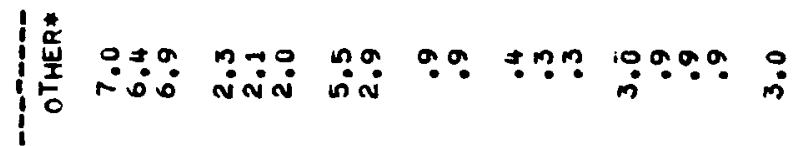

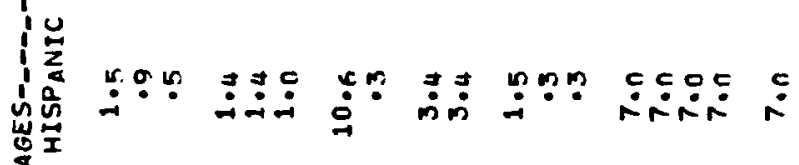

焉

岩弟

w

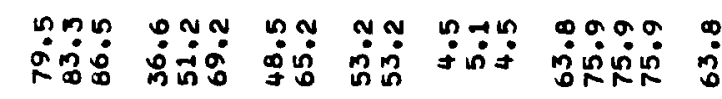

i

|

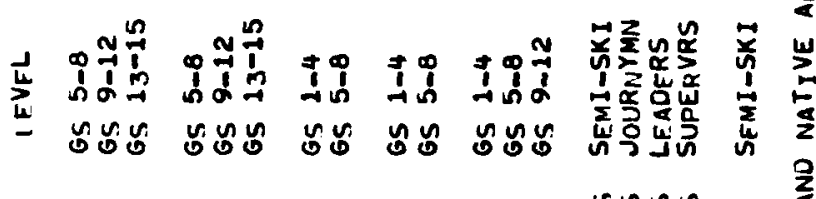

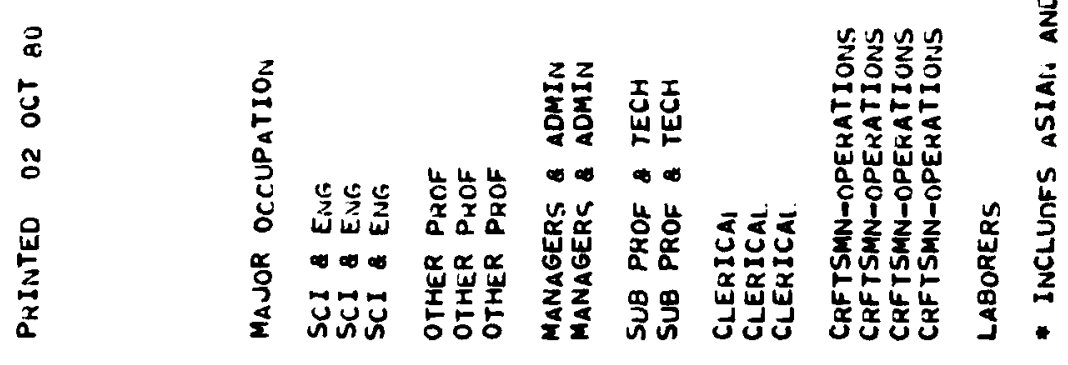




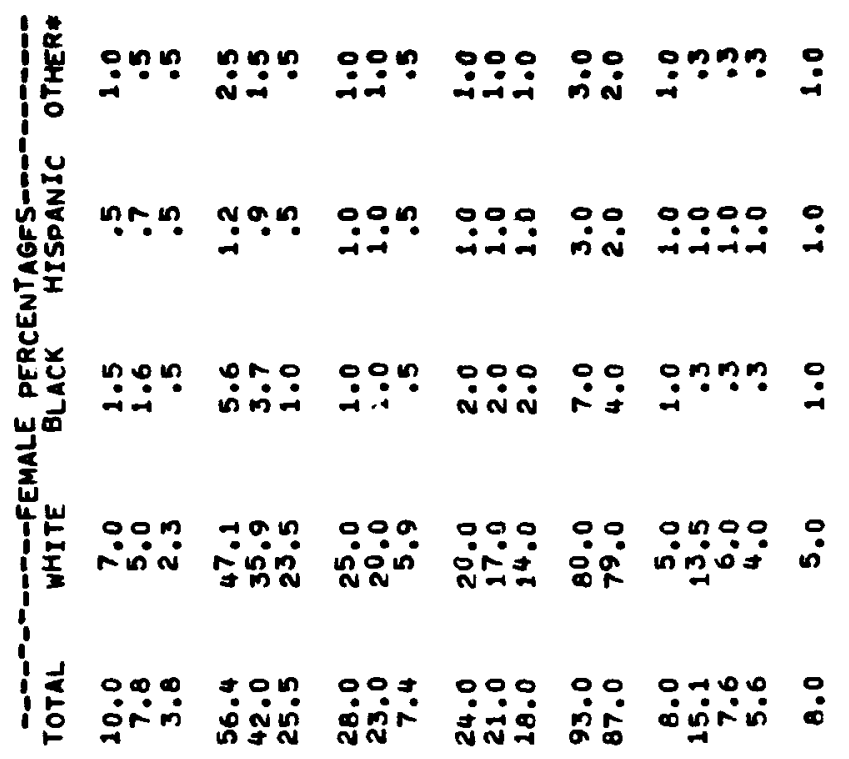

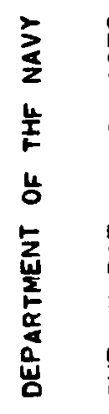

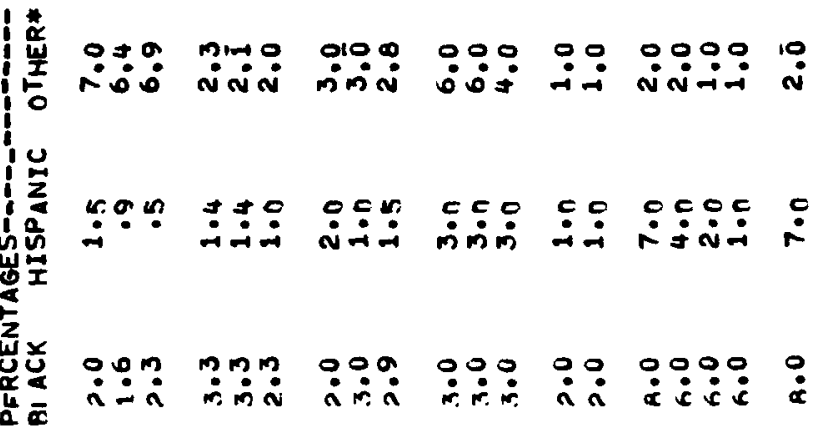
嵌 势

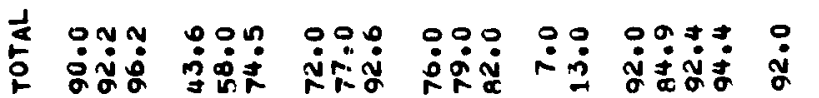

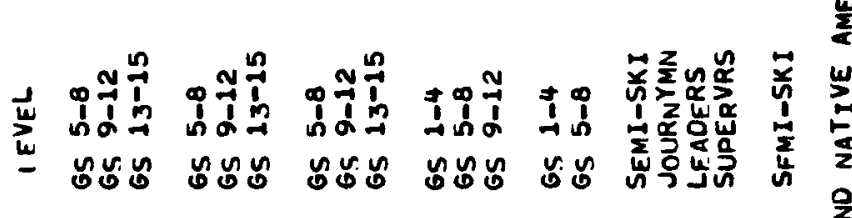

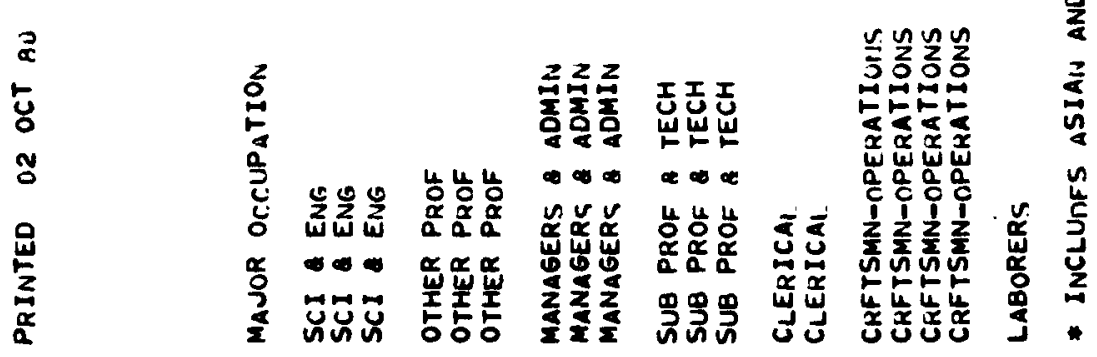



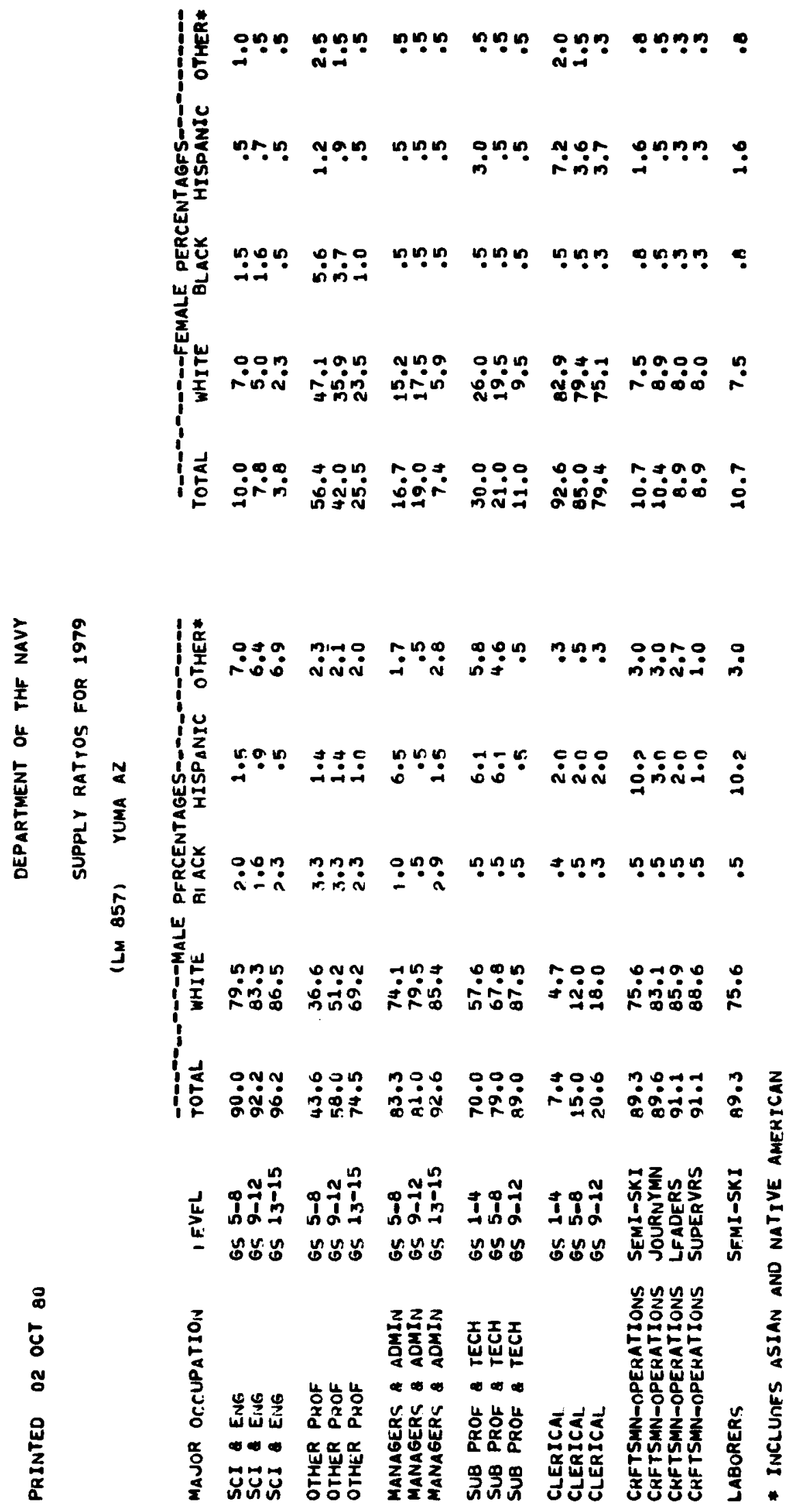


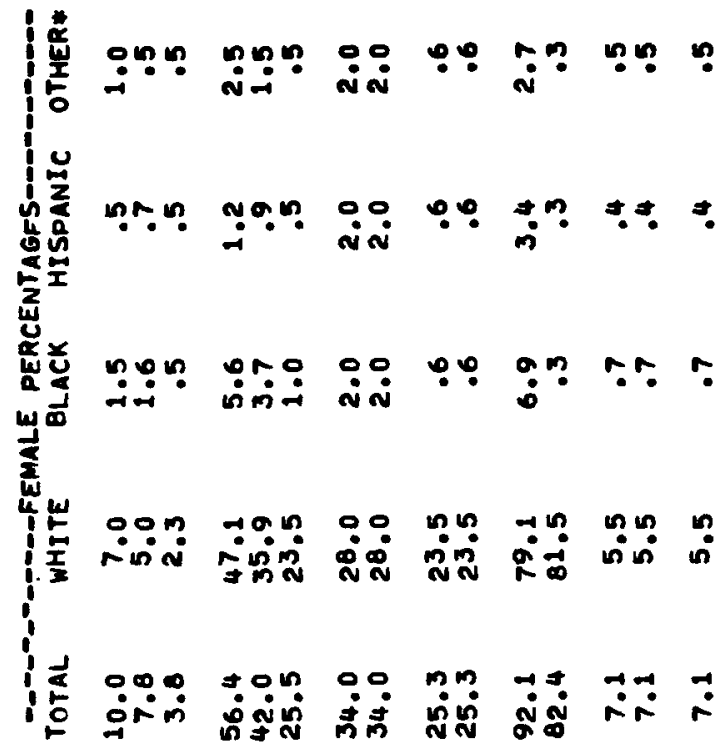

辛

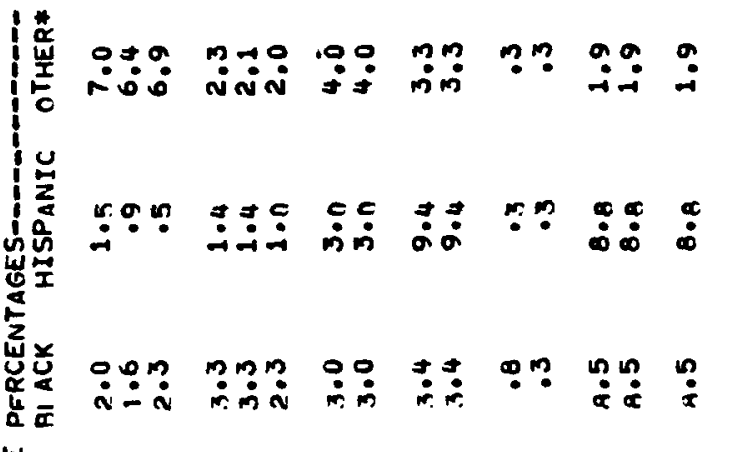
?

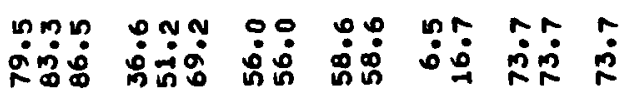

i

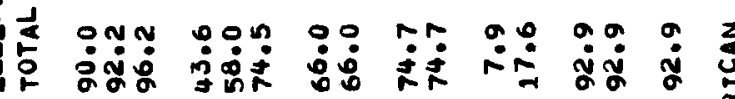

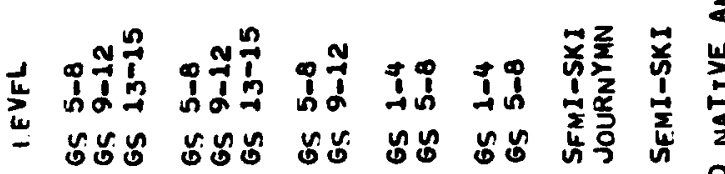

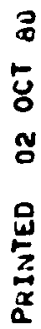

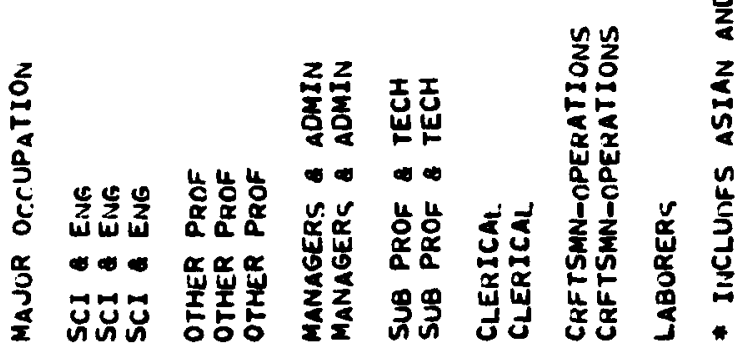




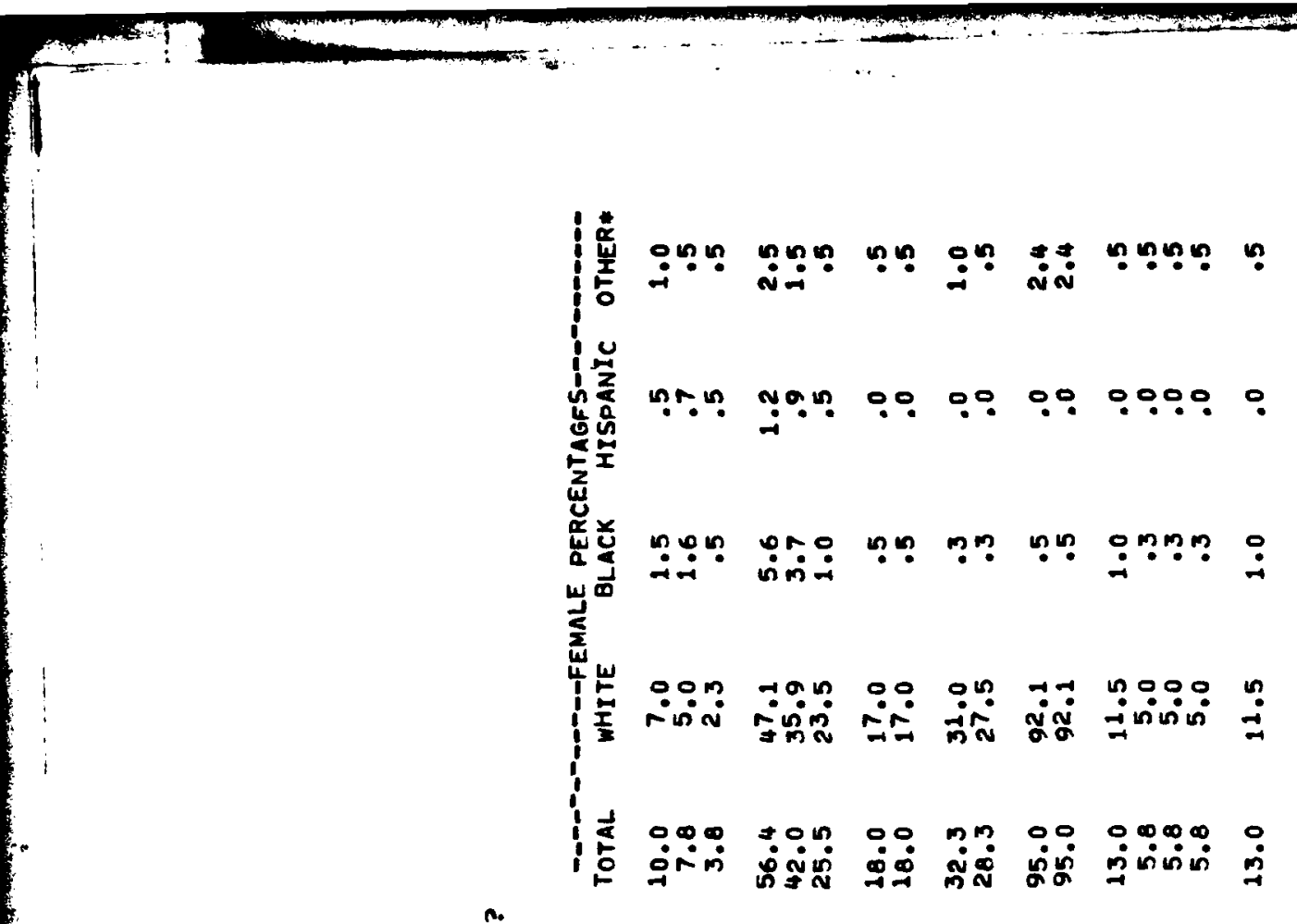

n.

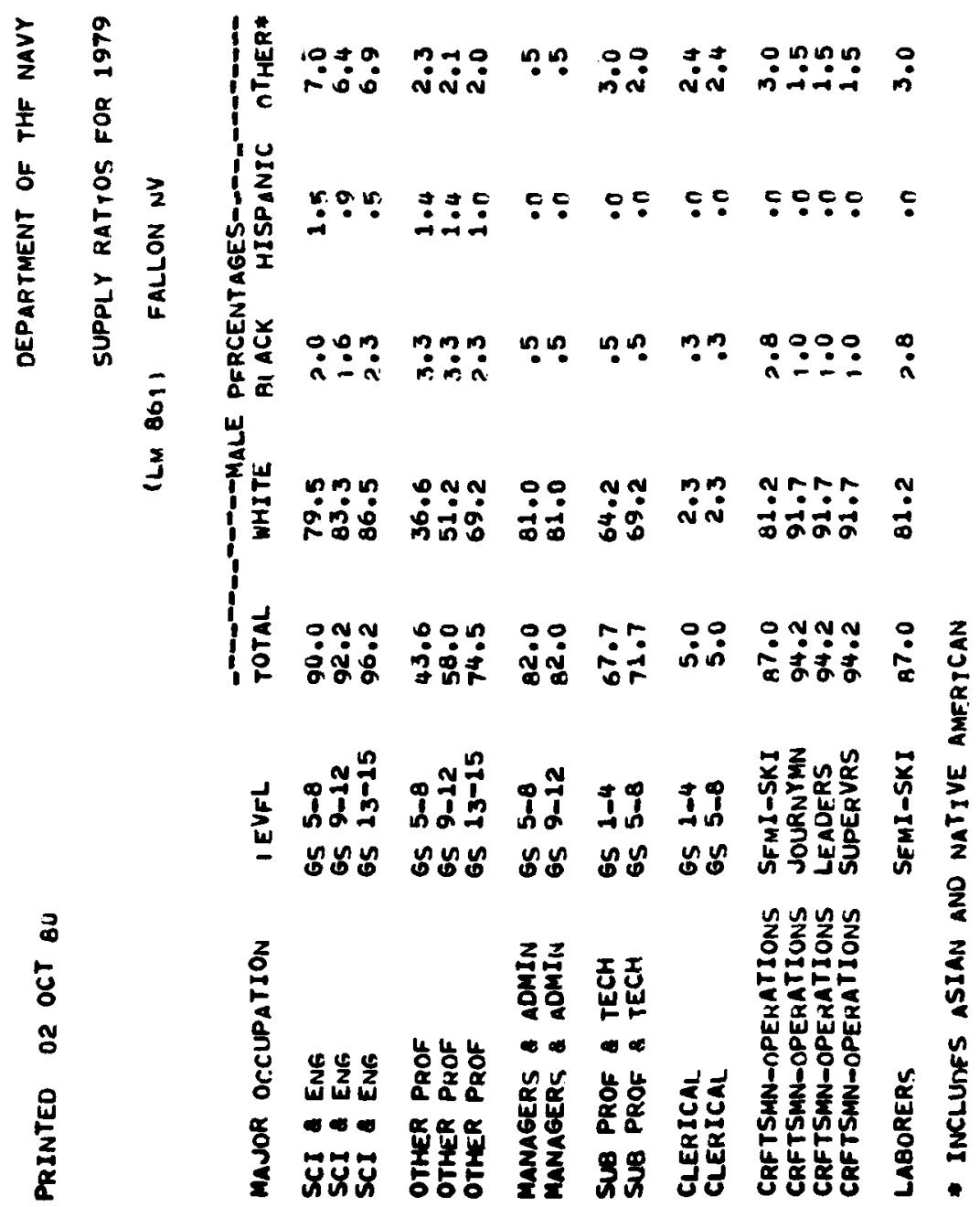




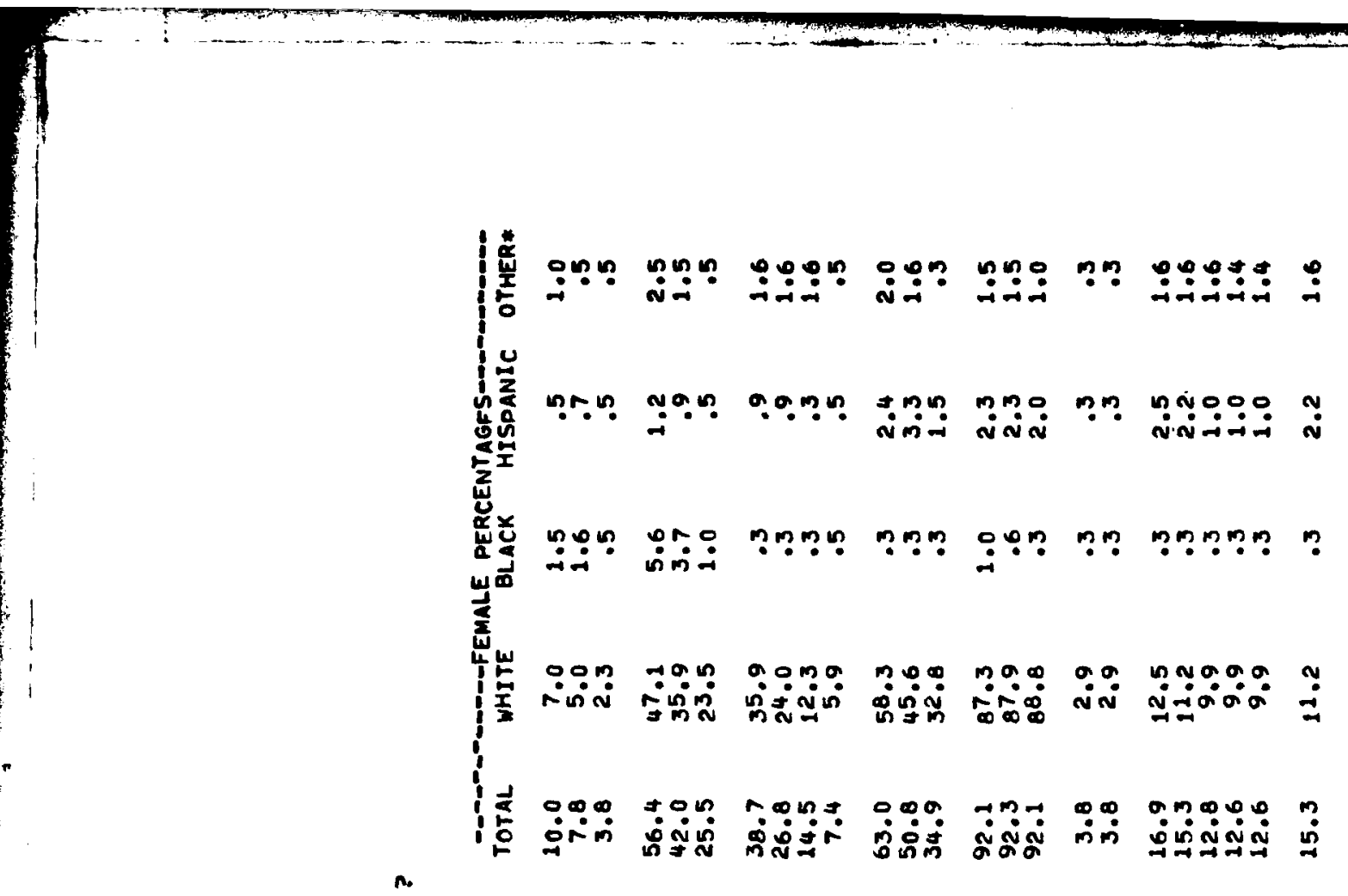

文

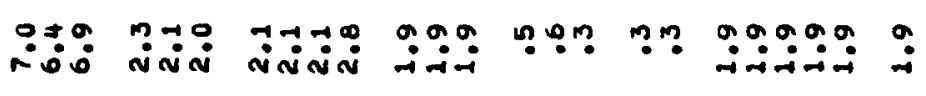

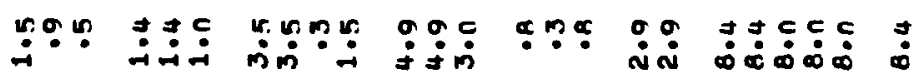

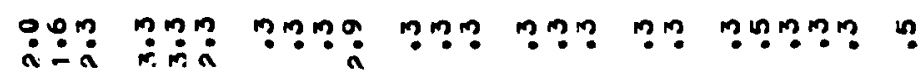

$\hat{s}$

崖

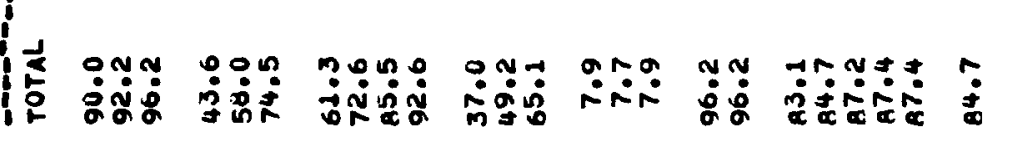

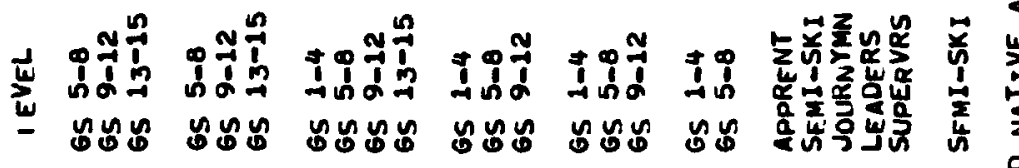

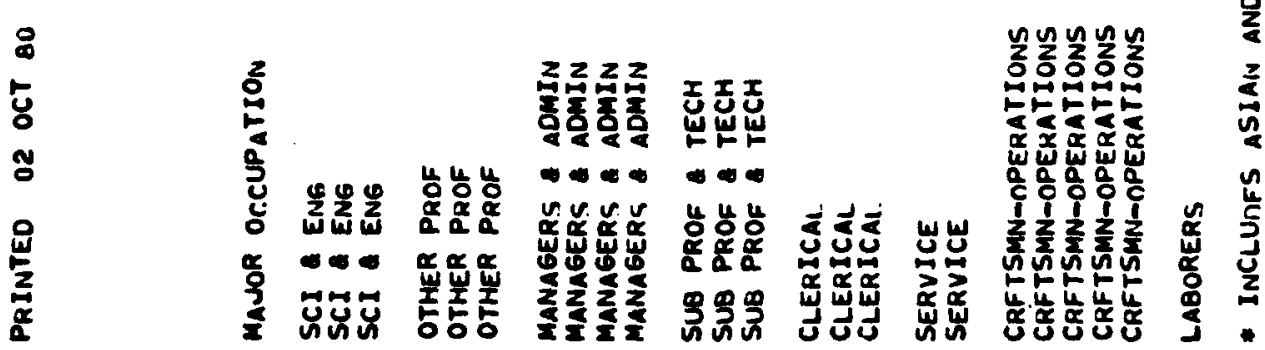




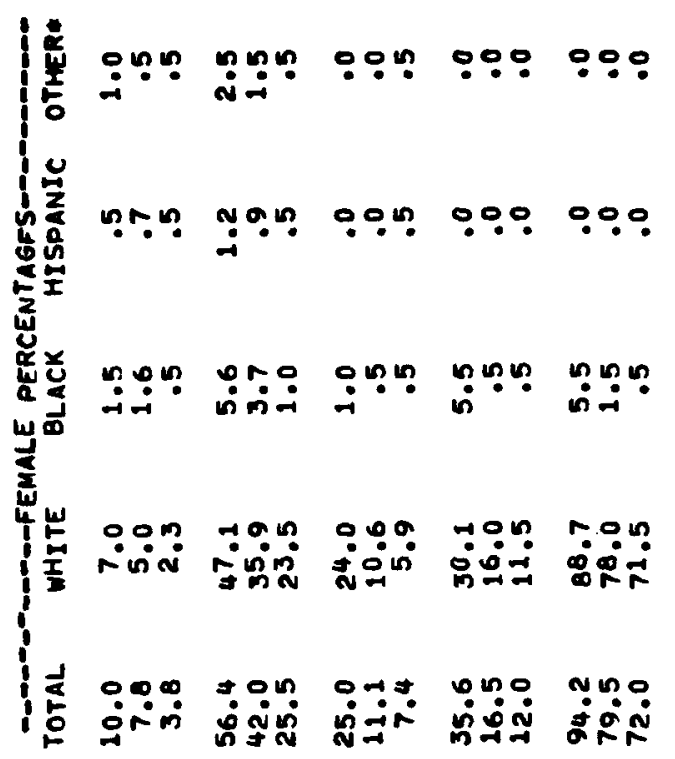

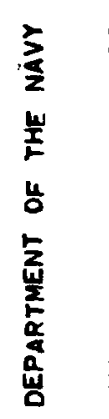

|

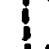

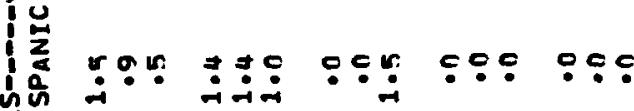

总

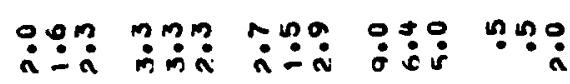

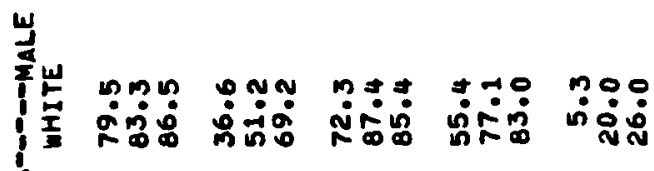

菌

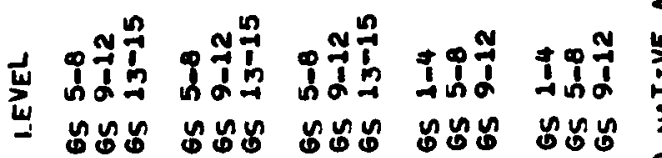

:

๖

ช

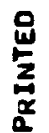

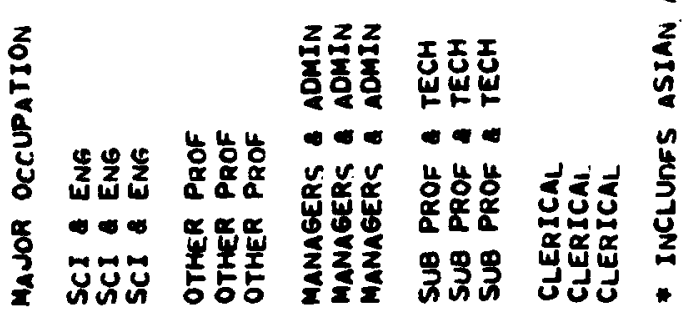

